\title{
Resolução numérica de equações de advecção-difusão empregando malhas adaptativas
}

\author{
Alexandre Garcia de Oliveira \\ DisSERTAÇÃO APRESENTADA \\ $\mathrm{AO}$ \\ Instituto DE MATEMÁtica E EstatísticA \\ $\mathrm{DA}$ \\ Universidade De SÃo PAulo \\ PARA \\ OBTENÇÃO DO TÍTULO \\ DE \\ Mestre em CiÊnCIAS \\ Programa: Matemática Aplicada \\ Orientador: Prof. Dr. Alexandre Megiorin Roma
}

Durante o desenvolvimento deste trabalho o autor recebeu auxílio financeiro da CAPES.

São Paulo, junho de 2015 


\title{
Resolução numérica de equações de advecção-difusão empregando malhas adaptativas
}

\author{
Esta dissertação contém as correções e alterações \\ sugeridas pela Comissão Julgadora durante a defesa \\ realizada por Alexandre Garcia de Oliveira em 07/07/2015. \\ O original encontra-se disponível no Instituto de \\ Matemática e Estatística da Universidade de São Paulo.
}

Comissão Julgadora:

- Prof. Dr. Alexandre Megiorin Roma (orientador) - IME-USP

- Prof. Dra. Priscila Cardoso Calegari - UFSC

- Prof. Dr. João Marcelo Vedovoto - UFU 
"Science is a differential equation. Religion is a boundary condition" Alan Turing. 


\section{Agradecimentos}

Primeiramente à minha família, meu pai Lázaro, minha mãe Cristina e minha irmã Vívian, pelo suporte emocional, serviço de quarto e por me aguentar durante o processo. À minha namorada Rosanne pelo carinho e pelas comidas e doces feitos durante estes anos. Ao meu orientador, Professor Dr. Alexandre M. Roma pela paciência com meus erros e sua tolerância com meu pouco tempo disponível por causa do meu trabalho. À Priscila, Catalina e Millena por me ajudarem com os erros iniciais que me tiravam o sono e pelo suporte durante todo o processo. Ao Vítor e Rafael de Uberlândia pela ajuda na verificação do módulo feito e dúvidas sobre a parte paralela do código e por serem muito solícitos. Aos meus colegas Vinícius, Diego, Caio e Marcelo por me ajudarem a chegar neste patamar. E, finalmente, à CAPES pelo suporte financeiro durante o ínicio do projeto. 


\section{Resumo}

Oliveira, A.G. Resolução numérica de equações de advecção-difusão empregando malhas adaptativas. 2015. Dissertação (Mestrado)- Instituto de Matemática e Estatística, Universidade de São Paulo, 2015.

Este trabalho apresenta um estudo sobre a solução numérica da equação geral de advecçãodifusão usando uma metodologia numérica conservativa. Para a discretização espacial, é usado o Método de Volumes finitos devido à natureza conservativa da equação em questão. O método é configurado de modo a ter suas variáveis centradas em centro de célula e, para as variáveis, como a velocidade, centradas nas faces um método de interpolação de segunda ordem é utilizado para um ajuste numérico ao centro. Embora a implementação computacional tenha sido feita de forma paramétrica de maneira a acomodar outros esquemas numéricos, a discretização temporal dá ênfase ao Método de Crank-Nicolson. Tal método numérico, sendo ele implícito, dá origem a um sistema linear de equações que, aqui, é resolvido empregando-se o Método Multigrid-Multinível. A corretude do código implementado é verificada a partir de testes por soluções manufaturadas, de modo a checar se a ordem de convergência prevista em teoria é alcançada pelos métodos numéricos. Um jato laminar é simulado, com o acoplamento entre a equação de Navier-Stokes e a equação geral de advecção-difusão, em um domínio computacional tridimensional. O jato é uma forma de verificar se o algoritmo de geração de malhas adaptativas funciona corretamente. O módulo produzido neste trabalho é baseado no código computacional AMR3D-P desenvolvido pelos grupos de pesquisa do IME-USP e o MFLab/FEMEC-UFU (Laboratório de Dinâmica de Fluidos da Universidade Federal de Uberlândia). A linguagem FORTRAN é utilizada para o desenvolvimento da metodologia numérica e as simulações foram executadas nos computadores do LabMAP(Laboratório da Matemática Aplicada do IME-USP) e do MFLab/FEMEC-UFU.

Palavras chave: equação de advecção-difusão, refinamento adaptativo de malhas, Método dos Volumes Finitos. 


\section{Abstract}

Oliveira, A.G. Numerical solution of advection-diffusion equations using adaptative mesh refinement.. 2015. Dissertation (Master's degree)- Institute of Mathematics and Statistics, University of São Paulo, 2015.

This work presents a study about the numerical solution of variable coeficients advectiondiffusion equation, or simply, general advection-diffusion equation using a conservative numerical methodology. The Finite Volume Method is choosen as discretisation of the spatial domain because the conservative nature of the focused equation. This method is set up to have the scalar variable in a cell centered scheme and the vector quantities, such velocity, are face centered and they need a second order interpolation to get adjusted to the cell center. The computational code is parametric, in which, any implicit temporal discretisation can be choosen, but the emphasis relies on Crank-Nicolson method, a well-known second order method. The implicit nature of aforementioned method gives a linear system of equations which is solved here by the Multilevel-Multigrid method. The correctness of the computational code is checked by manufactured solution method used to inspect if the theoretical order of convergence is attained by the numerical methods. A laminar jet is simulated, coupling the Navier-Stokes equation and the general advection-diffusion equation in a $3 \mathrm{D}$ computational domain. The jet is a good way to check the corectness of adaptative mesh refinement algorithm. The module designed here is based in a previous implemented code AMR3D-P designed by IME-USP and MFLab/FEMEC-UFU (Fluid Dynamics Laboratory, Federal University of Uberlândia). The programming language used is FORTRAN and the simulations were run in LabMAP(Applied Mathematics Laboratoy at IME-USP) and MFLab/FEMEC-UFU computers.

Keywords: advection-diffusion equation, adaptative mesh refinement, Finite Volume method. 


\section{Sumário}

Lista de Símbolos $\quad$ vii

Lista de Figuras $\quad$ viii

$\begin{array}{lc}\text { Lista de Tabelas } & \text { ix }\end{array}$

1 Introdução 1

1.1 Motivação e objetivos . . . . . . . . . . . . . . . . . . . 2

1.2 Equação de advecção-difusão . . . . . . . . . . . . . . . . . 3

1.3 Refinamento adptativo e método multigrid-multinível . . . . . . . . . . 3

1.4 Estrutura do trabalho . . . . . . . . . . . . . . . . . 4

2 Modelo Matemático $\quad 6$

2.1 Embasamento teórico . . . . . . . . . . . . . . . . . . . 7

2.2 Equação da conservação de massa . . . . . . . . . . . . . . . . . 10

2.3 Advecção e difusão em cinética química . . . . . . . . . . . . . . . . . . 12

2.4 Equação geral de advecção-difusão . . . . . . . . . . . . . . . . . 13

3 Metodologia Numérica $\quad 16$

3.1 Método dos Volumes Finitos . . . . . . . . . . . . . . . . . 16

3.2 Discretização temporal . . . . . . . . . . . . . . . . . . . 18

3.3 Discretização espacial . . . . . . . . . . . . . . . . . . . 20

3.4 Estabilidade . . . . . . . . . . . . . . . . . . . . 21

3.5 Malha adaptativa bloco-estruturada . . . . . . . . . . . . . . 22

3.5.1 Definição de uma malha adaptativa bloco-estruturada . . . . . . . . . 22

3.5.2 Geração de uma malha adaptativa bloco-estruturada . . . . . . . . . 24

3.5.3 Células fantasmas . . . . . . . . . . . . . . . 26

3.5.4 Critério de seleção de células computacionais para refinamento . . . . 26

3.6 Sumário da metodologia numérica . . . . . . . . . . . . . . . . . . 27

4 Método Multigrid-Multinível 28

4.1 Método multigrid . . . . . . . . . . . . . . . . . . . . 28

4.2 Cálculo do resíduo . . . . . . . . . . . . . . . . . . 30 


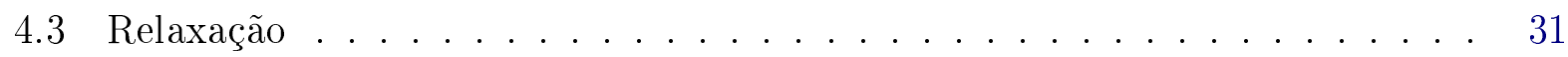

4.4 Sumário do método . . . . . . . . . . . . . . . . . . 33

5 Resultados e discussão $\quad 34$

5.1 Descrição dos testes e malhas . . . . . . . . . . . . . . 35

5.2 Testes com o modelo estacionário . . . . . . . . . . . . . . . 36

5.2 .1 Verificação por solução manufaturada . . . . . . . . . . . 37

5.2 .2 Performance do método multigrid-multinível . . . . . . . . . . . . . 40

5.2 .3 Verificação do Teorema da Divergência discreto . . . . . . . . . . 41

5.3 Testes com o modelo o transiente . . . . . . . . . . . . . . . . . 43

5.3 .1 Verificação por solução manufaturada . . . . . . . . . . . . . 43

5.4 Teste de conservação . . . . . . . . . . . . . . . . . . 45

5.5 Simulação de um jato laminar . . . . . . . . . . . . . . . 48

6 Considerações finais $\quad 56$

$\begin{array}{ll}\text { Referências Bibliográficas } & 57\end{array}$ 


\section{Lista de Símbolos}

u Campo de velocidade

$p \quad$ Campo de pressão

$\rho \quad$ Massa específica do fluido

$\mu \quad$ Viscosidade dinâmica

$\Omega \quad$ Domínio computacional

$\omega \quad$ Coeficiente de difusão

$\zeta \quad$ Coeficiente de decaimento

$Y \quad$ Fração mássica

z Escalar conservado

$\tilde{c} \quad$ Média de uma variável de progresso $c$

$c^{\tilde{\prime \prime} 2}$ Variância de uma variável de progresso $c$

$C_{\Omega} \quad$ Razão de escala de tempo assumida constante

$\tilde{D}_{T} \quad$ Coeficiente de difusão turbulento

$\Delta \quad$ Tamanho do filtro de Smagorinsky

Re Número de Reynolds

$P e \quad$ Número de Péclet

$t_{d} l_{d}$ Tolerância do critério de remalhagem

$I^{c \rightarrow f} \quad$ Operador de interpolação centro-face

$\mathcal{C} \quad$ Operador de correção de fluxo

$e \quad$ Direção leste de uma face ou célula, representa o índice $i+1 j k$

$w \quad$ Direção oeste de uma face ou célula, representa o índice $i-1 j k$

$n \quad$ Direção norte de uma face ou célula, representa o índice $i j+1 k$

$s \quad$ Direção sul de uma face ou célula, representa o índice $i j-1 k$

$t \quad$ Direção acima, top, de uma face ou célula, representa o índice $i j k+1$

$b \quad$ Direção abaixo, bottom, de uma face ou célula, representa o índice $i j k-1$ 


\section{Lista de Figuras}

3.1 Célula computacional e rótulo das faces. . . . . . . . . . . . . . 17

3.2 Projeção em 2D da interpolação das faces. . . . . . . . . . . . . . 20

3.3 (a) Malha composta em um domínio computacional $\Omega=[0,1] \times[0,1] \times[0,1]$ com cortes em (b) $\mathrm{x}=0.5$, (c) $\mathrm{y}=0.3$ e (d) $\mathrm{z}=0.5 \ldots \ldots . \ldots 24$

4.1 Interpolação trilinear no algortimo multigrid calaculados em centro de célula computacional. ........................... 30

$5.1 \quad$ (a) plano $z=0.71875$; (b) plano $z=0.125 \ldots \ldots \ldots \ldots$

5.2 Malha composta estática em três níveis. . . . . . . . . . . . . 36

5.3 (a) Erros cometidos: corte em $\mathrm{z}=0$; (b) Erros cometidos: corte em $\mathrm{z}=0$ com ampliação; (c) Erros cometidos: corte em $z=0.71875$; (d) Erros cometidos: corte em $\mathrm{z}=0.71875$ com ampliação; (e) Erros cometidos: corte em $\mathrm{z}=1$. . . .

5.4 Evolução da conservação no tempo, uniforme $\times$ composta, em malha $256 \times$ $256 \times 256$ com condição de Dirichlet . . . . . . . . . . . . . . . 47

5.5 Bocal centrado no plano $z=0 \ldots \ldots \ldots \ldots$

5.6 Escalar $\varphi$ disposto em malhas composta com três níveis de refinamento e uniforme respectivamente; . . . . . . . . . . . . . 51

5.7 Escalar $\varphi$ na direção do escoamento em diferentes instantes de tempo; . . . . 52

5.8 Número de células computacionais, em relação a malha uniforme, ao longo do tempo de simulação . . . . . . . . . . . . . . . . 53

5.9 Escalar $\varphi$ disposto em malhas uniforme em serial e paralelo; . . . . . . . . 54

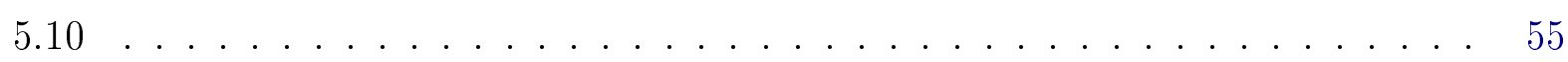

5.11 Malha gerada, tanto em serial quanto em paralelo, no instante de tempo $0.5 ; \quad 55$ 


\section{Lista de Tabelas}

5.1 Verificação da convergência numérica por refinamento de malha e uso de solução manufaturada suave do modelo simplificado (2.37). Resultados em malha uniforme, processamento serial. . . . . . . . . . . . 37

5.2 Verificação da convergência numérica por refinamento de malha e uso de solução manufaturada suave do modelo simplificado (2.37). Resultados em malha composta (estática), processamento serial. . . . . . . . . . 38

5.3 Número de V-ciclos obtidos para malhas uniforme e composta. . . . . . . . . 40

5.4 Razão entre os tempos de execução de malhas progressivamente mais finas. . 41

5.5 Verificação do Teorema da Divergência discreto por refinamento de malha e uso de solução manufaturada suave do modelo simplificado (2.37). Resultados em malha uniforme, processamento serial. . . . . . . . . . . . .

5.6 Verificação do Teorema da Divergência discreto por refinamento de malha e uso de solução manufaturada suave do modelo simplificado (2.37). Resultados em malha composta (estática), processamento serial. . . . . . . . . 42

5.7 Teste de convergência na malha uniforme com propriedades físicas variáveis. 44

5.8 Teste de convergência na malha composta estática com propriedades físicas variáveis. . . . . . . . . . . . . . . . . . . . . . . . . 44 4

5.9 Tempo de execução por passo de integração em malha uniforme . . . . . . . 45

5.10 Tempo de execução por passo de integração em malha composta . . . . . . . 45

5.11 Propriedade de conservação do método numérico, malha uniforme em $\mathrm{t}=0.3$. 46

5.12 Propriedade de conservação do método numérico, malha composta em $\mathrm{t}=0.147$

5.13 Teste de convergência na malha uniforme com propriedades físicas variáveis. $\quad 53$ 


\section{Capítulo 1}

\section{Introdução}

Ao longo dos anos, simulações computacionais têm sido alvo de um interesse crescente tanto em pesquisa como em tecnologia, pois auxiliam no entendimento de problemas práticos e teóricos em diversos ramos da engenharia e da ciência. Alguns exemplos podem ser enunciados nas áreas financeira, meteorológica, aerodinâmica, biologia, combustão e muitas outras. Em alguns problemas físicos é demandado um enorme esforço e custo para fazer experimentações em laboratório, com isso, a área de Dinâmica de fluidos computacional é um tópico de extrema importância para ser estudado. As subáreas de turbulência, transferência de calor, reações químicas, radiação entre outras formam a área de combustão que é uma importante área de pesquisa e com o tempo vem crescendo cada vez mais. Segundo [6] muito tem se investido em modelos matemáticos para predizer escoamentos, temperaturas, concentrações de espécies químicas de forma a evitar efeitos nocivos ao meio ambiente. Outra motivação para a pesquisa de tais modelos na área de combustão é o crescente uso de energia oriunda de processos de combustão nos últimos anos em transportes, usinas, processos industriais para geração de manufatura entre outros. A intenção do presente trabalho é prover um módulo de resolução de equações a derivadas parciais oriundas do processo de transporte e difusão de uma quantidade escalar, assim como investigar técnicas de discretização espacial e temporal e solução dos sistemas lineares gerados por estas discretizações. O objetivo foi acoplar o novo módulo ao código computacional AMR3D que foi amplamente discutido no trabalho de [16], [6] e [25] em sua versão paralela que nasceu do trabalho de [15]. O código computacional em questão vem sendo desenvolvido em várias frentes pelos grupos de pesquisa do Instituto de Matemática e Estatística (IME-USP) e da Faculdade de Engenharia Mecânica da Universidade Federal de Uberlândia (MFLab/FEMEC-UFU). Várias rotinas que já estavam prontas para a solução da equação de Navier-Stokes foram adaptadas para a equação do transporte e difusão de um escalar de modo a aproveitar os resultados obtidos durante os últimos anos pelo grupo de pesquisa em questão. O trabalho veio da necessidade de ter um solver deste tipo de equação, ou seja, é uma adaptação de uma parte dos trabalhos de [6] e [24]. A metodologia numérica para obtenção de soluções para a equação em questão é baseada em todos os outros trabalhos do grupo que é o uso de malhas compostas 
conforme [4] para o auxílio na discretização espacial, esquemas implícitos-explícitos como descrito em [3] para a discretização temporal e o método Multigrid-Multinível para a solução dos sistemas lineares obtidos como visto em [16], [6] e [15]. Vale observar que a discretização temporal é parametrizada para todos os esquemas implícitos-explícitos (IMEX) listados nos trabalhos de [6] e [16], porém, no presente trabalho é reportado resultados com enfoque no método de Crank-Nicolson. A parte paralela foi totalmente baseada na construção proposta por [15], nenhuma atualização foi feita no que tange o ferramental computacional para o uso de processos concorrentes. Este capítulo provê um panorama dos principais assuntos a serem abordados neste trabalho. Na primeira seção, é apresentado ao leito as motivações e objetivos gerais e específicos deste trabalho. A segunda seção apresenta uma breve descrição da motivação e objetivos do trabalho. A terceira seção é discutida de maneira introdutória as ferramentas numéricas usadas neste trabalho. Finalmente a última seção mostra a estrutura da dissertação.

\subsection{Motivação e objetivos}

A principal intenção deste trabalho é a resolução e os aspectos numéricos de uma equação a derivadas parciais (edp) geral de advecção-difusão escalar, ou seja, uma equação que possua um termo temporal, um termo que dependa da velocidade com qual a quantidade escalar será advectada pelo domínio, um termo difusivo, um termo linear e um termo forçante. Outro objetivo a ser destacado é investigar o desempenho das técnicas de refinamento adaptativo de malhas, assim como estudar a solução do sistema linear advindo da discretização espacial e temporal usando o método Multigrid-Multinível. O trabalho também tem como objetivo o estudo da discretização espacial por volumes finitos e sua propriedade de conservação. A partir do estudo aqui realizado foi desenvolvido um módulo de solução da equação e um módulo para o Multigrid-Multinível. Estes módulos possuem algumas sub-rotinas mais importantes, tais como:

- Subrotina timestep: Subrotina que calcula a discretização temporal, espacial e a resolve utilizando o método Multigrid-Multinível para um passo no tempo;

- Subrotina conservative_solver: Subrotina principal que prepara condições iniciais e de fronteira e modo a inicializar o solver. Aqui há o loop no tempo onde é chamada a função timestep.

- Subrotina status_cons: Subrotina que verifica se a discretização usada mantém a propriedade de conversação

- Subrotina v_cycle_varphi: Subrotina que executa todos os passos do algoritmo Multigrid-Multinível. 
O código computacional base para montar estes dois módulos foi o AMR3D-P em sua versão disponível em janeiro de 2014. Este trabalho foi desenvolvido com o apoio dos grupos IMEUSP e MFlab/FEMEC-UFU.

\subsection{Equação de advecção-difusão}

Equações de advecção-difusão modelam processos industriais e naturais como, por exemplo, em reações químicas e distribuições de nutrientes em lagos e rios. O comportamento de espécies químicas ou biológicas em meios tais como água ou ar também são descrito por estas equações [12]. As equações que descrevem este processo são equações a derivadas parciais lineares que podem ser escritas a partir de deduções de leis de conservação da física. Considere uma concentração de uma espécie qualquer $\varphi(x, t)$, com $x \in \mathbb{R}$ e $t \geq 0$. Se a espécie é carregada em um meio fluidoso com uma velocidade $u(x, t)$ então a Lei de Conservação implica que a mudança de $\varphi$ em relação ao tempo é a diferença entre os fluxos de entrada e saída no bordo do domínio em questão. Pode-se escrever

$$
\frac{d}{d t} \varphi(x, t)+\frac{d}{d x}(u(x, t) \varphi(x, t))=0,
$$

que é chamada de equação de advecção. Como visto em [12] se for levado em consideração que a mudança de $\varphi$ em relação ao tempo é causada por gradientes da solução com uma taxa $d(x, t)$ é possível também escrever a equação de difusão

$$
\frac{d}{d t} \varphi(x, t)+\frac{d}{d x}\left(d(x, t) \frac{d}{d x} \varphi(x, t)\right)=0 .
$$

A concentração total de uma espécie $\varphi$ é obtida juntando as três equações descritas acima

$$
\frac{d}{d t} \varphi(x, t)+\frac{d}{d x}(u(x, t) \varphi(x, t))=\frac{d}{d x}\left(d(x, t) \frac{d}{d x} \varphi(x, t)\right)+f(x, t, \varphi(x, t)) .
$$

Baseando-se nos estudos de [6] e [24], a equação (1.3) é implementada em três dimensões, usando o método dos volumes finitos para sua discretização espacial, o método IMEX para a discretização temporal e o algoritmo multigrid-multinível para a resolução dos sistemas lineares oriundos das discretizações espacial e temporal de (1.3).

\subsection{Refinamento adptativo e método multigrid-multinível}

Certos fenômenos numéricos mostram características especiais em locais específicos de um domínio computacional e para isso requerem um refinamento de forma a aumentar a acurácia do método. Neste processo é necessário que a malha usada seja mais fina no local desejado e não no domínio todo conforme o estudo de [4]. O refinamento adaptativo consiste em selecionar, em um domínio computacional, os pontos ruins ou bad points como é chamado 
em [4] de forma a se obter localmente uma malha mais fina de modo a concentrar todo o poder computacional nesta região de interesse [6]. Está seleção ocorre a partir de propriedades das variáveis computacionais estudadas atráves de critérios físicos a serem observados. As malhas compostas devem respeitar o critério de aninhamento para evitar que erros numéricos se disseminem comprometendo a solução numérica. O algoritmo Multigrid é usado, neste trabalho, para resolver os sistemas lineares que se originam na discretização espacial e temporal de forma a reduzir os erros de suavização cometidos por métodos iterativos, por exemplo, Gauss-Seidel [13]. O método Multigrid é uma hierarquia de discretizações ou refinamentos, onde, a solução numérica é obtida em malhas malhas grossas via uma operação chamada de restrição e depois estas são interpoladas de volta a malha inicial num processo chamado de interpolação ou prologamento. A cada nível onde a solução deve ser obtida um método de relaxação é empregado, aqui neste trabalho é usado o Gauss-Seidel. O método começa em uma malha de espaçamento h e é sucessivamente refinada gerando-se malhas de espaçamento $\frac{h}{2}, \frac{h}{4}, \frac{h}{8}$ e assim por diante. Dentro do arquivo de inicialização do programa computacional AMR3D é possível escolher quantas células computacionais o nível base (nível 1) possuirá a partir das variáveis mxm, mxy, mxz e quantos níveis virtuais nvl (refinamentos) serão gerados. Por exemplo, se forem escolhidos $m x m=m x y=m x z=8$ e $n v l=3$ obteremos uma malha $64 \times 64 \times 64$ no nível $4,32 \times 32 \times 32$ no nível $3,16 \times 16 \times 16$ no nível 2 e $8 \times 8 \times 8$ no nível 1. Neste trabalho será usado o método citado para malhas compostas (adaptativas). O método Multigrid-Multinível é usado e este consiste em uma ligeira adaptação do método Multigrid para malhas uniformes. Há etapas de restrição, relaxação e prologamento entre os níveis mais refinados e o nível base. Os refinamentos da malha composta são chamados de níveis físicos e são representados pela variável $n p l$. Cada bloco de refinamento local deve ser contido no arquivo inicial na forma de coordenadas cartesianas e o número de blocos correspondente. Há também uma flag chamada dynamic_mesh que inicia o processo de geração de malhas dinamicamente a cada passo no tempo também definido no arquivo de configuração.

\subsection{Estrutura do trabalho}

Para relatar a experiência obtida no desenvolvimento do código computacional em questão, o presente trabalho está organizado em seis capítulos. O Capítulo 2 apresenta o ferramental teórico necessário para o desenvolvimento e implementação dos métodos numéricos utilizados. São descritos também todos os modelos matematicos que podem ser obtidos a partir da edp geral do escalar que embasará outros trabalhos dos grupos de pesquisa do IME-USP e do MFlab/FEMEC-UFU. No Capítulo 3, é introduzida a metodologia numérica que envolve a equação em questão. Neste capítulo são discutidos as discretizações temporal e espacial, além de introduzir o refinamento adaptativo de malhas, seus critérios de seleção de pontos e trocas de malha e também questões de estabilidade. O Capítulo 4 detalha cada 
passo utilizado pelo algoritmo Multigrid-Multinível além de alertar para o número de Péclet de uma malha e o critério de estabilidade de Scarborough. No Capítulo 5, é apresentado a verificação da ordem de convergência para algumas equações derivadas da equação geral de advecção-difusão escalar, além de serem apresentados os resultados oriundos de um problema de um jato laminar que foi obtido a partir de um acoplamento desta equação em conjunto com a equação de Navier-Stokes a fim de verificar a corretude do refinamento adaptativo de malhas. Estatísticas sobre o método Multigrid-Multinível também são apresentadas. O Capítulo 6 encerra esta dissertação comentando as possíveis maneiras de se continuar este trabalho e fazendo as discussões e considerações finais. 


\section{Capítulo 2}

\section{Modelo Matemático}

Em dinâmica de fluidos, equações de conservação e de advecção-difusão ocupam grande destaque pois são elas que modelam um grande número de fenômenos relevantes na área. Algumas equações de conservação conhecidas são a de massa, a de quantidade de movimento (equação de Navier-Stokes), de energia e de transporte de espécies químicas, entre outras. O presente trabalho discute a equação de conservação de massa específica e de transportedifusão de espécies químicas e pode ser visto como uma vertente dos trabalhos de [24] e [6] tendo como meta auxiliar na resolução numérica de equações de conservação e de advecção-difusão de escalares em escoamentos reativos. O modelo matemático completo para o escoamento reativo na fase contínua pode ser visto em [6].

Neste Capítulo, são apresentadas as principais ferramentas teóricas para o desenvolvimento do modelo matemático e é abordado a obtenção e descrição da equação geral de conservação (equação de advecção-difusão ou equação de transporte) de uma quantidade escalar. Com base em [6] e [24], o presente trabalho agregará as equações de advecção-difusão que são estudadas por aqueles em um modelo matemático genérico para nortear os métodos numéricos a serem usados visando a solução de tal modelo.

Na Seção 2.1, são apresentados uma demonstração Teorema de Gauss (Teorema do Divergente) para regiões cúbicas e o Teorema do Transporte de Reynolds que são vitais para o modelo matemático e para o desenvolvimento da metodologia numérica que utiliza o Método dos Volumes Finitos em sua discretização espacial. A Seção 2.2 trata sobre o desenvolvimento das equações de conservação de massa. A Seção 2.3 apresenta a equação geral de conservação para o transporte de espécies químicas no qual assume que a reação química seja infinitamente rápida e estequiométrica como descrito em [6] e também é discutido o uso de variáveis de progresso como fator simplicador da equação de transporte de espécies químicas como descrito no trabalho [24]. Finalmente, na Seção 2.4 será apresentado o modelo geral para a equação de advecção-difusão. 


\subsection{Embasamento teórico}

O intuito desta seção é demonstrar o Teorema da Divergência (Gauss) para uma região cúbica no espaço e o Teorema do Transporte de Reynolds baseando-se no trabalho de [10]. Esta região possui a forma do domínio computacional usado por este trabalho a ser tratado nos próximos capítulos. A demonstração do teorema abaixo foi baseado no trabalho de [19]

Teorema 2.1.1. (Teorema de Gauss) Seja $\Omega \subset \mathbb{R}^{3}$ um cubo e seja $\mathbf{n}$ o vetor normal unitário exterior ao cubo. Se F é um campo de vetores $C^{\infty}$ definido em $\Omega$ então vale a seguinte igualdade

$$
\int_{\Omega} \nabla \cdot F d V=\int_{\partial \Omega} F \cdot \mathbf{n} d S
$$

Demonstração: Primeiramente denote $\Phi=\int_{\partial \Omega} F \cdot \mathbf{n} d S$, sendo assim $\Phi$ representa o fluxo que passa por $\Omega$. O dominio $\Omega$ é dividido em pequenos cubos, tão pequenos quanto se queira, e chame $\Omega_{i}$ com $i=1,2, \ldots, N$ cada pequeno cubo com ponto inicial em $\left(x_{i}, y_{i}, z_{i}\right) \in \mathbb{R}^{3}$ e ponto final em $\left(x_{i}+\Delta x, y_{i}+\Delta y, z_{i}+\Delta z\right)$. Tome um pequeno cubo $\Omega_{l}$ arbitrário, onde $1<l<N$, e note que o fluxo na direção $x$ é dado por

$$
\Phi_{x}=F_{x, e} d S_{e}+F_{x, w} d S_{w}
$$

onde $F_{x, e}$ é a componente $x$ do fluxo $F$ que entra pelo lado leste e $F_{x, w}$ é a mesma para o lado oeste. Note que $d S_{e}$ e $d S_{w}$ são as áreas das faces laterais que são iguais e valem $\Delta y \Delta z$. As coordenadas do centro das faces leste e oeste do pequeno cubo $\Omega_{l}$ são $\left(x_{l}, y_{l}+\frac{\Delta y}{2}, z_{l}+\frac{\Delta z}{2}\right)$ $e\left(x_{l}+\Delta x, y_{l}+\frac{\Delta y}{2}, z_{l}+\frac{\Delta z}{2}\right)$ respectivamente, o valor de $F_{x}$ nestes pontos podem ser obtidos expandindo em Séries de Taylor, que nos dá

$$
\begin{aligned}
F_{x}\left(x_{l}, y_{l}+\frac{\Delta y}{2}, z_{l}+\frac{\Delta z}{2}\right)=F_{x}\left(x_{l}, y_{l}, z_{l}\right) & +\frac{\partial F_{x}}{\partial y} \frac{\Delta y}{2}+\frac{\partial F_{x}}{\partial z} \frac{\Delta z}{2}+O\left(\Delta x^{2}, \Delta y^{2}, \Delta z^{2}\right) \\
F_{x}\left(x_{l}+\Delta y, y_{l}+\frac{\Delta y}{2}, z_{l}+\frac{\Delta z}{2}\right) & =F_{x}\left(x_{l}, y_{l}, z_{l}\right)+\frac{\partial F_{x}}{\partial x} \Delta x+\frac{\partial F_{x, e}}{\partial y} \frac{\Delta y}{2} \\
& +\frac{\partial F_{x}}{\partial z} \frac{\Delta z}{2}+O\left(\Delta x^{2}, \Delta y^{2}, \Delta z^{2}\right) .
\end{aligned}
$$

Substituindo (2.3) e (2.4) em (2.2)

$$
\begin{aligned}
\Phi_{x} & =F_{x, e} d S_{e}+F_{x, w} d S_{w} \approx\left(F_{x}\left(x_{l}, y_{l}, z_{l}\right)+\frac{\partial F_{x}}{\partial x} \Delta x+\frac{\partial F_{x}}{\partial y} \frac{\Delta y}{2}+\frac{\partial F_{x}}{\partial z} \frac{\Delta z}{2}\right)(\Delta y \Delta z) \\
& -\left(F_{x}\left(x_{l}, y_{l}, z_{l}\right)+\frac{\partial F_{x}}{\partial y} \frac{\Delta y}{2}+\frac{\partial F_{x}}{\partial z} \frac{\Delta z}{2}\right)(\Delta y \Delta z)+O\left(\Delta x^{2}, \Delta y^{2}, \Delta z^{2}\right) \\
& =\frac{\partial F_{x}}{\partial x} \Delta x \Delta y \Delta z+O\left(\Delta x^{2}, \Delta y^{2}, \Delta z^{2}\right) .
\end{aligned}
$$


Analogamente para as outra direções

$$
\begin{aligned}
\Phi_{y} & =F_{y, n} d S_{n}+F_{y, s} d S_{s} \approx\left(F_{y}\left(x_{l}, y_{l}, z_{l}\right)+\frac{\partial F_{y}}{\partial x} \frac{\Delta x}{2}+\frac{\partial F_{y}}{\partial y} \Delta y+\frac{\partial F_{y}}{\partial z} \frac{\Delta z}{2}\right)(\Delta x \Delta z) \\
& -\left(F_{y}\left(x_{l}, y_{l}, z_{l}\right)+\frac{\partial F_{y}}{\partial x} \frac{\Delta x}{2}+\frac{\partial F_{y}}{\partial z} \frac{\Delta z}{2}\right)(\Delta x \Delta z)+O\left(\Delta x^{2}, \Delta y^{2}, \Delta z^{2}\right) \\
& =\frac{\partial F_{y}}{\partial y} \Delta x \Delta y \Delta z+O\left(\Delta x^{2}, \Delta y^{2}, \Delta z^{2}\right), \\
\Phi_{z} & =F_{z, t} d S_{t}+F_{z, b} d S_{b} \approx\left(F_{z}\left(x_{l}, y_{l}, z_{l}\right)+\frac{\partial F_{z}}{\partial x} \frac{\Delta x}{2}+\frac{\partial F_{z}}{\partial y} \frac{\Delta y}{2}+\frac{\partial F_{z}}{\partial z} \Delta z\right)(\Delta x \Delta y) \\
& -\left(F_{z}\left(x_{l}, y_{l}, z_{l}\right)+\frac{\partial F_{z}}{\partial x} \frac{\Delta x}{2}+\frac{\partial F_{z}}{\partial y} \frac{\Delta y}{2}\right)(\Delta x \Delta y)+O\left(\Delta x^{2}, \Delta y^{2}, \Delta z^{2}\right) \\
& =\frac{\partial F_{z}}{\partial z} \Delta x \Delta y \Delta z+O\left(\Delta x^{2}, \Delta y^{2}, \Delta z^{2}\right) .
\end{aligned}
$$

Tendo em mente que

$$
\Phi=\int_{\partial \Omega} F \cdot \mathbf{n} d S=\sum_{i=1}^{N} \int_{\partial \Omega_{i}} F \cdot \mathbf{n} d S_{i}
$$

e que podemos aproximar $\int_{\partial \Omega_{i}} F \cdot \mathbf{n} d S_{i} \approx \sum_{\text {faces }}\left(F \cdot \mathbf{n} d S_{i}\right) \approx\left(\frac{\partial F_{x}}{\partial x}+\frac{\partial F_{y}}{\partial y}+\frac{\partial F_{z}}{\partial z}\right)(\Delta x \Delta y \Delta z)+$ $O\left(\Delta x^{2}, \Delta y^{2}, \Delta z^{2}\right)=(\nabla \cdot F)(\Delta x \Delta y \Delta z)+O\left(\Delta x^{2}, \Delta y^{2}, \Delta z^{2}\right)$ é permitido escrever

$$
\Phi=\int_{\partial \Omega} F \cdot \mathbf{n} d S=\sum_{i=1}^{N} \int_{\partial \Omega_{i}} F \cdot \mathbf{n} d S_{i}=\sum_{i=1}^{N}(\Delta x \Delta y \Delta z) \frac{\int_{\partial \Omega_{i}} F \cdot \mathbf{n} d S_{i}}{(\Delta x \Delta y \Delta z)}
$$

Fazendo agora $N \rightarrow \infty$, para o volume dos cubos ir a zero, na última identidade da equação acima

$$
\lim _{N \rightarrow \infty} \sum_{i=1}^{N}(\Delta x \Delta y \Delta z)\left(\frac{\int_{\partial \Omega_{i}} F \cdot \mathbf{n} d S_{i}}{\Delta x \Delta y \Delta z}\right)=\int_{\Omega} \nabla \cdot F d V
$$

Para regiões mais gerais a demonstração deste teorema pode ser encontrado em [2]. O próximo teorema a ser enunciado e demonstrado é o do Transporte de Reynolds baseando-se em [10]. Este é usado para a dedução das equações de conservação e também para o método dos volumes finitos para obtenção de uma solução numérica para tais equações. Para a demonstração do teorema são necessárias as seguintes definições:

Definição 2.1.1. Dada uma função $\phi(a, t)$ e para cada $a \in \Omega_{0}$, a curva $t \mapsto \phi(a, t)$ descreve a trajetória da partícula que ocupa a posição a no instante $t=0$. Se $\Omega_{t}$ é a região do espaço ocupada pelo fluido num instante $t$ será admitido que $\phi_{t}(\mathbf{x})=\phi(\mathbf{x}, t)$, ou seja, a função $\phi_{t}$ leva cada $\mathbf{x} \in \Omega_{0}$ em $\phi(\mathbf{x}, t) \in \Omega_{t}$ e além disso tal função é diferenciável e com inversa 
diferenciável. Tal função $\phi$ é definida em [10] como função fluxo.

Definição 2.1.2. Dada uma função $f(\mathbf{x}, t)$ com $\mathbf{x} \in \Omega \subset \mathbb{R}^{3}$ a derivada material de $f$ é dada por

$$
\frac{D f}{D t}=\mathbf{v} \cdot \nabla f+\frac{\partial f}{\partial t}
$$

onde $\mathbf{v}=\frac{d \mathbf{x}}{d t}$, ou seja, $\mathbf{x}$ é uma trajetoria escolhida de modo a ter a mesma velocidade de um fluido.

Teorema 2.1.2. Seja $\phi$ uma função fluxo como descrito na Definição 2.1.1 e $\Omega_{t}$ uma região na qual o Teorema da Divergência vale então temos

$$
\frac{d}{d t} \int_{\Omega_{t}} f(\mathbf{x}, t) d \mathbf{x}=\int_{\Omega_{t}}\left(\frac{D f}{D t}+f \nabla \cdot \mathbf{v}\right)(\mathbf{x}, t) d \mathbf{x}
$$

Demonstração: Fazendo na integral do lado esquerdo de (2.9) a mudança de variáveis $\mathbf{x}=\phi_{t}(\mathbf{y})$

$$
\int_{\Omega_{0}} f\left(\phi_{t}(\mathbf{y}), t\right) J(\mathbf{y}, t) d \mathbf{y}
$$

onde $J$ denota o determinante jacobiano

$$
J(\mathbf{y}, t)=\operatorname{det}\left(\left(\frac{\partial \phi_{i}}{\partial y_{j}}\right)\right)_{1 \leq i, j \leq 3}
$$

Por hipótese, $\phi_{t}$ é sempre inversivel no que acarreta em $J(\mathbf{x}, t)$ ser sempre não nula. Vale notar que o Jacobiano é contínuo e $J(\mathbf{y}, 0)$ é igual a 1 para todo $y \in \Omega_{0}$ então o determinante acima é sempre positivo. A integral obtida da mudança de variável é independente do tempo, com isso, é permitida a troca da ordem de derivação e integração

$$
\frac{d}{d t} \int_{\Omega_{t}} f(\mathbf{x}, t) d \mathbf{x}=\int_{\Omega_{0}} \frac{\partial f}{\partial t}\left(\phi_{t}(\mathbf{y}), t\right) J(\mathbf{y}, t) d \mathbf{y}+\int_{\Omega_{0}} f\left(\phi_{t}(\mathbf{y}), t\right) \frac{\partial J}{\partial t}(\mathbf{y}, t) d \mathbf{y} .
$$

Tendo em vista a Definição 2.1 .2 e usando a regra da cadeia é fácil ver que

$$
\int_{\Omega_{0}} \frac{\partial f}{\partial t}\left(\phi_{t}(\mathbf{y}), t\right) J(\mathbf{y}, t) d \mathbf{y}=\int_{\Omega_{t}} \frac{D f}{D t}(\mathbf{x}, t) d \mathbf{x} .
$$

O determinante Jacobiano é dado por

$$
J=\left|\begin{array}{lll}
\frac{\partial \phi_{1}}{\partial y_{1}} & \frac{\partial \phi_{1}}{\partial y_{2}} & \frac{\partial \phi_{1}}{\partial y_{3}} \\
\frac{\partial \phi_{2}}{\partial y_{1}} & \frac{\partial \phi_{2}}{\partial y_{2}} & \frac{\partial \phi_{2}}{\partial y_{3}} \\
\frac{\partial \phi_{3}}{\partial y_{1}} & \frac{\partial \phi_{3}}{\partial y_{2}} & \frac{\partial \phi_{3}}{\partial y_{3}}
\end{array}\right|,
$$


calculados todos no ponto $(\mathbf{y}, t)$. Desenvolvendo o determinante obtém-se

$J=\frac{\partial \phi_{1}}{\partial y_{1}} \frac{\partial \phi_{2}}{\partial y_{2}} \frac{\partial \phi_{3}}{\partial y_{3}}+\frac{\partial \phi_{1}}{\partial y_{2}} \frac{\partial \phi_{2}}{\partial y_{3}} \frac{\partial \phi_{3}}{\partial y_{1}}+\frac{\partial \phi_{1}}{\partial y_{3}} \frac{\partial \phi_{2}}{\partial y_{1}} \frac{\partial \phi_{3}}{\partial y_{2}}-\frac{\partial \phi_{1}}{\partial y_{2}} \frac{\partial \phi_{2}}{\partial y_{1}} \frac{\partial \phi_{3}}{\partial y_{3}}-\frac{\partial \phi_{1}}{\partial y_{1}} \frac{\partial \phi_{2}}{\partial y_{3}} \frac{\partial \phi_{3}}{\partial y_{2}}-\frac{\partial \phi_{1}}{\partial y_{3}} \frac{\partial \phi_{2}}{\partial y_{2}} \frac{\partial \phi_{3}}{\partial y_{1}}$

Para calcular $\frac{\partial J}{\partial t}$ deve-se usar a regra multiplicação e da cadeia para todos os termos da equação acima, por exemplo, para o primeiro termo

$$
\frac{\partial}{\partial t}\left(\frac{\partial \phi_{1}}{\partial y_{1}} \frac{\partial \phi_{2}}{\partial y_{2}} \frac{\partial \phi_{3}}{\partial y_{3}}\right)=\frac{\partial v_{1}}{\partial x_{1}} \frac{\partial \phi_{1}}{\partial y_{1}} \frac{\partial \phi_{2}}{\partial y_{2}} \frac{\partial \phi_{3}}{\partial y_{3}}+\frac{\partial \phi_{1}}{\partial y_{1}} \frac{\partial v_{2}}{\partial x_{2}} \frac{\partial \phi_{2}}{\partial y_{2}} \frac{\partial \phi_{3}}{\partial y_{3}}+\frac{\partial \phi_{1}}{\partial y_{1}} \frac{\partial \phi_{2}}{\partial y_{2}} \frac{\partial \phi_{3}}{\partial y_{3}} \frac{\partial v_{3}}{\partial x_{3}},
$$

é possivel notar que aparecem os termos das velocidades multiplicando todo o termo do determinante. Seguindo este processo para todos os fatores é possível notar que

$$
\begin{aligned}
& \frac{\partial J}{\partial t}=\sum_{k=1}^{3}\left|\begin{array}{ccc}
\frac{\partial v_{1}}{\partial x_{k}} \frac{\partial \phi_{1}}{\partial y_{1}} & \frac{\partial v_{1}}{\partial x_{k}} \frac{\partial \phi_{1}}{\partial y_{2}} & \frac{\partial v_{1}}{\partial x_{k}} \frac{\partial \phi_{1}}{\partial y_{3}} \\
\frac{\partial \phi_{2}}{\partial y_{1}} & \frac{\partial \phi_{2}}{\partial y_{2}} & \frac{\partial \phi_{2}}{\partial y_{3}} \\
\frac{\partial \phi_{3}}{\partial y_{1}} & \frac{\partial \phi_{3}}{\partial y_{2}} & \frac{\partial \phi_{3}}{\partial y_{3}}
\end{array}\right|+\sum_{k=1}^{3}\left|\begin{array}{ccc}
\frac{\partial \phi_{1}}{\partial y_{1}} & \frac{\partial \phi_{1}}{\partial y_{2}} & \frac{\partial \phi_{1}}{\partial y_{3}} \\
\frac{\partial v_{2}}{\partial x_{k}} \frac{\partial \phi_{2}}{\partial y_{1}} & \frac{\partial v_{2}}{\partial x_{k}} \frac{\partial \phi_{2}}{\partial y_{2}} & \frac{\partial v_{2}}{\partial x_{k}} \frac{\partial \phi_{2}}{\partial y_{3}} \\
\frac{\partial \phi_{3}}{\partial y_{1}} & \frac{\partial \phi_{3}}{\partial y_{2}} & \frac{\partial \phi_{3}}{\partial y_{3}}
\end{array}\right|+ \\
& \sum_{k=1}^{3}\left|\begin{array}{ccc}
\frac{\partial \phi_{1}}{\partial y_{1}} & \frac{\partial \phi_{1}}{\partial y_{2}} & \frac{\partial \phi_{1}}{\partial y_{3}} \\
\frac{\partial \phi_{2}}{\partial y_{1}} & \frac{\partial \phi_{2}}{\partial y_{2}} & \frac{\partial \phi_{2}}{\partial y_{3}} \\
\frac{\partial v_{3}}{\partial x_{k}} \frac{\partial \phi_{3}}{\partial y_{1}} & \frac{\partial v_{3}}{\partial x_{k}} \frac{\partial \phi_{3}}{\partial y_{2}} & \frac{\partial v_{3}}{\partial x_{k}} \frac{\partial \phi_{3}}{\partial y_{3}}
\end{array}\right|
\end{aligned}
$$

logo é obtido a seguinte igualdade

$$
\frac{\partial J}{\partial t}=J \nabla \cdot v
$$

com $J$ calculado em $(\mathbf{y}, t)$ e $v$ calculado em $(\phi(\mathbf{y}, t), t)$. Então é obtido

$$
\int_{\Omega_{0}} f(\phi(\mathbf{y}, t), t) \frac{\partial J}{\partial t}(\mathbf{y}, t) d \mathbf{y}=\int \Omega_{0} f(\phi(\mathbf{y}, t), t) \nabla \cdot v(\mathbf{y}, t) J(\mathbf{y}, t) d \mathbf{y}
$$

usando que $x=\phi_{t}(\mathbf{y})$ chega-se a

$$
\int_{\Omega_{t}} f(\mathbf{x}, t) \nabla v(\mathbf{x}, t) d \mathbf{x}
$$

\subsection{Equação da conservação de massa}

A equação de conservação de massa pode ser obtida observando que a variação de quantidade total de massa no tempo deve ser igual ao fluxo de massa através do bordo do domínio. A quantidade total de massa é dada por

$$
M(t)=\int_{\Omega} \rho(\mathbf{x}, t) d \mathbf{x},
$$


onde $\Omega \subset \mathbb{R}^{3}$ é uma região arbitrária e $\rho$ a densidade da massa. A taxa de variação no tempo da quantidade de massa é a sua derivada no tempo

$$
\frac{d M}{d t}=\frac{d}{d t} \int_{\Omega} \rho(\mathbf{x}, t) d \mathbf{x}
$$

Como é mostrado em [10] a hipótese de que a massa se conserva se expressa como

$$
\frac{d}{d t} \int_{\Omega_{0}} \rho(\mathbf{x}, 0) d \mathbf{x}=\frac{d}{d t} \int_{\Omega_{t}} \rho(\mathbf{x}, t) d \mathbf{x}
$$

onde $\Omega_{t}$ é uma região que é uma imagem de $\Omega_{0}$ pela função fluxo $\phi_{t}$. Assumindo que a densidade seja de classe $C^{1}$ e aplicando o Teorema do Transporte

$$
0=\frac{d}{d t} \int_{\Omega_{t}} \rho(\mathbf{x}, t) d \mathbf{x}=\int_{\Omega_{t}} \frac{D \rho}{D t}+\rho \nabla \cdot \mathbf{v}(\mathbf{x}, t) d \mathbf{x} .
$$

Se $\Omega$ é um aberto qualquer ocupado pelo fluido no instante t, então existe um aberto $\Omega_{0}$ tal que $\phi_{t}\left(\Omega_{0}\right)=\Omega$, já que $\phi_{t}$ é inversível e contínua por hipótese. É obtido que a função

$$
\frac{D \rho}{D t}+\rho \nabla \cdot v
$$

é contínua e sua integral em algum instante de tempo qualquer sobre algum aberto do espaço é nula. Este fato só é possível se a função (2.25) for identicamente nula. Assim,

$$
\frac{D \rho}{D t}+\rho \nabla \cdot v=0
$$

é dita a equação de conservação da continuidade. A equação acima pode ser simplificada. Sabemos que

$$
\frac{D \rho}{D t}=\frac{\partial \rho}{\partial t}+\nabla \rho \cdot v
$$

temos

$$
\frac{\partial \rho}{\partial t}+\underbrace{\nabla \rho \cdot v+\rho \nabla \cdot v}_{=\nabla \cdot(\rho v)}=0
$$

$\log 0$

$$
\frac{\partial \rho}{\partial t}+\nabla \cdot(\rho v)=0
$$

Nota-se que a equação (2.29) é a Lei de Conservação de Massa em sua forma diferencial e é equação a derivadas parciais do tipo hiperbólica. 


\subsection{Advecção e difusão em cinética química}

Um caso particular de uma equação de advecção-difusão é a equação do escalar conservado que é discutido nos trabalhos de [6] e [23]. Para tal, é considerada as hipóteses de reações químicas estequiométricas, infinitamente rápidas e irreversíveis. As reações químicas consideradas, por simplicidade, envolvem três espécies químicas: combustível (C), oxidante $(\mathrm{O})$ e produto $(\mathrm{P})$. A reação é descrita por

$$
C+s O \rightarrow(1+s) P
$$

que pode ser lida como combustível mais s vezes oxidante produz $(1+s)$ vezes o produto. O termo $s$ representa a razão da massa estequimométrica entre a quantidade de oxidante e combustível que pode ser escrito como

$$
s=\left(\frac{Y_{O}}{Y_{C}}\right)_{e s t},
$$

onde $Y_{O}$ e $Y_{C}$ são a fração mássica do oxidante e do combustível, respectivamente. As frações mássicas $Y_{O}, Y_{C}$ e $Y_{P}$ são dadas pelas equações abaixo

$$
\frac{\partial \rho Y_{l}}{\partial t}+\nabla \cdot\left((\rho \mathbf{u}) Y_{l}\right)=\nabla \cdot\left(D \rho \nabla Y_{l}\right)+\dot{\omega}_{l}, \text { para } 1=P, O, C .
$$

É válido ressaltar que (2.30) e (2.31) são encontradas e descritas em maior detalhes em [23] e [9]. Cada termo $\dot{\omega}_{l}$ representa a taxa de consumo ou criação do produto, oxidante e combustível respectivamente devido a reações químicas, $\rho$ representa a massa específica e $D$ o coeficiente de difusão expresso em $\mathrm{m}^{2} / \mathrm{s}$ [11]. A equação (2.31) representa matematicamente a lei: variação de massa da espécie somado a taxa de variação de diminuição de massa da espécie por convecção resulta em taxa de variação de aumento de massa da espécie por difusão somado a taxa de variação de aumento de massa da espécie por criação de fontes de criação volumétrica de espécies. A partir da resolução das equações que envolvem as frações mássicas $Y_{l}$ e a temperatura $T$, e de algumas simplicações que podem ser encontradas em [9] e [6] são introduzidas novas variáveis $Z_{i} \operatorname{com} i=1,2,3$ denominadas de fração de mistura. Estas satisfazem a equação de advecção-difusão sem o termo fonte

$$
\frac{\partial \rho Z_{i}}{\partial t}+\nabla \cdot\left(\rho \mathbf{u} Z_{i}\right)=\nabla \cdot\left(\rho D \nabla Z_{i}\right)
$$

Como pode ser visto em [6] uma chama de difusão, combustível e oxidante entram separadamente na zona de reação, assim os $Z_{i}$ assumem dois valores na entrada da zona de reação: $Z_{i, C}$ na região da entrada do combustível e $Z_{i, O}$ na regiãoo da entrada do oxidante. 
Os escalares $Z_{i}$ normalizados são definidos por

$$
z_{i}=\frac{Z_{i}-Z_{i, O}}{Z_{i, C}-Z_{i, O}} \text { para } \mathrm{i}=1,2,3
$$

com os quais satisfazem (2.32) e possuem o mesmo valor na entrada da zona de reação, quando $Z_{i}=Z_{i, C}$ tem-se $z_{i}=1$ que mostra presença de combustível e quando $Z_{i}=Z_{i, O}$ tem-se $z_{i}=0$, mostrando presença de oxidante. Com estas observações (2.32) pode ser reescrita como

$$
\frac{\partial \rho z}{\partial t}+\nabla \cdot((\rho \mathbf{u}) z)=\nabla \cdot(\rho D \nabla z)
$$

onde z é o escalar conservado que é uma variável introduzida de modo a reduzir o número de equações a serem resolvidas no processo de reação química descrita. Após solucionar numericamente a equação acima, é necessário para determinar a estrutura de uma chama as relações entre frações mássicas $Y_{l}(z)$ e a temperatura $T(z)$, e tais relações podem ser encontrados em [6], [11] e [9].

Outras equações aparecem como exemplo de transporte e difusão em cinética química. Dado uma variável filtrada de progresso $\tilde{c}$, que representa uma razão entre as temperaturas de gases queimados ou frescos conforme [24], é possível, em um campo euleriano, resolver

$$
\frac{\partial \bar{\rho} \tilde{c}}{\partial t}+\nabla \cdot(\bar{\rho} \tilde{\mathbf{u}} \tilde{c})=\nabla \cdot\left(\bar{\rho}\left(\tilde{D}+\tilde{D}_{T}\right) \nabla \tilde{c}\right)+\bar{S}(c)
$$

onde o termo de difusividade turbulenta $\tilde{D_{T}}$ é calculado pelo método euleriano e o termo $\bar{S}(c)$, que representa taxa de reação química, é calculada no método lagrangiano [24]. A variância de uma variável filtrada de progresso, ou o segundo momento central, é modelada como

$$
\frac{\partial \bar{\rho} c^{\prime \prime 2}}{\partial t}+\nabla \cdot\left(\bar{\rho} \tilde{\mathbf{u}} \tilde{c}^{\tilde{\prime \prime} 2}\right)=\nabla \cdot\left(\bar{\rho}\left(\tilde{D}+\tilde{D}_{T}\right) \nabla \tilde{c^{\prime \prime 2}}\right)-2 \bar{\rho}\left(\tilde{D}+\tilde{D}_{T}\right)(\nabla \tilde{c})^{2}-2 C_{\Omega} \tilde{c}^{\prime \prime 2} \Omega_{M}+2 \overline{(c-\tilde{c})}
$$

onde $C_{\Omega}$ é uma razão de escala de tempo que é assumida constante [24]. A descrição completa destas equações fogem do escopo deste trabalho e detalhes dos mesmos podem ser encontrados em [21], [24], [20].

\subsection{Equação geral de advecção-difusão}

Equações de advecção-difusão são apresentadas nos trabalhos de [24] e [6], este trabalho se adequa nos seguintes modelos propostos: continuidade de massa, escalar transportado [6] e acoplamento LES/PDF [24]. No presente trabalho é apresentado uma equação geral de advecção-difusão para que possa englobar os modelos descritos nos trabalhos acima re- 
feridos. Vale ressaltar que o presente trabalho objetiva apoiar futuros desenvolvimentos e implementações feitas em colaboração IME-USP/FEMEC-UFU. Esta equação geral tem a forma

$$
\frac{\partial(\rho \varphi)}{\partial t}+\nabla \cdot((\rho \varphi) \mathbf{u})=\nabla \cdot(\omega \rho \nabla \varphi)+S+\xi
$$

onde $\rho=\rho(\mathbf{x}, t)$ é a massa específica, $\varphi=\varphi(\mathbf{x}, t)$ um escalar qualquer a ser transportado, $S=S(\mathbf{x}, t)$ o termo forçante, $\xi=\xi(\varphi)$ uma função linear do escalar $\varphi, \omega=\omega(\mathbf{x}, t)$ uma função escalar qualquer que pode ser pensada como um coeficiente de difusão que irá variar e $\mathbf{u}=\mathbf{u}(\mathbf{x}, t)$ um campo de velocidades qualquer. É importante notar que o campo escalar deve ser pelo menos uma vez derivável em relação ao tempo e duas vezes derivável no espaço. Note que (2.37) é base para modelar muitos fenômenos físicos e químicos. Quando conveniente é possível escrever (2.37), pois esta é linear, na seguinte forma

$$
\frac{\partial(\rho \varphi)}{\partial t}+\nabla \cdot \mathbf{F}=S(\mathbf{x}, t)+\xi(\varphi)
$$

onde o fluxo $\mathbf{F}$ é escrito em função dos termos advectivo e difusivo, neste caso teremos

$$
\mathbf{F}=(\rho \mathbf{u}) \varphi-\omega(\mathbf{x}, t) \rho \nabla \varphi
$$

A equação (2.37) pode ser escrita também na forma de operador

$$
\mathbb{K}[\varphi]=\frac{\partial(\rho \varphi)}{\partial t}+\nabla \cdot((\rho \varphi) \mathbf{u})-\nabla \cdot(\omega(\mathbf{x}, t) \rho \nabla \varphi)-\xi \varphi
$$

que nos dá

$$
\mathbb{K}[\varphi]=S(\mathbf{x}, t)
$$

O operador linear de advecção-difusão $\mathbb{K}$ é útil para escrever o algoritmos multinvel-multigrid a ser apresentado nos próximos capítulos do presente trabalho.

É possível reduzir (2.37) a (2.35), (2.36) ou (2.34), bastando para isto realizar uma escolha conveniente para algumas funções ou parâmetros. Por exemplo, a escolha

$$
\begin{aligned}
& \rho=\bar{\rho} \\
& \varphi=\tilde{c}, \\
& \omega=\tilde{D}+\tilde{D}_{T}, \\
& S=\bar{S}(c), \\
& \xi(\varphi)=0 .
\end{aligned}
$$


faz com que (2.37) assuma a forma (2.35), a escolha

$$
\begin{aligned}
& \rho=\bar{\rho} \\
& \varphi=c^{\prime \prime 2} \\
& \omega=\tilde{D}+\tilde{D}_{T} \\
& S=2 \bar{\rho}\left(\Gamma+\Gamma_{S G S}\right)(\nabla \tilde{c})^{2}+2 \overline{(c-\tilde{c})} \\
& \xi(\varphi)=-2 C_{\Omega} \Omega_{m} \varphi .
\end{aligned}
$$

faz com que (2.37) assuma a forma (2.36), e finalmente a escolha

$$
\begin{aligned}
& \varphi=z, \\
& \omega=D, \\
& S=0, \\
& \xi(\varphi)=0 .
\end{aligned}
$$

faz com que (2.37) assuma a forma (2.34). 


\section{Capítulo 3}

\section{Metodologia Numérica}

Neste capítulo são apresentadas as metodologias empregadas para se para se obter a solução numérica de (2.37), o modelo matemático genérico, que é o foco do presente trabalho. A discretização temporal, baseada em [3] e [24], dá ênfase ao Método de Crank-Nicolson, ainda que, outros métodos implícitos de passo simples e múltiplo (Euler Implícito, Gear, etc...) tenham sido implementados parametricamente por um arquivo de entrada que chama a função correspondente a cada um deles. A discretização espacial é baseada em fluxos usando o Método dos Volumes Finitos como descrito em [17]. As soluções dos sistemas lineares oriundos do esquema implícito são obtidas pelo método multigrid-multinível que é abordado em detalhes no Capítulo 4. Na Seção 3.1, questões teóricas sobre o método dos volumes finitos são apresentadas ao leitor com o auxílio de alguns exemplos. A Seção 3.2 aborda a solução númerica da equação geral de advecção-difusão assim como sua discretização temporal. A discretização espacial é discutida na Seção 3.3. A montagem de malhas adaptativas blocoestruturadas, critério de seleção de pontos para refinamento e outras questões que envolvem malhas compostas são abordados na Seção 3.4. Na Seção 3.5, apresenta-se um sumário da metodologia numérica, assim como um algoritmo para um passo no tempo de maneira a resolver a equação geral de advecção-difusão.

\subsection{Método dos Volumes Finitos}

Uma das características do Método dos Volumes Finitos é que este pode ser aplicado tanto em malhas estruturadas como malhas não estruturadas. Segundo [8], uma malha não estruturada é constituída de formas geométricas simples, tais como, triângulos ou tetraedros sem buracos ou sobreposição. A disposição dessas formas geométricas para constituir a malha não possui padrão algum. O caso contrário é chamada de malha estruturada. Neste trabalho, são abordados apenas malhas estruturadas. Outra característica é o uso da forma integral das leis de conservação, que além de permitir o uso de um campo de vetores não necessariamente suave também nos produz uma discretização conservativa. Neste trabalho será usado o esquema de células centradas ou cell-centered scheme. De acordo com [6], os 
volumes de controle são as células computacionais, os valores escalares são definidos no centro de célula e os fluxos são definidos no centro das faces dos paralelepípedos. Dado uma célula computacional arbitrária é possível localizar seu centro usando

$$
\mathbf{x}_{i j k}=\left(a_{1}+\left(i-\frac{1}{2}\right) \Delta x, a_{2}+\left(j-\frac{1}{2}\right) \Delta y, a_{3}+\left(k-\frac{1}{2}\right) \Delta z\right)
$$

para $1 \leq i \leq N_{x}, 1 \leq j \leq N_{y}$ e $1 \leq k \leq N_{z}$. Denotam-se $e, w, n, s, t$ e $b$ as respectivas direções das faces, para localizar a face norte $x_{n}=x_{i j+\frac{1}{2} k}$, a face sul $x_{s}=x_{i j-\frac{1}{2} k}$, a face leste $x_{e}=x_{i+\frac{1}{2} j k}$, a face oeste $x_{w}=x_{i-\frac{1}{2} j k}$, a face de cima top $x_{t}=x_{i j k+\frac{1}{2}}$ e a face de baixo bottom $x_{b}=x_{i j k-\frac{1}{2}}$. Uma célula computacional com seus respectivos rótulos pode ser vista na Figura 3.1.

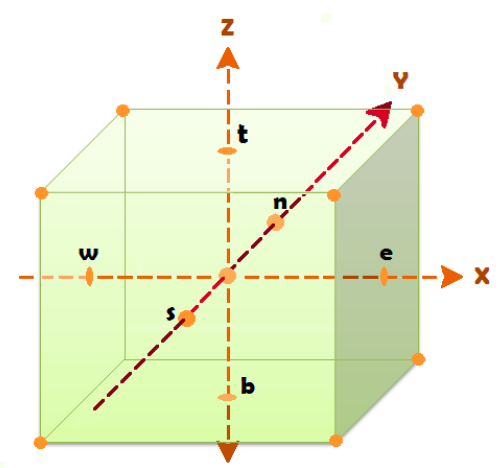

Figura 3.1: Célula computacional e rótulo das faces.

Considere a seguinte lei de conservação de uma quantidade $q$ arbitrária

$$
\frac{\partial q}{\partial t}+\nabla \cdot \mathbf{F}=S
$$

onde $\mathbf{F}$ é um fluxo qualquer ao menos uma vez derivável e $S$ um termo forçante qualquer. Considere um domínio computacional $\Omega$, calculando a integral em ambos os lados em (3.2) por toda a região do domínio obtém-se

$$
\int_{\Omega} \frac{\partial q}{\partial t} d \Omega+\int_{\Omega} \nabla \cdot \mathbf{F} d \Omega=\int_{\Omega} S d \Omega
$$

Em (3.3), aplica-se o Teorema da Divergência para obter

$$
\frac{\partial}{\partial t} \int_{\Omega} q d \Omega+\int_{\partial \Omega}(\mathbf{F} \cdot \mathbf{n}) d \partial \Omega=\int_{\Omega} S d \Omega
$$

Discretizando (3.4) no espaço, obtém-se

$$
\frac{\partial}{\partial t}\left(q_{i j k} V_{\Omega}\right)+\sum_{\text {faces }}(\mathbf{F} \cdot \mathbf{n}) \Delta \partial \Omega=S_{i j k} V_{\Omega},
$$


onde $V_{\Omega}$ é o volume de uma célula computacional, $q_{i j k}$ e $S_{i j k}$ são a quantidade escalar e o termo forçante calculados no centro de uma mesma célula computacional. Sejam $f, g$ e $h$ as componentes escalar do fluxo $\mathbf{F}$ e $\Delta x, \Delta y$ e $\Delta z$ os tamanhos das arestas da célula computacional. Para calcular o somatório da equação (3.5), faz-se necessário pegar o valor do fluxo nas faces de cada uma das direções do bordo do domínio e observar que $\mathbf{n}$ representa a normal exterior ao cubo, por exemplo, no eixo $x$ obtém-se

$$
\sum_{\text {faces }_{x}}(F \cdot n) \Delta \partial \Omega=f_{e} \Delta y \Delta z+f_{w}(-\Delta y \Delta z)=\left(f_{e}-f_{w}\right) \Delta y \Delta z
$$

onde $\Delta \partial \Omega=\Delta y \Delta z$ que é a área da face do cubo correspondente ao eixo $x, f_{e}=f_{i+\frac{1}{2} j k}$ e $f_{w}=f_{i-\frac{1}{2} j k}$ que correspondem a componente $f$ do fluxo $F$ calculada nas faces leste $(e)$ e oeste $(w)$. O mesmo raciocínio pode ser aplicado aos eixos y e $z$ e usando que $V_{\Omega}=\Delta x \Delta y \Delta z$ então a equação 3.5 fica na forma

$$
\frac{\partial}{\partial t}\left(q_{i j k}\right) \Delta x \Delta y \Delta z+\left(f_{e}-f_{w}\right) \Delta y \Delta z+\left(g_{n}-g_{s}\right) \Delta x \Delta z+\left(h_{t}-h_{b}\right) \Delta x \Delta y=S_{i j k} \Delta x \Delta y \Delta z
$$

Divide-se (3.7) pelo volume da célula e usando as coordenadas cartesianas vamos obter da discretização por volumes finitos. Vale ressaltar que a equação que é obtida também pode ser deduzida diretamente via diferenças finitas, porém, o método aplicado serve para malhas não estruturadas além de nos garantir a conservação da propriedade $q$

$$
\frac{\partial}{\partial t}\left(q_{i j k}\right)+\frac{\left(f_{i+\frac{1}{2} j k}-f_{i-\frac{1}{2} j k}\right)}{\Delta x}+\frac{\left(g_{i j-\frac{1}{2} k}-g_{i j+\frac{1}{2} k}\right)}{\Delta y}+\frac{\left(h_{i j k+\frac{1}{2}}-h_{i j k-\frac{1}{2}}\right)}{\Delta z}=S_{i j k} .
$$

\subsection{Discretização temporal}

O esquema temporal em uso neste trabalho é o totalmente implícito, como visto em [24]. Um esquema temporal implícito é aquele que, para a solução do problema numérico, depende do cômputo dos valores dos operadores espaciais calculados em tempos futuros, assim sendo, é obtido um sistema linear que é, em geral, esparso. Genericamente, os métodos implícitos de passo múltiplo podem ser escritos na forma

$$
\frac{(\rho \varphi)^{n+1}-(\rho \varphi)^{n}}{d t}=\theta m_{1}+(1-\theta) m_{0}
$$

onde o coeficiente $\theta=1$ ou $\theta=\frac{1}{2}$ nos dando respectivamente os métodos Euler Implícito e Crank-Nicolson. É possível ver que se $\theta=0$ obtemos o método de Euler Explícito. Os coeficientes $m$ são dados por

$$
m_{k+1}=\left(\nabla \cdot\left(\omega^{n+k} \rho^{n+k} \nabla \varphi^{n+k}\right)\right)+S^{n+k}+\xi\left(\varphi^{n+k}\right)-\left(\nabla \cdot\left((\rho \varphi)^{n+k} \mathbf{u}^{n+k}\right)\right)
$$


para $k \in\{0,1\}$. Note que supõem-se conhecidos no instante $t=t^{n+1}$ os valores de $\mathbf{u}$ e $\rho$ pois estes deverão ter sido calculados previamente. Como descrito em [6], considerando três instantes no tempo $t^{n-1}, t^{n}$ e $t^{n+1}$, implementou-se também esquemas de dois passos para a equação de advecção-difusão (2.37), dados parametricamente por

$$
\alpha_{2}(\rho \varphi)^{n+1}+\alpha_{1}(\rho \varphi)^{n}+\alpha_{0}(\rho \varphi)^{n-1}=\theta_{2} m_{2}+\theta_{1} m_{1}+\theta_{0} m_{0}
$$

onde os termos $m_{k}$ são dados pela expressão (3.10) para $k=-1,0,1$. Os coeficientes $\theta$ e $\alpha$ descrevem quais métodos numéricos devem ser utilizados sendo que $\alpha_{2} \neq 0$ e $\theta_{2} \neq 0$. Os parâmetros em questão são dados por

$$
\begin{gathered}
\alpha_{2}=\frac{\Delta t^{n}+2 \gamma \Delta t^{n+1}}{\Delta t^{n}+\Delta t^{n+1}} \\
\alpha_{1}=\frac{\Delta^{t} n+1-\Delta t^{n}-2 \gamma \Delta t^{n+1}}{\Delta t^{n}} \\
\alpha_{0}=-\left(\alpha_{2}+\alpha_{1}\right) \\
\theta_{2}=\gamma+c \frac{\Delta t^{n+1}}{\Delta t^{n}+\Delta t^{n+1}} \\
\theta_{1}=1-\gamma-c \frac{\Delta t^{n+1}}{\Delta t^{n}} \\
\theta_{0}=c\left(\frac{\Delta t^{n+1}}{\Delta t^{n}}-\frac{\Delta t^{n+1}}{\Delta t^{n}+\Delta t^{n+1}}\right)
\end{gathered}
$$

No trabalho de [26], são apresentados várias combinações dos parâmetros $\gamma$ e $c$ de modo a obter discretizações temporais diferentes e como consequência geram sistemas lineares diferentes para a discretização de (2.37). As escolhas para o par $(c, \gamma)$ são

- Crank-Nicolson Adams-Bashforth $(0,0.5)$;

- Crank-Nicolson Adams-Bashforth Modificado (0.125,0.5);

- Gear extrapolado $(0,1)$;

- Crank-Nicolson Leap-Frog $(1,0)$.

Embora tenham sido implementadas ambas as discretizações paramétricas, para esquemas temporais de um e de dois passos, manteve-se o foco nos esquemas de um passo (3.9) e, dentre estes, em particular nos métodos de Crank-Nicolson e alguns métodos de passo múltiplo. 


\subsection{Discretização espacial}

A discretização espacial da equação geral de advecção-difusão (2.37) apresentada neste trabalho é uma adaptação do método dos volumes finitos apresentada na Seção 3.1 deste capítulo. Primeiramente, as variáveis escalares definidas no centro de célula devem ser interpoladas para as faces usando o operador $I^{c \rightarrow f}$ que pode ser definido como

$$
\begin{aligned}
& I_{y z}^{c \rightarrow f}(q)_{i+\frac{1}{2} j k}=\frac{q_{i+1 j k}+q_{i j k}}{2}, \\
& I_{x z}^{c \rightarrow f}(q)_{i j+\frac{1}{2} k}=\frac{q_{i j+1 k}+q_{i j k}}{2}, \\
& I_{x y}^{c \rightarrow f}(q)_{i j k+\frac{1}{2}}=\frac{q_{i j k+1}+q_{i j k}}{2},
\end{aligned}
$$

onde $q=\zeta, \omega, \varphi, \rho$ que são todas as variáveis definidas no centro de célula usadas neste trabalho. As componentes da velocidade $\mathbf{u}=(u, v, w)$ são definidas na face e não necessitam de interpolação alguma, ou seja, o operador $I^{c \rightarrow f}$ é o operador identidade quando é aplicado a tais variáveis.

Para a completa discretização do termo difusivo, a quantidade vetorial $\omega_{f} \rho_{f} \nabla \varphi$ que aparece neste caso deve ser corrigida em caso de malha composta, isto é, os valores de cada face já receberam a média dos valores das faces mais finas que a recobrem (se tais faces existirem) como é ilustrado na Figura 3.2.

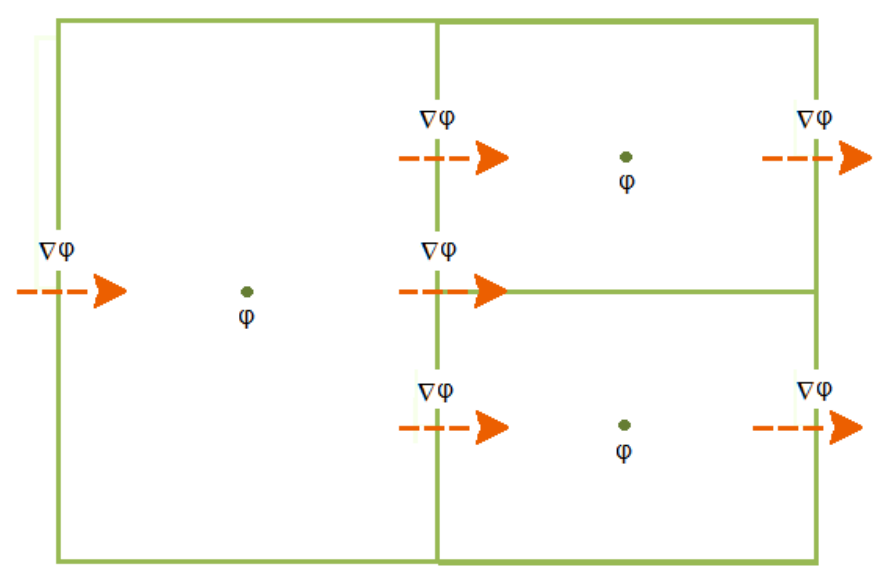

Figura 3.2: Projeção em $2 D$ da interpolação das faces.

Esta operação, que será chamada de correção de fluxo, é feita do nível mais fino para o mais grosso. Tal operador será denotado aqui como $\mathcal{C}$, onde este recebe um vetor como argumento em uma dada face e efetua a correção descrita. Note que este operador devolverá o mesmo valor caso não houver intersecção da face com outros níveis. Este operador age como identidade quando a malha em questão é a uniforme. 
O gradiente discreto para a variável $\varphi$ pode ser escrito como

$$
\left(\nabla^{h} \varphi\right)_{i j k}=\left(\frac{\varphi_{i j k}-\varphi_{i-1 j k}}{\Delta x}, \frac{\varphi_{i j k}-\varphi_{i j-1 k}}{\Delta y}, \frac{\varphi_{i j k-1}-\varphi_{b}}{\Delta z}\right) .
$$

Aplicando o operador de correção aos escalares de centro obtém-se

$$
\mathbf{G}=\mathcal{C}\left(I^{c \rightarrow f}\left(\omega_{i j k} \rho_{i j k}\right) \nabla \varphi_{i j k}^{n}\right),
$$

Finalmente o termo difusivo é dado por

$$
\nabla \cdot\left(\omega^{n} \rho^{n} \nabla \varphi^{n}\right)=\frac{G_{1, i+1 j k}^{n}-G_{1, i-1 j k}^{n}}{\Delta x}+\frac{G_{2, i j+1 k}^{n}-G_{2,1 j-1 k}^{n}}{\Delta y}+\frac{G_{3, i j k+1}^{n}-G_{3, i j k-1}^{n}}{\Delta z} .
$$

Uma estratégia análoga é aplicada para o termo advectivo

$$
\mathbf{U}=\mathcal{C}\left(I^{c \rightarrow f}\left(\rho_{i j k}^{n} \varphi_{i j k}^{n}\right) \mathbf{u}_{i j k}^{n}\right)
$$

que nos permite escrever sua discretização

$$
\nabla \cdot\left(\rho^{n} \varphi^{n} \mathbf{u}^{n}\right)=\frac{U_{1, i+1 j k}^{k}-U_{1, i-1 j k}^{k}}{\Delta x}+\frac{U_{2, i j+1 k}^{n}-U_{2, i j-1 k}^{n}}{\Delta y}+\frac{U_{3, i j k+1}^{n}-U_{3, i j k-1}^{n}}{\Delta z} .
$$

A ordem de convergência esperada é a mesma que o método dos volumes finitos para malhas uniformes que é 2 .

\subsection{Estabilidade}

O método de análise da estabilidade analisado neste trabalho é o de von Neumann que estuda o crescimento de ondas $e^{i k x}$ similares a métodos de Fourier [14]. Nesta seção será analisada a estabilidade do método de Crank-Nicolson para a equação (2.37). O método de discretização citado foi escolhido por estar no centro da discussão no capítulo de resultados deste trabalho. A análise será feita em 1D por questões de simplicidade e em uma malha uniforme com coeficientes constantes, onde os métodos de volumes finitos e de diferenças finitas são iguais [17]. A versão 1D da discretização de (2.37) é escrita como

$$
\begin{array}{r}
\rho\left(\frac{\varphi_{k}^{n+1}-\varphi_{k}^{n}}{\Delta t}\right)+\frac{1}{2} \rho U\left(\frac{\varphi_{k}^{n+1}-\varphi_{k-1}^{n+1}}{\Delta x}+\frac{\varphi_{k}^{n}-\varphi_{k-1}^{n}}{\Delta x}\right)= \\
\rho \omega \frac{1}{2}\left(\frac{\varphi_{k+1}^{n+1}+2 \varphi_{k}^{n+1}-\varphi_{k-1}^{n+1}}{\Delta x^{2}}+\frac{\varphi_{k+1}^{n}+2 \varphi_{k}^{n}-\varphi_{k-1}^{n}}{\Delta x^{2}}\right)+\frac{\zeta}{2}\left(\varphi_{k}^{n+1}+\varphi_{k}^{n}\right) .
\end{array}
$$

Segundo [14] a análise da estabilidade sob a ótica de von Neumann é baseado no fato de que a função $W_{j}(\xi)=e^{i j h \xi}$ é uma auto-função de qualquer operador na discretização por 
diferenças finitas. Substituindo $W_{j}$ em (3.26)

$$
\begin{aligned}
& \rho\left(\frac{g(\xi) e^{i j h \xi}-e^{i j h \xi}}{\Delta t}\right)+\frac{1}{2} \rho U\left(\frac{g(\xi) e^{i j h \xi}-g(\xi) e^{i(j-1) h \xi}}{\Delta x}+\frac{e^{i j h \xi}-e^{i(j-1) h \xi}}{\Delta x}\right)= \\
& \rho \omega \frac{1}{2}\left(\frac{g(\xi) e^{i(j+1) h \xi}+2 g(\xi) e^{i j h \xi}-g(\xi) e^{i(j-1) h \xi}}{\Delta x^{2}}+\frac{e^{i(j+1) h \xi}+2 e^{i j h \xi}-e^{i(j-1) h \xi}}{\Delta x^{2}}\right)+ \\
& \frac{\zeta}{2}\left(g(\xi) e^{i j h \xi}+e^{i j h \xi}\right),
\end{aligned}
$$

onde $g(\xi)$ é o fator de amplicação do erro de um passo de integração $k$ para um passo futuro $k+1$. Agrupando-se os termos necessários em (3.27) temos

$$
g=1-\frac{(1+g) U \Delta t}{2 \Delta x}\left(1-e^{-i h \xi}\right)+\frac{(1+g) \omega \Delta t}{2 \Delta x^{2}}\left(e^{i h \xi}-2+e^{-i h \xi}\right)+\frac{\zeta \Delta t}{2}(1+g),
$$

e isolando $g$ e fazendo $\alpha=\frac{U \Delta t}{2 \Delta x}, \beta=\frac{\omega \Delta t}{2 \Delta x^{2}}$ e $\gamma=\frac{\zeta \Delta t}{2}$

$$
g=\frac{1-\alpha\left(1-e^{-i h \xi}\right)+2 \beta(\cos (h \xi)-1)+\gamma}{1+\alpha\left(1-e^{-i h \xi}\right)-2 \beta(\cos (h \xi)-1)-\gamma}
$$

que nos dá $|g| \leq 1$ para todo $\xi$ o que implica que o método é estável, ou seja, o fator de amplificação não impacta no erro do método, para qualquer escolha de $\Delta x$ e $\Delta t$.

\subsection{Malha adaptativa bloco-estruturada}

Nesta seção é abordada a técnica de malha adaptativa, incialmente proposta por [4], que concentra uma melhor aproximação das soluções numéricas em regiões de interesse. $\mathrm{O}$ refinamento estático consiste em definir blocos de refinamento no domínio computacional antes da execução do método numérico e o dinâmico, que consiste em inspecionar regiões do domínio que necessitam de um refinamento local. Estas regiões são obtidas em tempo de execução por um critério de adaptatividade apropriado [6].

Assim como nos trabalhos de [6] e [16] o presente trabalho usará uma malha adaptativa bloco-estruturada com refinamento adaptativo e dinâmico.

\subsubsection{Definição de uma malha adaptativa bloco-estruturada}

A malha adaptativa bloco-estruturada é formada por um conjunto de blocos (paralelepípedos) discretizados com diferentes níveis de refinamento, sendo que cada bloco é um conjunto de células computacionais [6]. Os blocos que compõem cada nível hierárquico têm arestas alinhadas com os eixos coordenados e têm, entre si, os mesmos espaçamentos em cada direção (note que $\Delta x, \Delta y$ e $\Delta z$, não precisam ser idênticos, num mesmo nível de refinamento). A razão de refinamento $r$ entre o espaçamento de dois níveis consecutivos é constante. O conjunto de refinamentos locais mais finos, em um mesmo nível, de uma região no domínio computacional é denominado por nível físico. O primeiro nível físico é represen- 
tado por LBOT e o último de LTOP, a quantidade de níveis físicos é representado por NPL. É interessante notar que se $\mathrm{LTOP}=\mathrm{LBOT}$ e $\mathrm{NPL}=1$ teremos a convencional malha uniforme, ou seja, não há refinamentos localizados em nenhuma região do domínio computacional [16].

Os paralelepípedos oriúndos de uma discretização local devem satisfazer algumas propriedades para que se possa fazer estudos sobre ordem de convergência da solução numérica [16]. Segundo [4] a malha composta é o conjunto de paralelepípedos aninhados

$$
G_{l, k}, \mathrm{k}=1,2,3, \ldots, n_{l} \text { e l=LBOT,LBOT }+1, \mathrm{LBOT}+2, \ldots, \mathrm{LTOP}
$$

onde $n_{l}$ é o número de regiões dentro do mesmo e l é uma sequência que define de níveis progressivamente mais finos. Os $G_{l, k}$ devem ser alinhados com os eixos coordenados e possuem passo espacial de $\Delta x_{l}, \Delta y_{l}$ e $\Delta z_{l}$, sendo assim o nível físico l denotado por $p_{l}$ é dado por

$$
p_{l}=\bigcup_{k=1}^{n_{l}} G_{l, k}
$$

que deve satisfazer

$$
G_{l, j} \cap G_{l, k}=\emptyset, \forall j \neq k
$$

Note que (3.31) garante que um nível 1 seja dado pela união dos paralelepípedos que refinam regiões diferentes de um mesmo nível físico, também chamadas de malhas irmãs, e que estes paralelepípedos não se sobreponham de maneira alguma. Para terminar a descrição de uma malha composta é necessário definir o conceito de malhas aninhadas, blocos propriamente aninhados conforme [4], isto posto basta obedecer duas regras básicas:

1. um bloco em um nível fino deve começar e terminar no canto de uma célula computacional do próximo nível mais grosso;

2. para cada canto de um bloco do nível fino, deve existir pelo menos uma célula computacional do próximo nível mais grosso em todas as direções (à direita, à esquerda, para frente, para trás, para cima e para baixo) que separa este bloco do nível fino de uma célula computacional do segundo próximo nível mais grosso com exceção de que este bloco toque alguma fronteira do domínio computacional [6]. 


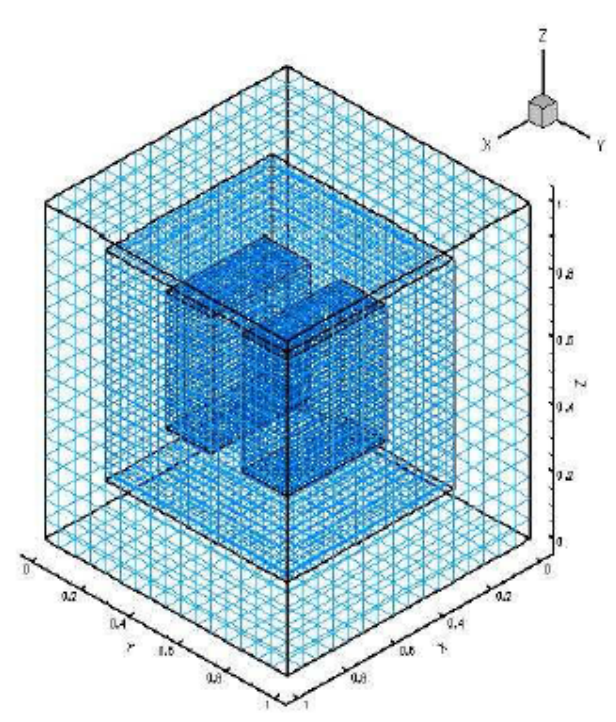

(a)

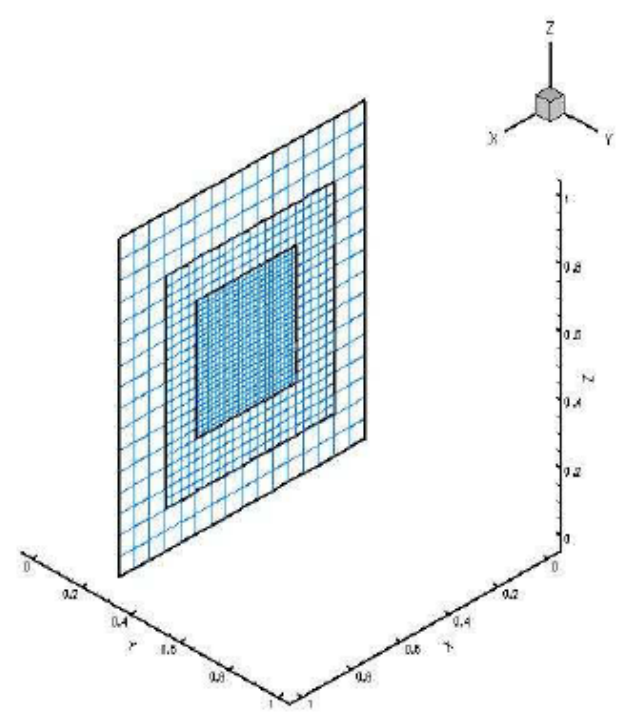

(c)

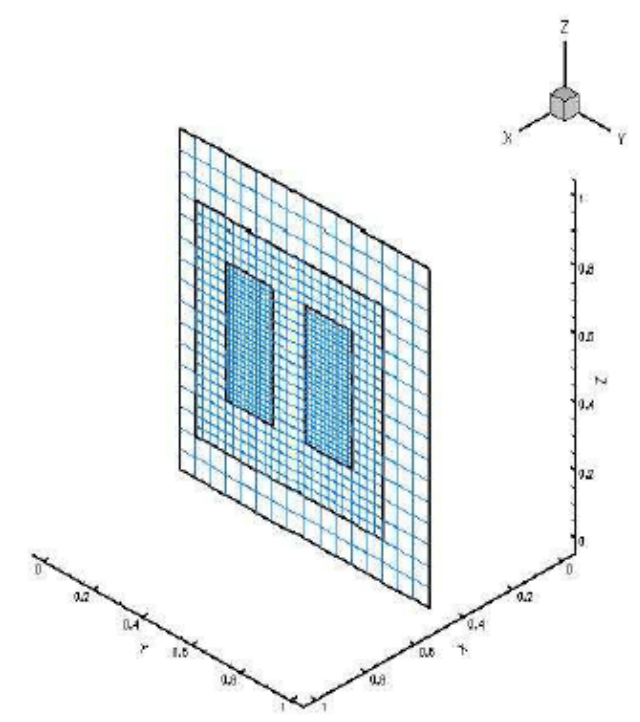

(b)

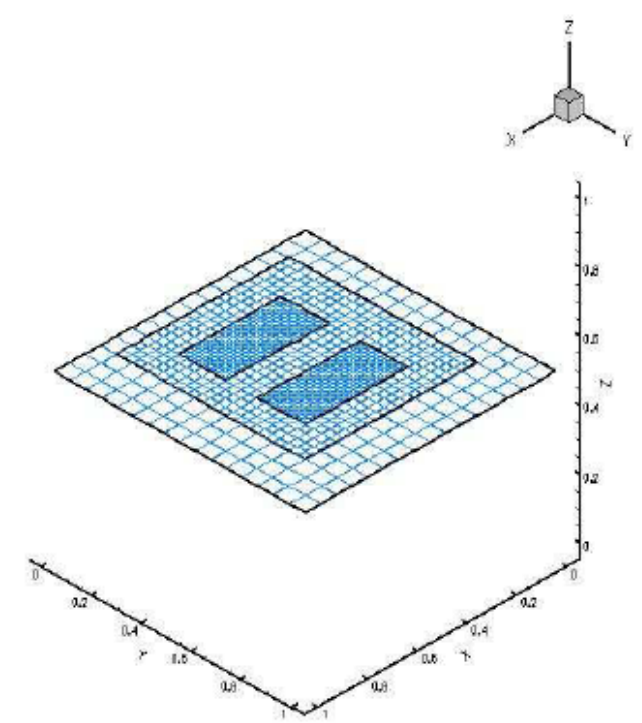

(d)

Figura 3.3: (a) Malh a composta em um dominio computacional $\Omega=[0,1] \times[0,1] \times[0,1]$ com cortes em (b) $x=0.5$, (c) $y=0.3$ e (d) $z=0.5$

Fonte: [16] p. 48

A Figura 3.3 ilustra um exemplo de domínio computacional com refinamento local propriamente aninhado com apresentação de cortes transversais nas direções $x, y$ e $z$ para melhor visualização dos blocos de refinamento.

\subsubsection{Geração de uma malha adaptativa bloco-estruturada}

Neste algoritmo, as células dos níveis $l$ top -1 , ltop $-2, \ldots$, lbot são selecionadas para refinamento. Quando uma célula de um nível $l$ é selecionada para ser refinada, o resultado deste refinamento são células correspondentes no nível $l+1$ [6]. Segundo [5], células, selecionadas para refinamento, são agrupadas em blocos (não discretizados) de um nível físico $l$ 
de forma que o volume de todas as células dadas na lista é coberto. O volume do bloco que não precisa de refinamento e o número de blocos gerados são tão pequenos quanto se queira [6]. O parâmetros $\epsilon_{\min }$ ajusta tais quantidades e é estimado por

$$
\epsilon_{\text {min }} \leq \frac{\text { ncells }}{\text { ncellsm }}
$$

onde ncells é o número de células escolhidas pelo critério e ncellsm é o número total de células computacionais que formam este mesmo bloco em um nível $l$. Nota-se que $\epsilon_{\min } \in(0,1)$ e se $\epsilon_{\min }=0.9$ signfica que $90 \%$ das células computacionais são escolhidas pelo critério [6] e [25]. Neste trabalho a malha inicial usada procederá da mesma forma como em [6], ou seja, a malha bloco-estruturada inicial é gerada por meio de um refinamento estático, de maneira que o refinamento local contenha a região de entrada do jato, ver Capítulo 5, (denominada bocal). De acordo com [6], para garantir a segunda restrição de malhas propriamente aninhadas, os blocos do nível $l-1$ são aumentados com pelo menos duas células computacionais em todas as direções. Esse refinamento estático continua sendo gerado a cada remalhagem. Os fenômenos físicos que ocorrem na região de entrada do jato precisam ser capturados durante toda a simulação e, por isso, esta região de entrada precisa de um refinamento local. As células escolhidas, pelo critério de seleção, são determinadas por pontos que satisfazem uma propriedade física do fluído ou do jato [16].

No contexto computacional quando uma nova malha é criada e é necessário copiar as variáveis envolvidas no processo da malha antiga para a nova malha. No presente trabalho temos apenas a variável $\varphi$ e esta deverá ser interpolada para a nova malha enquanto as quantidades não variáveis (dadas) serão re-calculadas nos novos pontos da nova malha. Será necessário também um expurgo computacional da malha antiga de modo a não sobrecarregar a memória virtual usada pelo programa e acarretar lentidão em processos futuros ou até estouro de memória levando a uma parada brusca na execução do programa [25]. $\mathrm{O}$ algoritmo abaixo desceve passo-a-passo o processo de criação de uma malha adaptativa bloco-estruturada

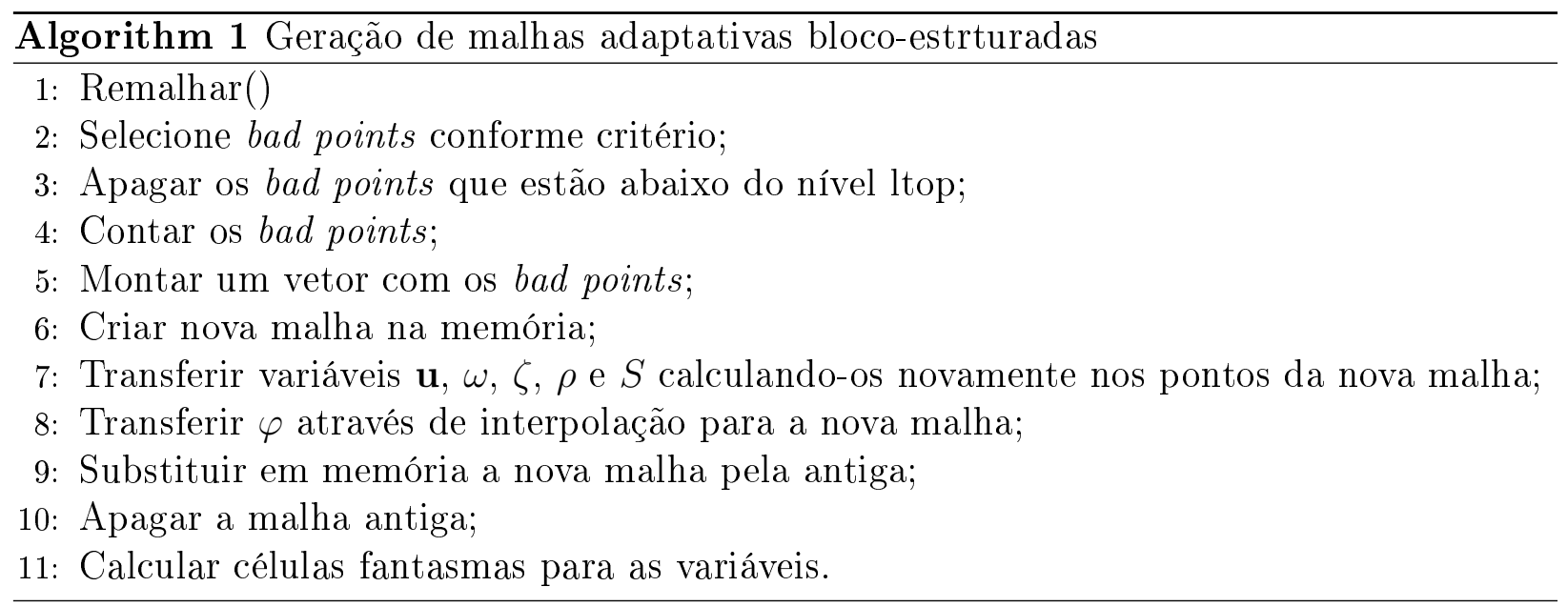

Para descrever completamente o processo de geração de malhas dinâmicas resta a descri- 
ção de células fantasmas e do critério de seleção de células computacionais a serem refinadas.

\subsubsection{Células fantasmas}

São células computacionais auxiliares que controlam os blocos discretizados e também fornecem condições de fronteiras por intermédio de interpolações polinomiais de células computacionais de blocos discretizados e que pertençam ao mesmo nível de refinamento além de serem vizinhos (blocos irmãos) e entre blocos discretizados de níveis diferentes [6]. Elas armazenam valores para condições de contorno, impossibilitando que os operadores diferenciais sejam redefinidos nas bordas das malhas, isto é, o mesmo estêncil usado no interior das células de uma malha pode ser usado nas células da borda [25].

Existem três diferentes formas de condições de contorno para as células fantasmas. A primeira possibilidade é um procedimento de interpolação que envolve valores de malha grossa e de malha fina, que determinam os valores das células fantasmas nas quais não pertencem a nenhuma outra malha do mesmo nível. A segunda forma, chamada de injeção, os valores são determinados por meio de uma importação dos valores anteriormente definidos na malha irmã. E na terceira os valores das células fantasmas próximas ao domínio são substituídos por valores reais das condições de contorno. Estes comportamentos evitam erros decorrentes dos processos de interpolação entre as malhas (fina e grossa) ao longo do tempo [25].

\subsubsection{Critério de seleção de células computacionais para refina- mento}

O critério de seleção abordado neste trabalho será análogo ao critério de seleção para uma variável de centro como descrito em [25]. Porém, uma simples modificação será feita: ao invés de usar o gradiente da pressão (como usado para o solver das equações de NavierStokes do mesmo código) é usado o gradiente numérico da propriedade escalar $\varphi$, ou seja, $\nabla^{h}(\varphi)$. O gradiente deverá ser calculado na malha composta. Após este cálculo, para cada ponto euleriano deve ser cálculado sua norma e multiplicado pelo mínimo entre os passos espaciais, sendo assim

$$
\psi_{i j k}=\min (\Delta x, \Delta y, \Delta z)\left\|\nabla I^{c \rightarrow f}\left(\varphi_{i j k}\right)\right\|_{2}
$$

Para marcar as células escolhidas para o refinamento adaptativo o critério escolhido é

$$
0<\psi_{i j k}<t o l_{d}
$$

Neste trabalho usou-se $t_{0} l_{d}=0.005$. 


\subsection{Sumário da metodologia numérica}

Seguindo os procedimentos descritos nas seções anteriores é possível escrever o algoritmo abaixo que representa um passo no tempo da discretização da equação do transporte escalar. Este algoritmo deve ser repetido para cada passo no tempo $\Delta t$. O cálculo de $\varphi^{n+1}$ será calculado pelo método multigrid-multinível. Este algoritmo é uma descrição etérea de uma parte do novo módulo eul_transp_multigrid.f90 produzido pelo autor que reflete o conteúdo numérico do presente trabalho.

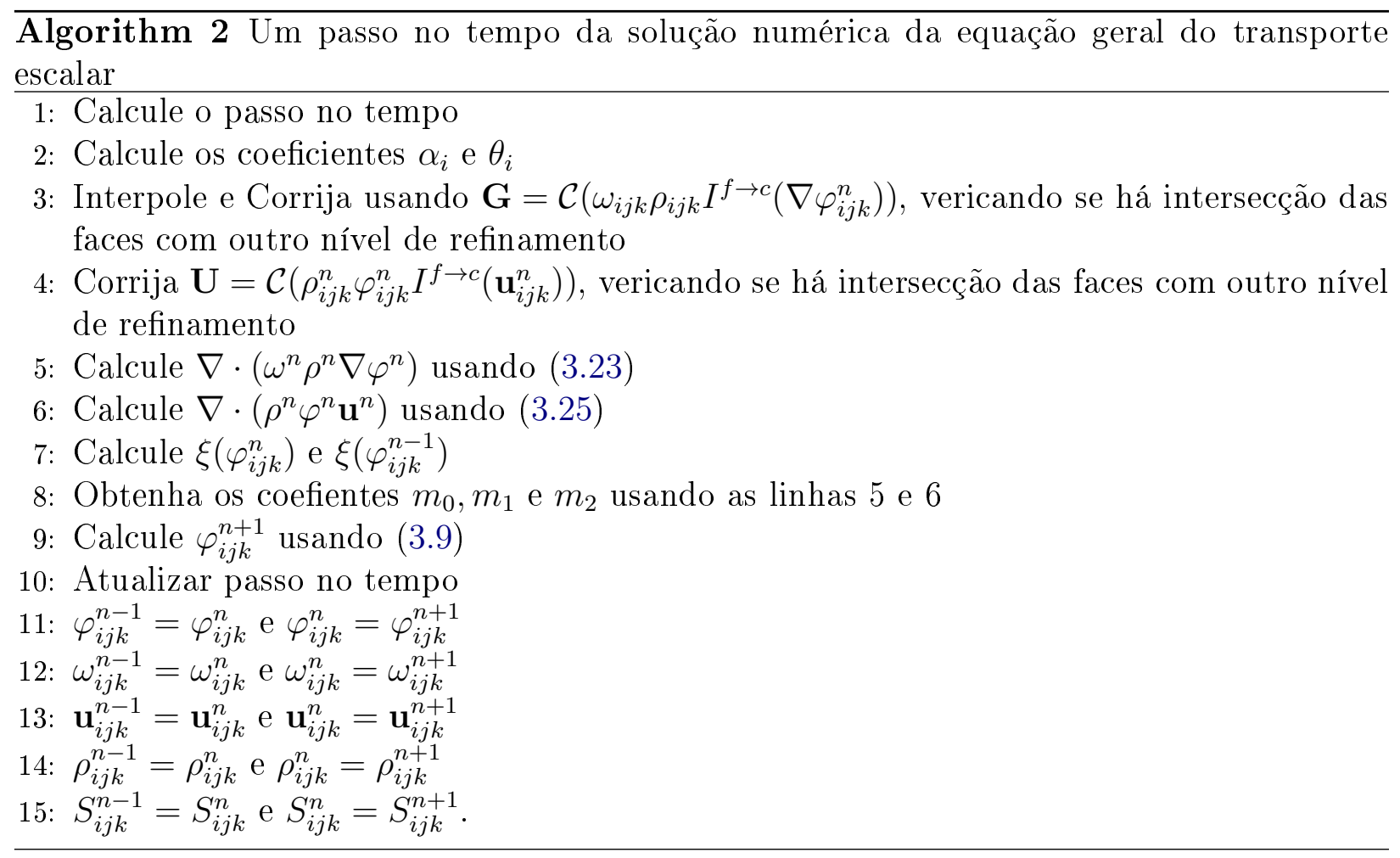




\section{Capítulo 4}

\section{Método Multigrid-Multinível}

Neste Capítulo, é abordado o método multigrid-multinível que tem o papel de resolver os sistemas lineares provenientes das discretizações apresentadas nas seções anteriores de forma a obter numericamente a solução da equação geral de advecção-difusão (2.37). Essa resolução é feita a cada passo no tempo de modo a obter a solução numérica em todo o instante até obter a solução no tempo final. O método aqui empregado, para malhas uniformes, é baseado em [22]. No contexto de malhas bloco-estruturadas, este algoritmo é chamado de multigridmultinível que é uma alusão aos níveis físicos que serão descritos no Capítulo 5. Na primeira seção, é descrita passo-a-passo a construção do método multigrid para malhas uniformes e os trabalhos de [6], [16] e [25] serão o norte deste estudo. Na segunda seção, é abordado com detalhes o cálculo do resíduo para (2.37). A relaxação da qual o método multigrid depende, o cálculo dos coeficientes $a_{p}, a_{e}, a_{w}, a_{s}, a_{n}, a_{t}$ e $a_{b}$ e questões sobre estabilidade são encontrados na terceira seção. Na quarta seção, é discutido o algoritmo em questão para malhas compostas e, finalmente, na última seção o algoritmo completo multigrid-multinível é apresentado ao leitor.

\subsection{Método multigrid}

Como visto nas seções anteriores a discretização temporal e espacial da equação geral do transporte escalar gera um sistema linear da forma

$$
K \varphi=S
$$

onde $\mathrm{K}$ é a matriz proveniente do operador linear de advecção-difusão $\mathbb{K}$, definido em (2.40), após sua discretização, $\varphi$ é o escalar a ser transportado e difundido e S o termo forçante da equação. Em uma visão geral, o multigrid é um algoritmo de solução de sistemas lineares que consiste de três etapas chave: Cálculo de resíduos; Restrição; Solução; Relaxação e Interpolação. Conforme [13], a primeira razão de se usar o método multigrid em detrimento aos métodos iterativos é que você pode usar malhas grossas para, gradativamente, melhorar o chute inicial usado na relaxação em malhas mais finas. O erro de suavização é mais oscilatório 
em uma malha mais grossa fazendo com que a relaxação seja mais efetiva produzindo uma maior razão de convergência. Para descrever o método seja $v$ uma aproximação para $\varphi$ então

$$
\varphi=v+e
$$

onde e é o erro que é cometido nesta equação é chamada de correção residual. Substituindo (4.2) em (4.1)

$$
K\left(v_{l}+e_{l}\right)=S,
$$

da linearidade de K, é obtida o que é chamada de equação residual

$$
K e_{l}=r_{l}
$$

onde $r_{l}=S-K v_{l}$ é o resíduo. Note que $v_{l}$ e $e_{l}$ são produtos de uma primeira relaxação em malha mais fina $\Omega_{l}$. Após a relaxação inicial o erro calculado em (4.4) deve ser relaxado também na malha mais grossa. Como o refinamento usado é 2, as malhas grossas serão denotadas por

$$
\Omega_{l} \text { para } l=l b o t, \ldots, 3,2,1 \text {. }
$$

A descrição usada aqui assume $h=d x=d y=d z$, porém, para $d x$, $d y$ e $d z$ com valores distintos, o raciocínio é análogo. Note que $l$ é a variável que denota em qual nível virtual está na malha uniforme. Um nível virtual é um refinamento de espaçamento da ordem de 2 até obter $2 \times 2 \times 2$ que representa uma malha mais grossa de modo a reproduzir o efeito descrito acima [16]. A representação do resíduo numa malha mais grossa é feita atráves do operador restrição

$$
r_{l-1}=\mathcal{R}_{l-1}^{l} r_{l}
$$

que toma como argumento o resíduo $r_{l}$ e o interpola do nível $l$, se $l=l b o t$ estaremos no nível físico e se $l<$ lbot no virtual, para a malha no nível $l-1$ [25]. O operador de restrição usado neste trabalho é a média simples dos 8 centros vizinhos a um ponto na malha grossa, essa relação é dada por

$$
\begin{aligned}
r_{l-1}(i, j, k) & =\frac{1}{8}\left(r_{l}(2 i-1,2 j-1,2 k)+r_{l}(2 i-1,2 j, 2 k)+r_{l}(2 i, 2 j-1,2 k)+r_{l}(2 i, 2 j, 2 k)\right. \\
& +r_{l}(2 i-1,2 j-1,2 k-1)+r_{l}(2 i-1,2 j, 2 k-1)+ \\
& \left.r_{l}(2 i, 2 j-1,2 k-1)+r_{l}(2 i, 2 j, 2 k)\right) .
\end{aligned}
$$

Após as restrições sucessivas do resíduo até a malha mais grossa possível deve-se solucionar o seguinte sistema

$$
K e_{1}=r_{1},
$$

que pode ser feito por um método direto já que a matriz do operador $K$ é pequena nesta malha, porém, neste trabalho é relaxado $\nu$ vezes em outros níveis que não seja o último 
será relaxado $\nu_{1}$ vezes. O procedimento usado até aqui é chamado de descida do algoritmo multigrid. Deve-se agora ser corrigido sucessivamente os erros e a cada passagem deve ser relaxado o sistema (4.4) usando como aproximação inicial a interpolação (prologamento) do erro em $\Omega_{l-1}$ para uma malha mais fina $\Omega_{l}$. A interpolação usada é a trilinear que é baseada no trabalho de [16], pode ser escrita como

$$
\begin{array}{r}
y_{f}(x, y, z)=\left(1-t_{1}\right)\left(1-t_{2}\right)\left(1-t_{3}\right) y_{g_{1}}+t_{1}\left(1-t_{2}\right)\left(1-t_{3}\right) y_{g_{2}}+ \\
t_{1} t_{2}\left(1-t_{3}\right) y_{g_{3}}+t_{1}\left(1-t_{2}\right) t_{3} y_{g_{4}}+\left(1-t_{1}\right)\left(1-t_{2}\right) t_{3} y_{g_{5}}+ \\
t_{1}\left(1-t_{2}\right) t_{3} y_{g_{6}}+t_{1} t_{2} t_{3} y_{g_{7}}+\left(1-t_{1}\right) t_{2} t_{3} y_{g_{8}}
\end{array}
$$

onde as variáveis $t_{1}, t_{2}$ e $t_{3}$ definem pesos e podem valer $\frac{1}{4}$ ou $\frac{3}{4}$. A correção $y_{f}$ da malha mais fina é a soma dos pesos das oito correções $y_{g}$ segundo (4.9), a Figura 4.1 mostra esta situação.

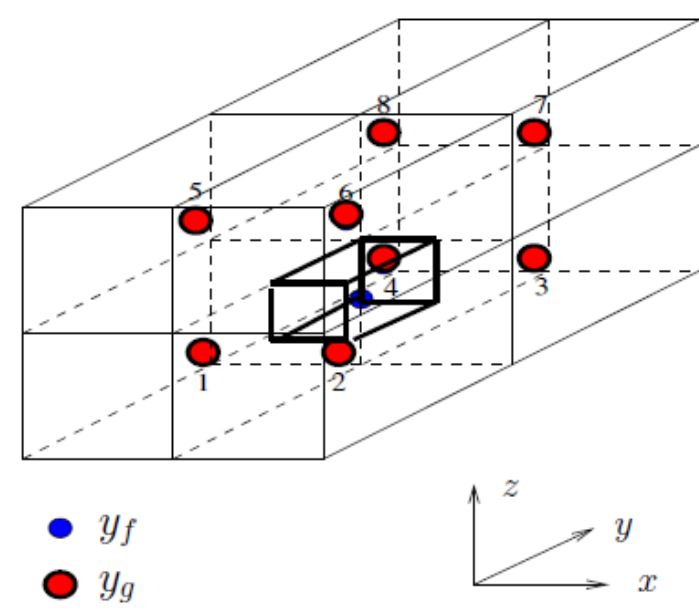

Figura 4.1: Interpolação trilinear no algortimo multigrid calaculados em centro de célula computacional.

Fonte: [16] p. 58

\subsection{Cálculo do resíduo}

O resíduo, que é uma parte do método multigrid-multinível, é obtido por $r=S-K \varphi$, onde $\mathrm{K}$ é o operador de conservação descrito no segundo capítulo e S o lado direito. Para efeitos de simplicidade e para não gerar qualquer tipo de confusão a variável $v$ que foi usada como aproximação na seção anterior será denotada como $\varphi$. Se a malha for composta, é necessário interpolar do centro para a face, como descrito na discretização espacial, as variáveis $\rho$ e $\varphi$ e depois aplicar-se-á o operador. Os fluxos são calculados como

$$
F_{i j k}^{x}=\underbrace{\frac{\rho_{i-1 j k} \varphi_{i-1 j k}+\rho_{i j k} \varphi_{i j k}}{2} u_{i j k}}_{\text {termo advectivo }}-\underbrace{\frac{\left((\rho \omega)_{i-1 j k}+(\rho \omega)_{i j k}\right)}{2} \frac{\left(\varphi_{i-1 j k}-\varphi_{i j k}\right)}{\Delta x}}_{\text {termo difusivo }},
$$




$$
\begin{aligned}
& F_{i j k}^{y}=\frac{\rho_{i j-1 k} \varphi_{i j-1 k}+\rho_{i j k} \varphi_{i j k}}{2} v_{i j k}-\frac{\left((\rho \omega)_{i j-1 k}+(\rho \omega)_{i j k}\right)}{2} \frac{\left(\varphi_{i j-1 k}-\varphi_{i j k}\right)}{\Delta y}, \\
& F_{i j k}^{z}=\frac{\rho_{i j k-1} \varphi_{i j k-1}+\rho_{i j k} \varphi_{i j k}}{2} w_{i j k}-\frac{\left((\rho \omega)_{i j k-1}+(\rho \omega)_{i j k}\right)}{2} \frac{\left(\varphi_{i j k-1}-\varphi_{i j k}\right)}{\Delta z} .
\end{aligned}
$$

Substituindo as três equações no divergente

$$
\nabla_{h} \cdot F_{i j k}=\frac{F_{i+1 j k}^{x}-F_{i j k}^{x}}{\Delta x}+\frac{F_{i j+1 k}^{y}-F_{i j k}^{y}}{\Delta y}+\frac{F_{i j k+1}^{z}-F_{i j k}^{z}}{\Delta z} .
$$

O resíduo será completamente definido após ser escolhido um método numérico a partir dos coeficientes $\alpha_{2}$ e $\theta_{2}$, então

$$
r=S^{n}-\left(\alpha_{2} \frac{\rho_{i j k}^{n+1} \varphi_{i j k}^{n+1}}{\Delta t}+\theta_{2}\left(\nabla_{h} F_{i j k}^{n+1}-\zeta_{i j k}\left(\varphi_{i j k}^{n+1}\right)\right)\right) .
$$

\subsection{Relaxação}

Após o cálculo dos fluxos, do resíduo e da restrição, o método multigrid-multinível prossegue para o cálculo da relaxação como descrito no algoritmo da seção anterior. O método de relaxação usado é o já citado SOR, para isso escrevemos na forma

$$
\varphi_{i j k}^{k+1}=S_{i j k}-\omega_{S O R}\left(\frac{a_{w} \varphi_{i+1 j k}^{k}+a_{e} \varphi_{i-1 j k}^{k}+a_{n} \varphi_{i j+1 k}^{k}+a_{s} \varphi_{i j-1 k}^{k}+a_{t} \varphi_{i j k+1}^{k}+a_{b} \varphi_{i j k-1}^{k}}{a_{p}}\right)+
$$

onde $\omega_{S O R}$ é o parâmetro do método SOR, que geralmente é usado $\omega_{S O R}=1.3$. Vale ressaltar que $k$ se refere a iteração do método, onde $k+1$ é o novo valor e $k$ é o antigo. O passo temporal empregado é sempre $n+1$. Os coeficientes $a_{e}, a_{w}, a_{s}, a_{n}, a_{t}$ e $a_{b}$ são originados na discretização espacial descrita no Capítulo 3 , enquanto que $a_{p}$ além de conter termos da discretização espacial conterá termos da discretização temporal e dos termos lineares. O termo $S_{i j k}$ representa os termos de tempos anteriores somado ao termo forçante. Para não causar qualquer tipo de confusão é necessário levantar que neste ponto do algoritmo multigrid-multinível, a variável $\varphi$ já foi submetida as interpolações devido a malha composta como descrito na seção 3.3 e a restrição para o nível um virtual como descrito em seu algoritmo. De (3.9), (3.25) e (3.23) e com simples manipulações algébricas, os coeficientes em questão são dados por

$$
a_{e}=\theta_{2}(\frac{1}{2} \underbrace{\left(\frac{\rho_{i+1 j k}+\rho_{i j k}}{2 \Delta x}\right) u_{i+1 j k}}_{\text {termo advectivo }}-\underbrace{\left.\frac{1}{\Delta x^{2}} \frac{\rho_{i+1 j k}+\rho_{i j k}}{2} \frac{\omega_{i+1 j k}+\omega_{i j k}}{2}\right)}_{\text {termo convectivo }},
$$




$$
\begin{aligned}
& a_{w}=\theta_{2}\left(-\frac{1}{2}\left(\frac{\rho_{i-1 j k}+\rho_{i j k}}{2 \Delta x}\right) u_{i j k}-\frac{1}{\Delta x^{2}} \frac{\rho_{i-1 j k}+\rho_{i j k}}{2} \frac{\omega_{i-1 j k}+\omega_{i j k}}{2}\right), \\
& a_{n}=\theta_{2}\left(\frac{1}{2}\left(\frac{\rho_{i j+1 k}+\rho_{i j k}}{2 \Delta y}\right) v_{i j+1 k}-\frac{1}{\Delta y^{2}} \frac{\rho_{i j+1 k}+\rho_{i j k}}{2} \frac{\omega_{i j+1 k}+\omega_{i j k}}{2}\right), \\
& a_{s}=\theta_{2}\left(-\frac{1}{2}\left(\frac{\rho_{i j-1 k}+\rho_{i j k}}{2 \Delta y}\right) v_{i j k}-\frac{1}{\Delta y^{2}} \frac{\rho_{i j-1 k}+\rho_{i j k}}{2} \frac{\omega_{i j-1 k}+\omega_{i j k}}{2}\right), \\
& a_{t}=\theta_{2}\left(\frac{1}{2}\left(\frac{\rho_{i j k+1}+\rho_{i j k}}{2 \Delta z}\right) w_{i j k+1}-\frac{1}{\Delta z^{2}} \frac{\rho_{i j k+1}+\rho_{i j k}}{2} \frac{\omega_{i j k+1}+\omega_{i j k}}{2}\right), \\
& a_{b}=\theta_{2}\left(-\frac{1}{2}\left(\frac{\rho_{i j k-1}+\rho_{i j k}}{2 \Delta z}\right) w_{i j k}-\frac{1}{\Delta z^{2}} \frac{\rho_{i j k-1}+\rho_{i j k}}{2} \frac{\omega_{i j k-1}+\omega_{i j k}}{2}\right) . \\
& a_{p}=-\left(a_{e}+a_{w}+a_{n}+a_{s}+a_{t}+a_{b}\right)-\underbrace{\frac{\alpha_{2} \rho_{i j k}}{\Delta t}}_{\text {termo temporal }}-\underbrace{\theta_{2} \zeta_{i j k}}_{\text {termo linear }} .
\end{aligned}
$$

Conforme [11], é importante notar que o método SOR governado pela equação 4.22 diverge em alguns casos. Para se obter a convergência o critério de Scarborough que é dado por

$$
C_{s}=\frac{\left|a_{e}\right|+\left|a_{w}\right|+\left|a_{n}\right|+\left|a_{s}\right|+\left|a_{t}\right|+\left|a_{b}\right|}{\left|a_{p}\right|}
$$

deve ser respeitado. O critério estabelece a seguinte regra

$$
\begin{aligned}
& C_{s}<1 \text { para ao menos uma equação } \\
& C_{s} \leq 1 \text { para todas as equações. }
\end{aligned}
$$

Como visto em [11], a matriz formada pelos coeficientes gerados pela discretização usada deve ser diagonal dominante. A condição de Péclet vista em [6] e [11], se satisfeita, garante que a aproximação da equação de conservação de massa é convergente. A condição de Péclet é dada pela inequação

$$
P e=\frac{u \Delta x}{\omega} \leq 2
$$

ou seja, a razão entre os coeficientes de advecção e difusão deve se manter abaixo ou igual a 2. Note que em (4.25) vale para a direção x, para as outras a escrita é a mesma. Suponha agora uma situação numérica na qual u é um campo de vetores positivo, a malha usada é a uniforme, que $a_{w}<0$ e $a_{e}>0$, então

$$
a_{e}>0 \Rightarrow \frac{1}{2}\left(\frac{\rho_{i+1 j k}+\rho_{i j k}}{2 \Delta x}\right) u_{i+1 j k}>\frac{1}{\Delta x^{2}} \frac{\rho_{i+1 j k}+\rho_{i j k}}{2} \frac{\omega_{i+1 j k}+\omega_{i j k}}{2} \Rightarrow \frac{\frac{1}{2} u_{i+1 j k} \Delta x}{\frac{\omega_{i+1 j k}+\omega_{i j k}}{2}}>1 \text {, }
$$


que nos dá

$$
\frac{u_{i+1 j k} \Delta x}{\frac{\omega_{i+1 j k}+\omega_{i j k}}{2}}=P e>2,
$$

que contradiz o critério de Péclet na direção x (o raciocínio é análogo em todas as direções). Logo, se $a_{e}>0$ ou $-a_{e}<0$ obtém-se que o termo advectivo domina o difusivo e assim esta situação não obedece o critério e com isso não é possível garantir a convergência do método iterativo. Um exemplo análogo pode ser descrito para todos os outros coeficientes vizinhos. Para evitar problemas com a discretização espacial, deve-se manter a inequação de Péclet, se não for possível, duas soluções podem ser possíveis quando o critério for violado

- Mudar o método de resolução do sistema linear de multigrid para um método direto como apresentou [1];

- Mudar a interpolação $I^{f \rightarrow c}(\varphi)$ dada pela média dos vizinhos para alguma outra, por exemplo, o esquema QUICK, como em [6].

Vale ressaltar que estas soluções não serão abordadas neste trabalho e mais detalhes podem ser achados nos trabalhos acima citados.

\subsection{Sumário do método}

De acordo com as discussões abordadas no discorrer deste capítulo o método multigridmultinível pode ser implementado seguindo o seguinte algoritmo que foi baseado no trabalho de $[6]$.

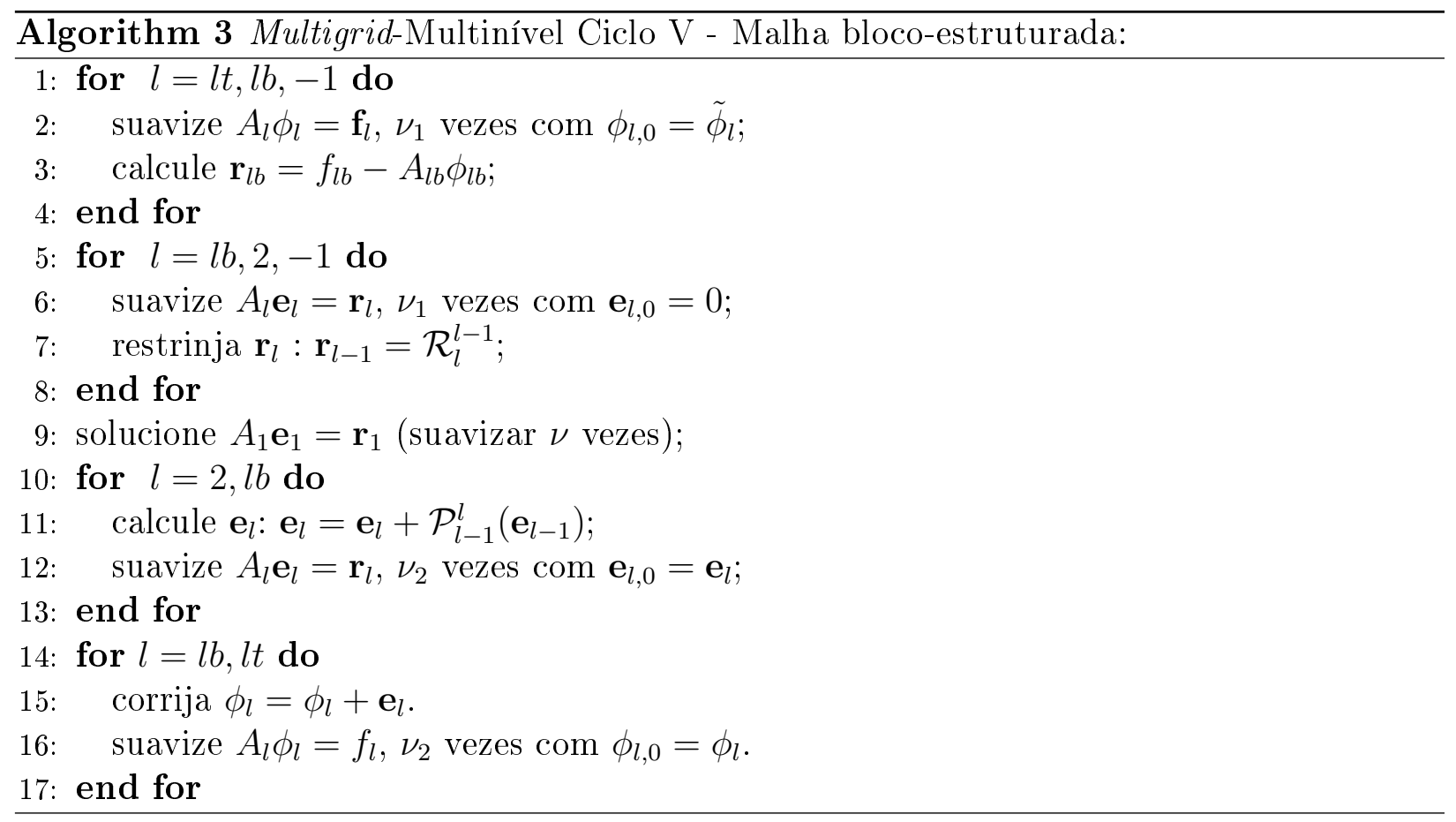




\section{Capítulo 5}

\section{Resultados e discussão}

Neste capítulo, é mostrado uma série de levantamentos sobre o módulo implementado que contém os algoritmos citados focando a resolução numérica da equação geral do escalar. A Seção 5.1 apresenta um estudo do estado estacionário da equação de advecção-difusão (2.37). Neste estudo, determinam-se por intermédio do uso de solução manufaturada e análise de convergência por refinamento de malha, a ordem espacial e as propriedades de conservação, além de levantamentos sobre o método multigrid-multinível. Um estudo sobre o erro numérico cometido pela metodologia numérica em malha composta também é realizado. Na Seção 5.2, com o uso das técnicas de solução manufaturada e análise de convergência, tem como foco central a equação geral de advecção-difusão com os termos temporal e linear. A ordem de convergência, tanto no tempo quanto no espaço para as malhas uniforme e composta e as condições de fronteira Dirichlet e Neumann serão investigadas. A seção 5.3 apresenta um teste da propriedade de conservação do Método de Volumes Finitos implementado. Na Seção 5.4, um problema de jato laminar é resolvido baseando-se em [6], de modo a testar a parte dinâmica do código computacional além do acoplamento com outra equação, por exemplo, a de Navier-Stokes e verificar por completo o funcionamento correto do código escrito. A análise de convergência por refinamento de malha é uma estratégia de verificação de implementação de código computacional que emprega soluções manufaturadas suaves e o conhecimento do erro produzido pela discretização em malhas progressivamente mais finas. A razão entre estes erros tem comportamento conhecido, previsto pela teoria. O objetivo é averiguar se tal comportamento obtido na prática corresponde ao previsto pela teoria. Neste capítulo, são relatados verificações em malhas compostas também. Segundo [6] tais verificações têm por objetivo confirmar que o uso deste tipo de malha não deteriora a acurácia do método número que, quando a solução do problema é suave em todo lugar, deve ser a mesma que se tem em uma malha uniforme. 


\subsection{Descrição dos testes e malhas}

A razão de refinamento entre níveis sucessivos da malha é dois. As normas usadas para medir o erro do escalar $\varphi$ que possui propriedade de centro de célula computacional são $L_{2}$ e $L_{\infty}$. Tais normas são dadas por

$$
\begin{gathered}
\|\varphi\|_{2}=\sqrt{\sum_{n}\left|\varphi_{n}\right|^{2} \Delta x \Delta y \Delta z} \\
\|\varphi\|_{\infty}=\max _{n}\left|\varphi_{n}\right|
\end{gathered}
$$

onde $n$ é um índice que varia entre todas as células computacionais visíveis contidas no domínio. O domínio computacional utilizado, para o modelo estacionário, é $\Omega_{c_{e}}=[0,1] \times$ $[0,2] \times[0,4]$ e para o transiente $\Omega_{c_{t}}=[0,1] \times[0,2] \times[0,2]$. A malha composta estática usada possui três níveis de refinamento (dois adicionais, acima do nível base). As Figuras 5.1a e 5.1b fornecem a malha composta estática empregada. A malha composta estática é formada por um bloco no nível de base dado por $\Omega_{c}$, três blocos: o amarelo, o azul e o rosa, dados por $[0.375,0.625] \times[0.125,0.75] \times[0.25,0.75],[0.625,0.875] \times[0.25,0.5] \times[0.25,0.75] \mathrm{e}$ $[0.0,0.125] \times[0.0,0.125] \times[0.0,0.125]$ respectivamento. O terceiro nível de refinamento é dado por um bloco, o vermelho, é dado por $[0.5625,0.6875] \times[0.3125,0.375] \times[0.65625,0.71875]$. A quantidade de células computacionais contidas nas figuras 5.1a e 5.1b são meramente ilustrativas e serão descritas em detalhes nas próximas seções. O método numérico para a discretização temporal utilizado é o de Crank-Nicolson, apenas para os testes de verificação dos modelos estacionário e transiente, que tem uma ordem esperada de 2 para o tempo e 2 para o espaço. O problema transiente é resolvido para o intervalo de tempo $[0,2]$. Note que para os testes, usou-se $\Delta x=\Delta y=\Delta z$. O passo de integração no tempo utilizado é de $\Delta t=\min (\Delta x, \Delta y, \Delta z)$. Os parâmetros do método multigrid-multinível são dez relaxações no nível base, três na subida e quatro na descida. 


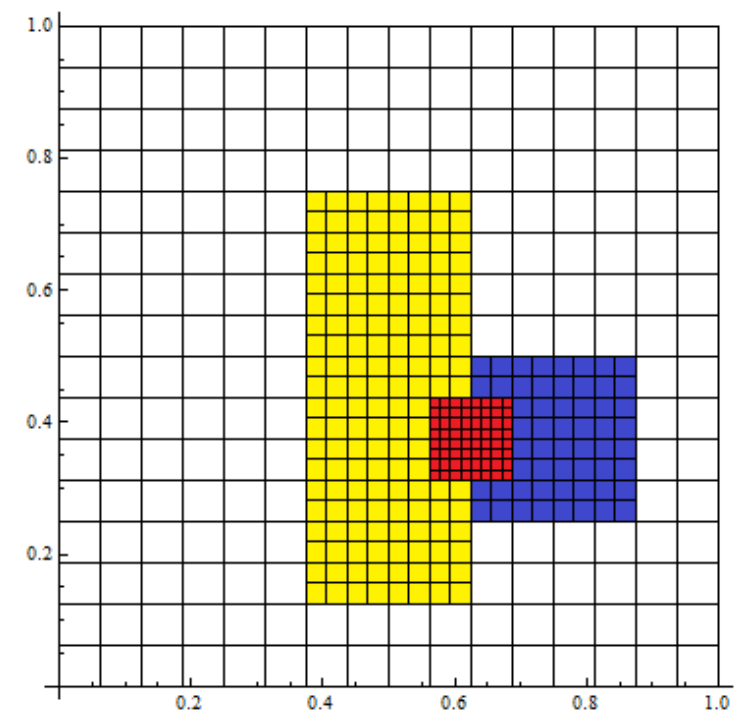

(a)

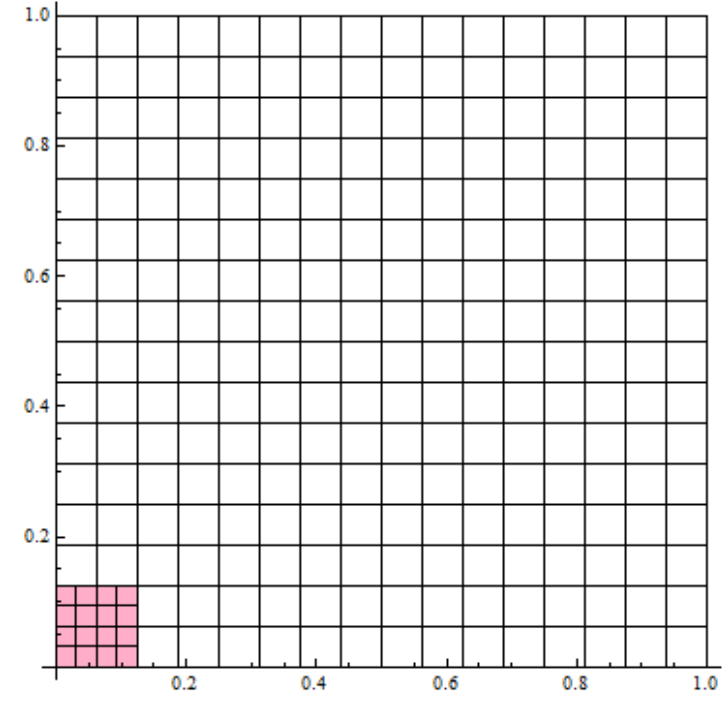

(b)

Figura 5.1: (a) plano $z=0.71875$; (b) plano $z=0.125$

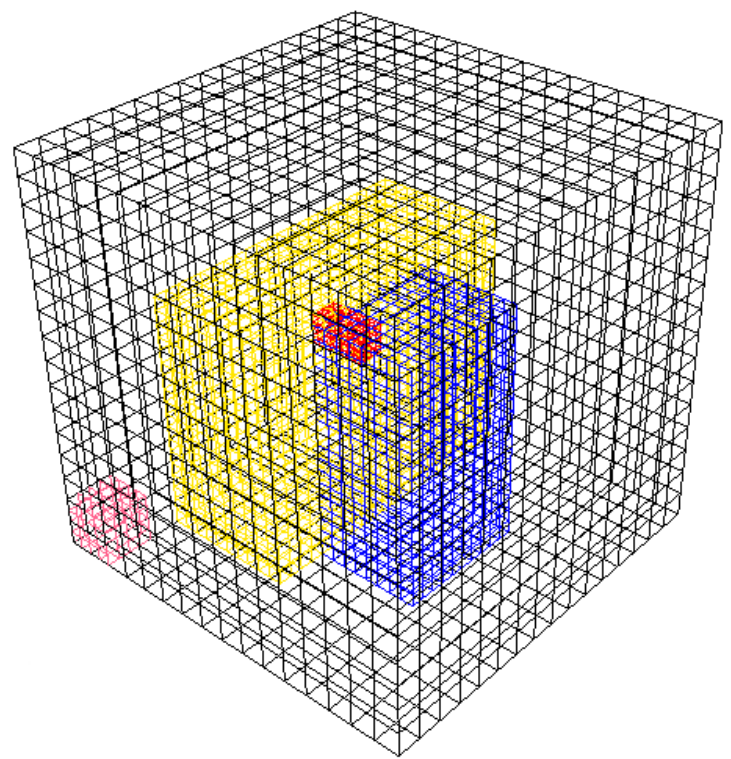

Figura 5.2: Malha composta estática em três níveis.

\subsection{Testes com o modelo estacionário}

Nesta seção, trata-se da implementação computacional da equação estacionária, simplificação obtida a partir do modelo genérico (2.37),

$$
\nabla \cdot((\rho \mathbf{u}) \varphi)=\nabla \cdot(\omega(\mathbf{x}, t) \rho \nabla \varphi)+S(\mathbf{x}, t)+\xi(\varphi)
$$

São relatadas a verficação da ordem de convergência via solução manufaturada, a per- 
formance do método multigrid-multinível e a validade do Teorema da Divergência em sua versão discreta. O critério de parada para o método multigrid-multinível é que o resíduo seja menor que ou igual a $10^{-8}$ com o número máximo de vinte $\mathrm{V}$-ciclos. O domínio usado e a malha composta são os descritos na seção anterior. A soluação manufaturada usada é dada por

$$
\begin{aligned}
\varphi_{e} & =\left(\frac{1}{2 \pi}\right) \sin (2 \pi(x+y+z)), \\
\rho & =2+\cos ^{2}(2 \pi(x+y+z)), \\
\omega & =2+e^{-x-y-z} \\
\xi & =\sin (x y z) \varphi
\end{aligned}
$$

O termo forçante S em (5.29), no caso de soluções manufaturadas, se escreve como

$$
S(\mathbf{x}, t)=-\nabla \cdot((\rho \mathbf{u}) \varphi)+\nabla \cdot(\omega(\mathbf{x}, t) \rho \nabla \varphi)+\xi(\varphi)
$$

onde $\rho, \omega, \varphi, \xi$ são como em (5.4)-(5.7). O vetor velocidade $\mathbf{u}$ é escolhido de acordo com o teste implementado sendo especificado mais adiante.

\subsubsection{Verificação por solução manufaturada}

Para $\mathbf{u}=(1,1,1)$, a Tabela 5.1 mostra as razões obtidas para condições de contorno de Dirichlet e de Neumann numa sequência de malhas uniformes progressivamente mais finas. Como se vê a razão entre os erros obtidos em malhas sucessivas aproxima-se de 4 o que

\begin{tabular}{ccccc}
\hline \multicolumn{4}{c}{ Malha uniforme } \\
\hline \multicolumn{4}{c}{ Dirichlet } & \multicolumn{2}{c}{ Neumann } \\
\hline Malha & $\left\|\varphi-\varphi_{e}\right\|_{2}$ & $R\left(\|\cdot\|_{2}\right)$ & $\left\|\varphi-\varphi_{e}\right\|_{2}$ & $R\left(\|\cdot\|_{2}\right)$ \\
\hline $16 \times 32 \times 64$ & $2.447261 \mathrm{E}-3$ & & $2.686872 \mathrm{E}-03$ & \\
$32 \times 64 \times 128$ & $6.108582 \mathrm{E}-04$ & 4.006 & $6.645990 \mathrm{E}-04$ & 4.04 \\
$64 \times 128 \times 256$ & $1.527713 \mathrm{E}-04$ & 3.998 & $1.657223 \mathrm{E}-04$ & 4.01 \\
$128 \times 256 \times 512$ & $3.820213 \mathrm{E}-05$ & 3.999 & $4.140415 \mathrm{E}-05$ & 4.002 \\
\hline
\end{tabular}

Tabela 5.1: Verificação da convergência numérica por refinamento de malha e uso de solução manufaturada suave do modelo simplificado (2.37). Resultados em malha uniforme, processamento serial.

significa segunda ordem no espaço. A Tabela 5.2 mostra que a razão esperada também é obtida para a malha composta estática, para ambas as condições de contorno estudadas.

Pode-se afirmar que o código implementado apresenta a ordem de convergência esperada pela teoria para a discretização espacial apresentada na Seção 3.3.

A Figura 5.3 mostra o erro cometido pelo método de discretização empregado para resolver (5.29). Para cada ponto do domínio computacional, a seguinte expressão é calculada

$$
e=\left|\varphi-\varphi_{e}\right|
$$




\begin{tabular}{ccccc}
\hline \multicolumn{3}{c}{ Malha composta estática } \\
\hline Malha & $\left\|\varphi-\varphi_{e}\right\|_{2}$ & $R\left(\|\cdot\|_{2}\right)$ & $\left\|\varphi-\varphi_{e}\right\|_{2}$ & $R\left(\|\cdot\|_{2}\right)$ \\
\hline $64 \times 128 \times 256 L 3$ & $2.181274 \mathrm{E}-03$ & & $2.966067 \mathrm{E}-03$ & \\
$128 \times 256 \times 512 L 3$ & $5.390008 \mathrm{E}-04$ & 4.046 & $7.395681 \mathrm{E}-04$ & 4.01 \\
$256 \times 512 \times 1024 L 3$ & $1.343724 \mathrm{E}-04$ & 4.011 & $1.848077 \mathrm{E}-04$ & 4.002 \\
$512 \times 1024 \times 2048 L 3$ & $3.356951 \mathrm{E}-05$ & 4.002 & $4.619877 \mathrm{E}-05$ & 4 \\
\hline
\end{tabular}

Tabela 5.2: Verificação da convergência numérica por refinamento de malha e uso de solução manufaturada suave do modelo simplificado (2.37). Resultados em malha composta (estática), processamento serial.

A expressão (5.9) representa a diferença absoluta entre a solução exata $\varphi_{e}$ e a solução numérica $\varphi$. Para analisar o erro, é consideradas condição de contorno de Dirichlet e na malha composta $512 \times 1024 \times 2048$ L3. 

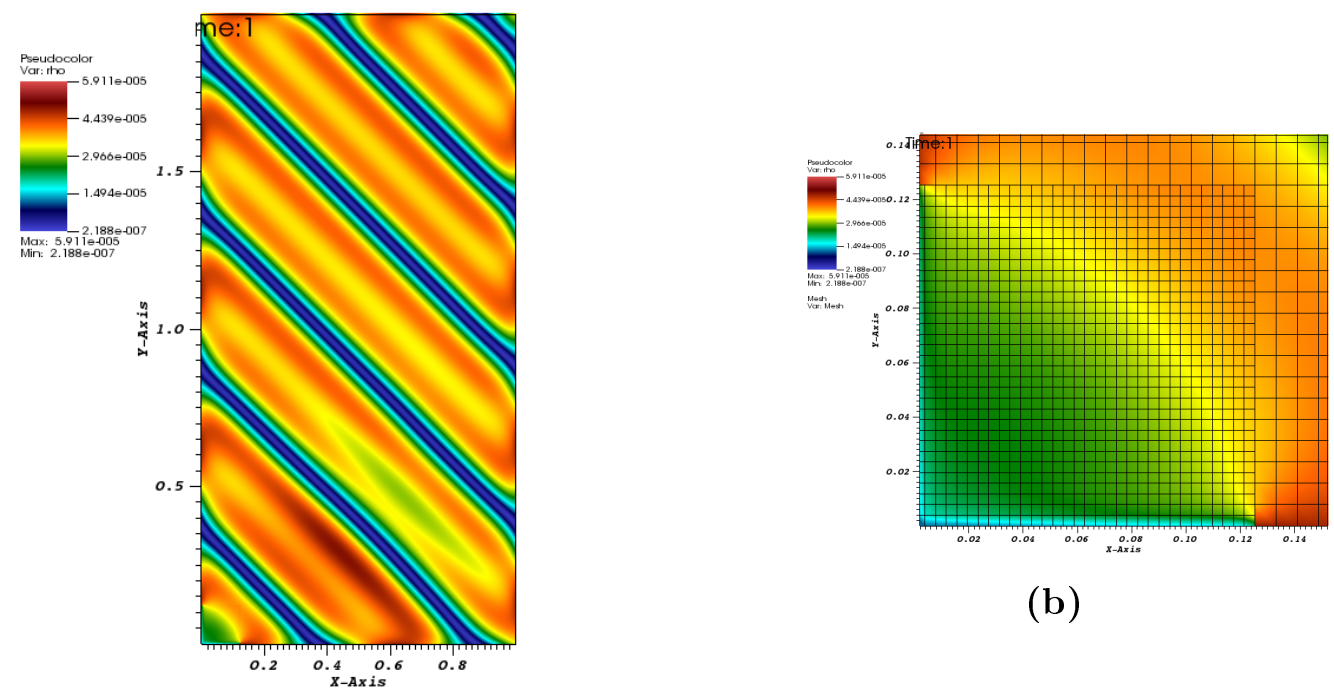

(b)

(a)
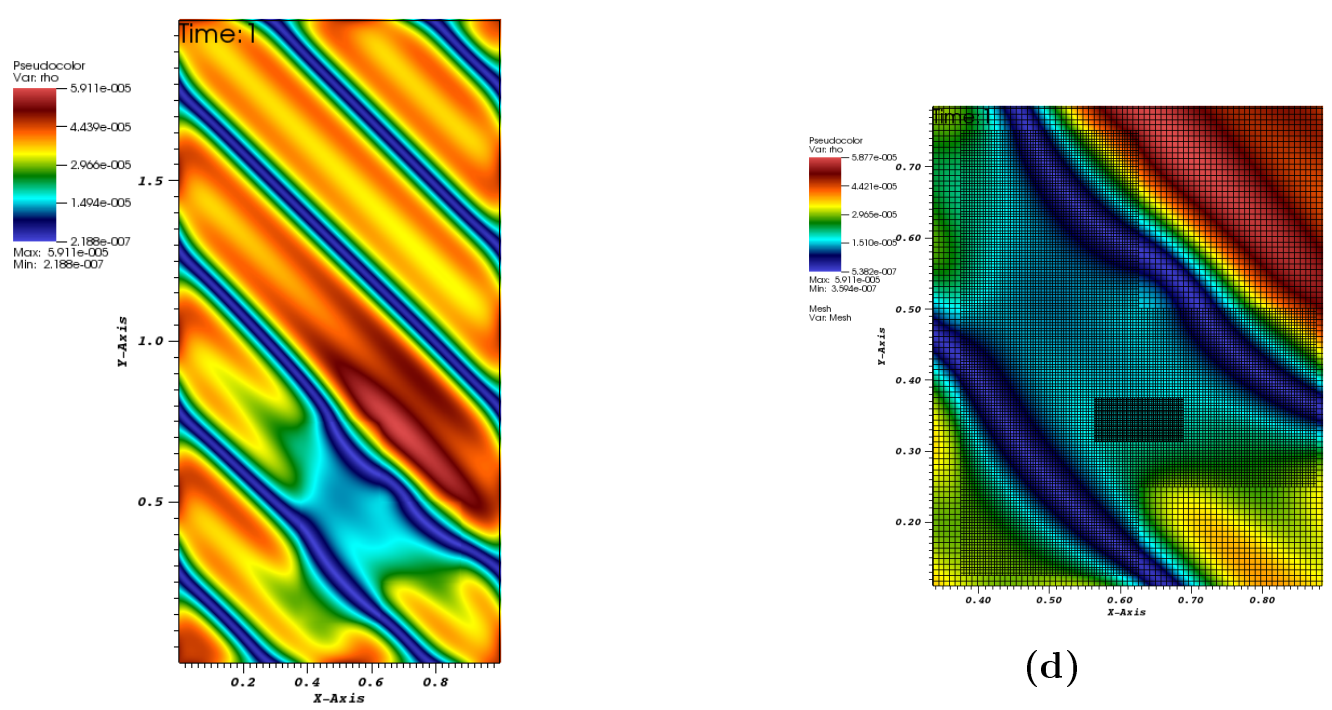

(d)

(c)

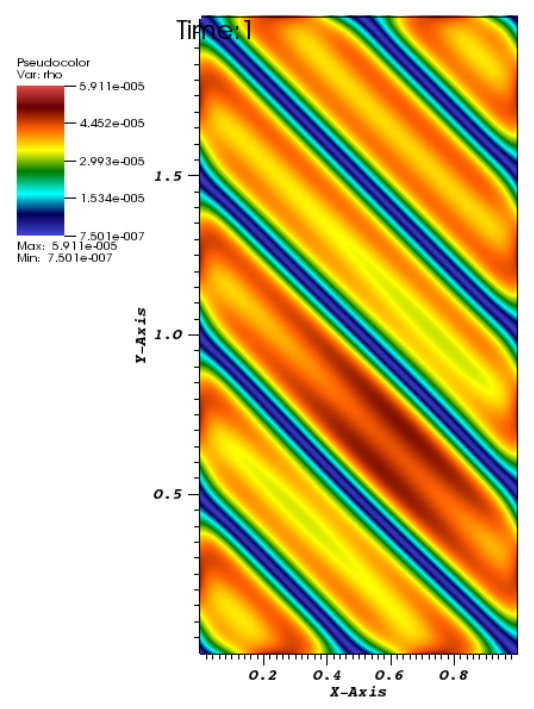

(e)

Figura 5.3: (a) Erros cometidos: corte em $z=0$; (b) Erros cometidos: corte em $z=0$ com ampliação; (c) Erros cometidos: corte em $z=0.71875$; (d) Erros cometidos: corte em $z=0.71875$ com ampliação; (e) Erros cometidos: corte em $z=1$. 
É possível oberservar que na Figura $5.3 a$ o menor erro cometido ocorre no canto inferior esquerdo o qual está está recoberto pelo bloco de refinamento $[0,0.125] \times[0,0.125] \times[0,0.125]$ pertencente ao segundo nível de refinamento (vide zoom na Figura 5.3b). Vale a pena ressaltar também que, nas interfaces entre dois níveis sucessivos de refinamento, o erro aumenta consideravelmente. Este fato deve-se aos erros introduzidos pelos esquemas de interpolação utilizado no cálculo dos valores fantasmas. Na Figura $5.3 c$, observa-se uma distorção saliente no interior da região pelos blocos de refinamento do segundo nível que formam um " $\mathrm{T}$ ". É evidente que tal distorção é produzida por um tamanho menor de erro cometido nesta região. A Figura 5.3d detalha a região em questão que foi amplificada deixando claro o efeito do uso da malha composta: esta faz com que o erro seja menor no interior de uma região refinada quando comparado com outras regiões na mesma seção transversal $(z=0.71875)$. Os erros aumentam conforme estudam-se seções transversais que contêm intersecções progressivamente menores com o bloco de refinamento em " $\mathrm{T}$ ". Isto pode ser visto na Figura 5.3e para a seção transversal $z=1$ a qual não contém mais nenhum ponto refinado.

\subsubsection{Performance do método multigrid-multinível}

O número de $\mathrm{V}$-ciclos produzidos pelo algoritmo multigrid-multinível para o modelo estacionário (5.29) é mostrado na Tabela 5.3. Como se observa, o número de V-ciclos mostrouse constante independentemente do nível de refinamento da malha sendo cinco ciclos em malhas uniformes e sete para malhas compostas.

\begin{tabular}{ccc}
\hline \multicolumn{3}{c}{ Número de V-ciclos } \\
\hline Nível mais grosso & Malha Uniforme & Malha Composta \\
\hline $16 \times 32 \times 64$ & 5 & 7 \\
$32 \times 64 \times 128$ & 5 & 7 \\
$64 \times 128 \times 256$ & 5 & 7 \\
$128 \times 256 \times 512$ & 5 & 7 \\
\hline
\end{tabular}

Tabela 5.3: Número de V-ciclos obtidos para malhas uniforme e composta.

O tempo de execução para a resolução numérica do modelo estacionário (5.29) também é relatado. Para isso, antes do ínicio da simulação e após o seu término, uma rotina de cálculo do tempo da cpu é chamada. Antes do fim da execução do programa principal, a diferença entre as duas chamadas é calculada. Os resultados obtidos sobre as execuções foram divididos pelo número de ciclos do método multigrid-multinível e apresentados na Tabela 5.4. Os dados apresentados são relativos a razão de tempo gasto em um passo no tempo entre malhas progressivamente refinadas. 


\begin{tabular}{ccc}
\hline \multicolumn{3}{c}{ Tempo relativo de execução por V-ciclo } \\
\hline Nível mais grosso & Razão malha uniforme & Razão malha composta \\
\hline $32 \times 64 \times 128$ & 3.45 & 3.43 \\
$64 \times 128 \times 256$ & 5.72 & 6.15 \\
$128 \times 256 \times 512$ & 7.45 & 7.54 \\
\hline
\end{tabular}

Tabela 5.4: Razão entre os tempos de execução de malhas progressivamente mais finas.

De acordo com a Tabela 5.4, na malha uniforme $64 \times 128 \times 256$ é gasto $32 \times 64 \times 128$ De um nível para o outro na malha uniforme, a razão entre o tempo de execução da malha grossa e da fina é de aproximadamente 7 . Com base na mesma tabela, é possível ver que não há muito impacto no tempo de um ciclo multigrid para a malha composta descrita no início deste capítulo.

\subsubsection{Verificação do Teorema da Divergência discreto}

Nesta seção, um teste é executado para verificar se o método de discretização espacial, definido no Capítulo 3, respeita numericamente o Teorema da Divergência. O teste consiste em verificar a versão discreta de

$$
\iiint_{\Omega_{c}} \nabla \cdot \mathbf{F} d V=\iint_{\partial \Omega_{c}} \mathbf{F} \cdot \mathbf{n} d S,
$$

onde $\mathbf{F}$ é o fluxo dado por

$$
\mathbf{F}=\rho \varphi \mathbf{u}-\omega \rho \nabla \varphi
$$

e $\mathbf{n}$ é a normal exterior ao domínio. A solução exata manufaturada definida em (5.4) é usada, assim como os parâmetros físicos definidos em (5.5)-(5.7). Os componentes da velocidades são

$$
\begin{gathered}
u=\frac{\sin (8 \pi(y-z))}{\cos ^{2}(2 \pi(x+y+z))+2}, \\
v=\frac{1}{8} y \cos (2 \pi(x+z)), \\
w=\frac{e^{-x-y-z}}{\cos ^{2}(2 \pi(x+y+z))+2} .
\end{gathered}
$$

Para o cálculo da integral de volume, lado esquerdo de (5.10), é necessário redefinir no centro das faces a solução manufaturada $\varphi$ e outras variáveis de centro. Tal procedimento por intermédio de interpolações como visto em (3.18)-(3.20) para o cálculo do divergente discreto. Se a malha usada for composta, os valores de centro de face devem receber a média dos valores definidos das faces mais finas que o recobrem, conforme descrito no Capítulo 3 e ilustrado na Figura 3.2. A Regra do Ponto Médio é usada como método de quadratura 
numérica para aproxima o lado esquerdo de (5.10),

$$
\iiint_{\Omega_{c}} \nabla \cdot \mathbf{F} d V \approx \sum_{i} \sum_{j} \sum_{k} \nabla_{h} \cdot \mathbf{F}_{i j k} \Delta x \Delta y \Delta z
$$

onde $\nabla_{h} \cdot \mathbf{F}_{i j k}$ representa o divergente númerico do fluxo (5.11), conforme (3.23) e (3.25), o qual está definido no centro das células computacionais visíveis, possuindo índices $i j k$. A quadratura do lado direito de (5.10) é aproximada por,

$$
\begin{aligned}
\iint_{\partial \Omega_{c}} \mathbf{F} \cdot \mathbf{n} d S \approx \sum_{j} \sum_{k}\left(-F_{i j k}+F_{i+n x j k}\right) \Delta y \Delta z & +\sum_{i} \sum_{k}\left(-F_{i j k}+F_{i j+n y k}\right) \Delta x \Delta z \\
& +\sum_{i} \sum_{j}\left(-F_{i j k}+F_{i j k+n z}\right) \Delta x \Delta y
\end{aligned}
$$

onde $i, j$ e $k$ são os índices que representam as faces do bordo do domínio computacional. As quantidades inteiras $n x$, ny e $n z$, representam o número de células computacionais necessárias para chegar à face oposta do bordo.

O erro absoluto, $\epsilon_{h}$, entre as quadraturas deve ser da ordem do zero de máquina.

A Tabela 5.5 mostra o erro $\epsilon_{h}$ para malhas uniformes progressivamente mais finas. De

\begin{tabular}{ccc}
\hline \multicolumn{3}{c}{ Malha uniforme } \\
\hline Dirichlet & Neumann \\
\hline Malha & $\epsilon_{h}$ & $\epsilon_{h}$ \\
$32 \times 64 \times 128$ & $1.08 \mathrm{E}-15$ & $3.6 \mathrm{E}-16$ \\
$64 \times 128 \times 256$ & $2.25 \mathrm{E}-14$ & $1.22 \mathrm{E}-15$ \\
$128 \times 256 \times 512$ & $2.84 \mathrm{E}-14$ & $2.63 \mathrm{E}-14$ \\
\hline
\end{tabular}

Tabela 5.5: Verificação do Teorema da Divergência discreto por refinamento de malha e uso de soluçẫo manufaturada suave do modelo simplificado (2.37). Resultados em malha uniforme, processamento serial.

acordo com a Tabela 5.5, nota-se um erro próximo ao erro de máquina para todas as malhas testadas, confirmando-se então que o Teorema da Divergência discreto é verificado em malhas uniformes. A Tabela 5.6 mostra a mesma tendência para as malhas compostas estáticas e, com isso, a validade do teorema numericamente.

\begin{tabular}{ccc}
\hline \multicolumn{3}{c}{ Malha composta estática } \\
\hline & Dirichlet & Neumann \\
\hline Malha & $\epsilon_{h}$ & $\epsilon_{h}$ \\
$64 \times 128 \times 256 L 3$ & $1.31 \mathrm{E}-15$ & $1.36 \mathrm{E}-15$ \\
$128 \times 256 \times 512 L 3$ & $1.51 \mathrm{E}-15$ & $6.66 \mathrm{E}-16$ \\
$256 \times 512 \times 1024 L 3$ & $3.33 \mathrm{E}-14$ & $1.99 \mathrm{E}-14$ \\
\hline
\end{tabular}

Tabela 5.6: Verificação do Teorema da Divergência discreto por refinamento de malha e uso de solução manufaturada suave do modelo simplificado (2.37). Resultados em malha composta (estática), processamento serial.

A verificação do Teorema da Divergência em sua versão discreta implica que os fluxos do 
interior do domínio estão cancelando corretamente como é esperado numa implementação do Método dos Volumes Finitos.

\subsection{Testes com o modelo o transiente}

\subsubsection{Verificação por solução manufaturada}

As equações para o escalar a ser advectado-difundido $\varphi_{e}$, o campo de velocidades $\mathbf{u}_{e}=$ $(u, v, w)$, a massa específica $\rho$ e os coeficientes $\omega$ e $\xi$ são escolhidos como

$$
\begin{aligned}
\varphi_{e} & =\frac{1}{3} e^{3 \sin (t+x+y+z)}, \\
u & =\frac{x^{2}}{100(2+\sin (2 \pi(t+x+y+z)))}, \\
v & =\frac{y \cos (2 \pi(t+x+z))}{100(\sin (2 \pi(t+x+y+z))+2)}, \\
w & =\frac{3}{100} e^{-3 \sin (t+x+y+z)} \sin ^{2}(t x y z), \\
\rho & =\sin (2+x+y+z))+2, \\
\omega & =1+t^{2}+x^{4}+y^{4}+z^{4}, \\
\xi & =e^{-x y t} \varphi .
\end{aligned}
$$

É possível notar que todas as funções escolhidas são $C^{\infty}$ e que o campo de velocidades não é solenoidal, ou seja, $\nabla \cdot \mathbf{u} \neq 0$, para algum $\left(x_{i j k}, y_{i j k}, z_{i j k}\right) \in[0,1] \times[0,2] \times[0,2]$ que é o domínio computacional escolhido para este teste.

Para obter o termo forçante $S$, calculam-se os operadores diferenciais que definem o divergente, o laplaciano e a derivada temporal da equação geral de advecção-difusão (2.37) o quais se escrevem como

$$
\begin{aligned}
& \nabla \cdot\left(\left(\rho \omega \nabla \varphi_{e}\right) \mathbf{u}\right)=-3\left(t^{2}+x^{4}+y^{4}+z^{4}+1\right) e^{3 \sin (t+x+y+z)} \sin (t+x+y+z) \rho(t, x, y, z)+ \\
& 9\left(t^{2}+x^{4}+y^{4}+z^{4}+1\right) e^{3 \sin (t+x+y+z)}(\sin (2 \pi(t+x+y+z))+2) \cos ^{2}(t+x+y+z)+ \\
& 6 \pi\left(t^{2}+x^{4}+y^{4}+z^{4}+1\right) e^{3 \sin (t+x+y+z)} \cos (t+x+y+z) \cos (2 \pi(t+x+y+z))+ \\
& 4 x^{3} e^{3 \sin (t+x+y+z)}(\sin (2 \pi(t+x+y+z))+2) \cos (t+x+y+z)+ \\
& 4 y^{3} e^{3 \sin (t+x+y+z)}(\sin (2 \pi(t+x+y+z))+2) \cos (t+x+y+z)+ \\
& 4 z^{3} e^{3 \sin (t+x+y+z)}(\sin (2 \pi(t+x+y+z))+2) \cos (t+x+y+z)
\end{aligned}
$$




$$
\begin{aligned}
& \nabla \cdot\left(\left(\rho \varphi_{e}\right) \mathbf{u}\right)=\frac{1}{100} x^{2} e^{3 \sin (t+x+y+z)}+ \\
& \cos (t+x+y+z)+\frac{1}{150} x e^{3 \sin (t+x+y+z)}+\frac{1}{50} \pi \sin ^{2}(t x y z) \cos (2 \pi(t+x+y+z))+ \\
& \frac{1}{50} t x y \sin (t x y z)(\sin (2 \pi(t+x+y+z))+2) \cos (t x y z)+ \\
& \frac{1}{300} \cos (2 \pi(t+x+z)) e^{3 \sin (t+x+y+z)}+ \\
& \frac{1}{100} y \cos (2 \pi(t+x+z)) e^{3 \sin (t+x+y+z)} \cos (t+x+y+z)
\end{aligned}
$$

A Tabela 5.7 apresenta os resultados obtidos numa sequência de malhas uniformes progressivamente mais finas com espaçamentos associados a 32, 64, 128 e 256 células computacionais em todas as direções $\left(\frac{d x}{d y}=\frac{d x}{d z}=\frac{d y}{d z}\right)$. As condições de contorno utilizadas são Dirichlet e Neumann puras. Como se nota obteve-se segunda ordem como prevê a teoria para o método Crank-Nicolson.

\begin{tabular}{ccccc}
\hline \multicolumn{5}{c}{ Malha uniforme serial e paralelo } \\
\hline \multicolumn{5}{c}{ Dirichlet } \\
\hline Malha & $\left\|\varphi-\varphi_{e}\right\|_{2}$ & $R\left(\|\cdot\|_{2}\right)$ & \multicolumn{2}{c}{ Neumann } \\
\hline $16 \times 32 \times 32$ & $4.87 \mathrm{E}-03$ & & $3.53 \mathrm{E}-02$ & $R\left(\|\cdot\|_{2}\right)$ \\
$32 \times 64 \times 64$ & $1.16 \mathrm{E}-03$ & 4.19 & $8.82 \mathrm{E}-03$ & 4.01 \\
$64 \times 128 \times 128$ & $2.89 \mathrm{E}-04$ & 4.01 & $2.20 \mathrm{E}-03$ & 4.004 \\
$128 \times 256 \times 256$ & $7.26 \mathrm{E}-05$ & 3.99 & $5.52 \mathrm{E}-04$ & 3.98 \\
\hline
\end{tabular}

Tabela 5.7: Teste de convergência na malha uniforme com propriedades físicas variáveis.

A Tabela 5.8 apresenta os resultados obtidos numa sequência de malhas compostas estáticas progressivamente mais finas. As condições de contorno utilizadas são Dirichlet e Neumann puras. Como se nota obteve-se segunda ordem como prevê a teoria para o método Crank-Nicolson.

\begin{tabular}{ccccc}
\hline \multicolumn{5}{c}{ Malha composta estática serial e paralelo } \\
\hline Malha & Dirichlet & \multicolumn{2}{c}{ Neumann } \\
\hline $64 \times 128 \times 128 L 3$ & $4.79 \mathrm{E}-03$ & $R\left(\|\cdot\|_{2}\right)$ & $3 \varphi-\varphi_{e} \|_{2}$ & $R\left(\|\cdot\|_{2}\right)$ \\
\hline $128 \times 256 \times 256 L 3$ & $1.19 \mathrm{E}-03$ & & $3.67 \mathrm{E}-02$ & \\
$256 \times 512 \times 512 L 3$ & $2.98 \mathrm{E}-04$ & 4.02 & $9.16 \mathrm{E}-03$ & 4.006 \\
$512 \times 1024 \times 1024 L 3$ & $7.44 \mathrm{E}-05$ & 3.99 & $2.28 \mathrm{E}-03$ & 4.01 \\
\hline
\end{tabular}

Tabela 5.8: Teste de convergência na malha composta estática com propriedades físicas variáveis.

O passo temporal é escolhido em função do passo espacial $h=\min (\Delta x, \Delta y, \Delta z) \mathrm{e}$ $d t=\min \left(t_{f}-t, h\right)$, onde $t_{f}=0.44$ representa o tempo final da simulação e $t$ o tempo corrente, conclui-se que a razão de quatro para o tempo também é obtida, implicando então que, o método implementado de Crank-Nicolson implementado atinge a ordem de convergência teórica dois tanto no espaço quanto no tempo. Vale ressaltar que outros esquemas numéricos temporais de segunda ordem também foram implementados e o módulo desenvolvido é configurável para eles, porém, os resultados obtidos aqui foram suprimidos. A ordem de 
convergência esperada é obtida em todos os casos. Note que tanto no caso serial quanto no paralelo, as tabelas obtidas foram as mesmas. A simulação em paralelo ocorreu com quatro e dois processadores respectivamente na direção x. Os tempos de simulação por passo de integração dos casos rodados estão sumarizados na Tabela 5.9.

\begin{tabular}{cccc}
\hline \multicolumn{4}{c}{ Malha uniforme } \\
\hline Malha & 1 proc & 2 procs & 4 procs \\
\hline $16 \times 32 \times 32$ & 0.34 & 0.22 & 0.19 \\
$32 \times 64 \times 64$ & 1.61 & 0.9 & 0.77 \\
$64 \times 128 \times 128$ & 10.57 & 6.82 & 4.15 \\
$128 \times 256 \times 256$ & 124.12 & 76.58 & 48.31 \\
\hline
\end{tabular}

Tabela 5.9: Tempo de execução por passo de integração em malha uniforme

De acordo com a Tabela 5.9, as simulações que tiveram um uso de quatro processadores foram em média quase três vezes mais eficiente do que no caso serial. Usando dois processadores, o ganho de eficiência girou em torno de quase duas vezes mais do que no caso serial. A tabela a seguir sumariza os mesmos resultados para a malha composta descrita na Seção 5.1 .

\begin{tabular}{cccc}
\hline \multicolumn{4}{c}{ Malha composta } \\
\hline Malha & 1 proc & 2 procs & 4 procs \\
\hline $64 \times 128 \times 128 L 3$ & 0.63 & 0.34 & 0.23 \\
$128 \times 256 \times 256 L 3$ & 2.07 & 1.02 & 0.75 \\
$256 \times 512 \times 512 L 3$ & 13.31 & 6.41 & 4.79 \\
$512 \times 1024 \times 1024 L 3$ & 90.02 & 59.84 & 33.7 \\
\hline
\end{tabular}

Tabela 5.10: Tempo de execução por passo de integração em malha composta

A Tabela 5.10 mostra um comportamento análogo à tabela anterior indicando um ganho de eficiência similar. As duas tabelas mostram que, para este caso, o código paralelo consegue um desempenho melhor do que o código em serial e com isso indica a corretude do método numérico também em paralelo.

\subsection{Teste de conservação}

O método de volumes finitos provê naturalmente a propriedade de conservação, pois, o fluxo que entra por uma célula computacional é o mesmo que sai. Com a validade numérica do Teorema do Divergente discreto como visto na Seção 5.3 é possível realizar um teste para a conservação da propriedade $\varphi$. O intuito deste teste é verificar se a quantidade $\varphi$ não possui pontos de criação ou decaimento durante o tempo de simulação, isto implica que a integral de $\varphi$ deve ser constante no tempo. Este teste é baseado em [7] e com isso, o domínio computacional é definido como $[-2,2] \times[-2,2] \times[-2,2]$ e a malha composta possui a mesma topologia descrita na Seção 5.1. Os tempos inicial e final são respectivamente $t=0$ e $t=0.1$. 
O método numérico usado neste teste é o de Crank-Nicolson. Os parâmetros físicos são

$$
\begin{array}{r}
\rho=1, \\
\omega=0.0001, \\
\zeta=0, \\
u=-4 y, \\
v=4 x, \\
w=0 .
\end{array}
$$

O valor de $\varphi$ exato é dado por

$$
\varphi(x, y, z, t)=\frac{2 \sigma^{2}}{2 \sigma^{2}+4 \omega t} e^{-\frac{(\bar{x}+0.25)^{2}+\bar{y}^{2}}{2 \sigma^{2}+4 \omega t}}
$$

onde $\sigma=0.0477, \bar{x}=x \cos 4 t+y \sin 4 t$ e $\bar{y}=-x \sin 4 t+y \cos 4 t$. A condição inicial é $\varphi_{0}(x, y, z)=\varphi(x, y, z, 0)$ com condição de fronteira de Dirichlet. Esta configuração nos permite obter uma função $\varphi$ que se anula nas bordas e representa um pulso Gaussiano sendo advectado em um campo de velocidade rotacional, conforme [7].

A equação geral de advecção-difusão (2.37), com a substituição dos parâmetros físicos e usando o Teorema 2.1.1 em conjunto com a função definida em (5.26), reduz-se a

$$
\iiint_{\Omega} \frac{\partial \varphi}{\partial t} d \Omega=\iint_{\partial \Omega}(\varphi \mathbf{u}) \cdot \mathbf{n} d \partial \Omega-\omega \iint_{\partial \Omega} \nabla \varphi \cdot \mathbf{n} d \partial \Omega
$$

Nota-se que o lado direito de (5.27) é nulo, como pode ser visto em detalhes em [7], se usadas as condições de contorno de Dirichlet e o tempo for suficientemente pequeno. Trocando-se a ordem de integração do lado esquerdo usando o Teorema 2.1.2 obtém-se

$$
\frac{d}{d t} \iiint_{\Omega} \varphi d \Omega=0
$$

Para checar numericamente o resultado obtido em (5.28), em cada instante de tempo é guardado o valor da integral acima e comparada o primeiro valor obtido no primeiro instante de tempo. Espera-se que a diferença obtida mantenha patamares próximos de zero de máquina. A Tabela 5.11 mostra o erro $e_{c}$ relativo ao valor obtido na discretização de 5.28 em relação à malhas progressivamente refinadas correspondente ao instante $t=0.3$.

\begin{tabular}{cc}
\hline Malha & $e_{c}$ \\
\hline $64 \times 64 \times 64$ & $4.02 \mathrm{E}-12$ \\
$128 \times 128 \times 128$ & $4.66 \mathrm{E}-18$ \\
$256 \times 256 \times 256$ & $-5.16 \mathrm{E}-16$ \\
\hline
\end{tabular}

Tabela 5.11: Propriedade de conservação do método numérico, malha uniforme em $t=0.3$

A Tabela 5.12 mostra o erro $e_{c}$ relativo ao valor obtido na discretização de 5.28 em relação 
à malhas compostas progressivamente refinadas correspondente ao instante $t=0.1$.

\begin{tabular}{cc}
\hline Malha & $e_{c}$ \\
\hline $64 \times 64 \times 64 L 3$ & $9.49 \mathrm{E}-9$ \\
$128 \times 128 \times 128 L 3$ & $4.01 \mathrm{E}-12$ \\
$256 \times 256 \times 256 L 3$ & $3.12 \mathrm{E}-15$ \\
\hline
\end{tabular}

Tabela 5.12: Propriedade de conservação do método numérico, malha composta em $t=0.1$

O resultado para a propriedade de conservação foi o esperado como reportado no capítulo de metodologia numérica. Ambos os casos tiveram os mesmos resultados tanto em serial quanto em paralelo com quatro processadores. Resultados indicando erros de ordem entre $10^{-15}$ a $10^{-18}$ são obtidos para todos os casos testados, na malha mais fina, em todos os instantes de tempo. Estes resultados são ilustrados na Figura .

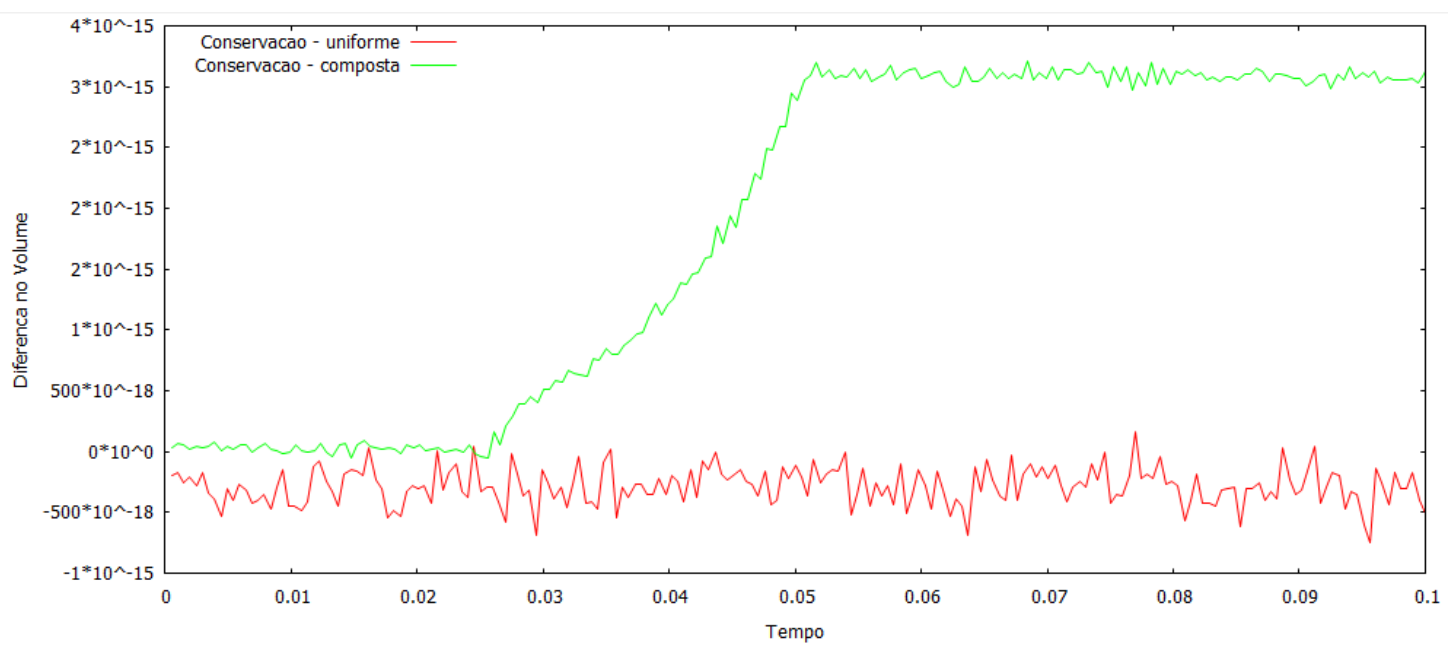

Figura 5.4: Evolução da conservação no tempo, uniforme $\times$ composta, em malha $256 \times 256 \times 256$ com condição de Dirichlet

A figura acima mostra que a integral do domínio é constante durante a simulação indicando assim que nada entra ou sai pelos bordos do domínio computacional. Em relação a malha composta, o mesmo resultado foi obtido usando a malha descrita na seção 5.1. Este fato implica que o método numérico utilizado para discretizar este problema possui a propriedade de conservação desejada garantindo então a corretude do código computacional implementado. 


\subsection{Simulação de um jato laminar}

Nesta seção, é resolvido um problema prático utilizando o módulo desenvolvido neste trabalho em conjunto com o módulo da equação de Navier-Stokes previamente implementado no código computacional AMR3D. O principal objetivo aqui é verificar que o módulo desenvolvido emprega de maneira adequada a dinamicidade da malha composta para resolver o problema em questão. O problema consiste em criar um ponto de entrada de um jato laminar pela face de baixo no eixo z do domínio computacional fazendo com que o escalar $\varphi$ seja empurrado na direção z. Esta quantidade escalar é advectada com a velocidade do jato e difundida, com coeficiente de difusão constante, pelo domínio. O problema proposto é modelado pelo seguinte conjunto de equações

$$
\begin{gathered}
\frac{\partial(\rho \varphi)}{\partial t}+\nabla \cdot((\rho \mathbf{u}) \varphi)=\nabla \cdot(\omega(\mathbf{x}, t) \rho \nabla \varphi)+S(\mathbf{x}, t)+\xi(\varphi) \\
\left(\rho \frac{\partial \mathbf{u}}{\partial t}+\mathbf{u} \cdot \nabla \mathbf{u}\right)=-\nabla p+\nabla \cdot\left(\mu\left(\nabla \mathbf{u}+\nabla \mathbf{u}^{T}\right)\right)+\mathbf{F} \\
\nabla \cdot \mathbf{u}=0
\end{gathered}
$$

A primeira equação se refere a (2.37) e a segunda é a equação de Navier-Stokes. A discretização da equação de Navier-Stokes baseia-se no método da Projeção de Chorin aproveitando os trabalhos já implementados conforme [6], [25] e [16]. Note que agora (5.29) pode ser acoplada a (5.30) fazendo com que a quantidade escalar $\varphi$ seja advectada e difundida pelo domínio computacional por um escoamento incompressível. O termo forçante da equação de Navier-Stokes será nulo e e de acordo com a equação acima os parâmetros físicos escolhidos, baseando-se em [6], são

$$
\begin{gathered}
\omega=\frac{1}{240}, \\
\rho=1.184, \\
\mu=3.7 \times 10^{-3}, \\
\zeta=0 .
\end{gathered}
$$

O domínio computacional utilizado consiste em um cubo com dimensões $1 \mathrm{~m} \times 1 \mathrm{~m}, \times 1 \mathrm{~m}$ e a condição inicial será definida e modo a ser criado uma entrada para o jato laminar, bocal, na parte inferior do domínio que corresponde ao plano $z=0$. Este bocal pode ser definido de modo parecido como em [6], ou seja, no centro do plano em questão um pequeno círculo de diamtero de $4 \mathrm{~mm}$ ao qual no interior do círculo o valor inicial da velocidade na direção normal ao plano assume o valor de $w=10 \frac{\mathrm{m}}{\mathrm{s}}$ que nos dá $R e=64$. Na zona do plano $z=0$, exterior ao bocal, o valor da velocidade é definida como $w=0.002$. No mesmo plano $z=0$, define-se $\varphi=1$ obtendo-se $P e=48$ na região do bocal da velocidade e $P e=0.48$ fora. As 
outras componentes das velocidades terão valores nulos nesta região. A Figura 5.5 mostra a condição inicial descrita.

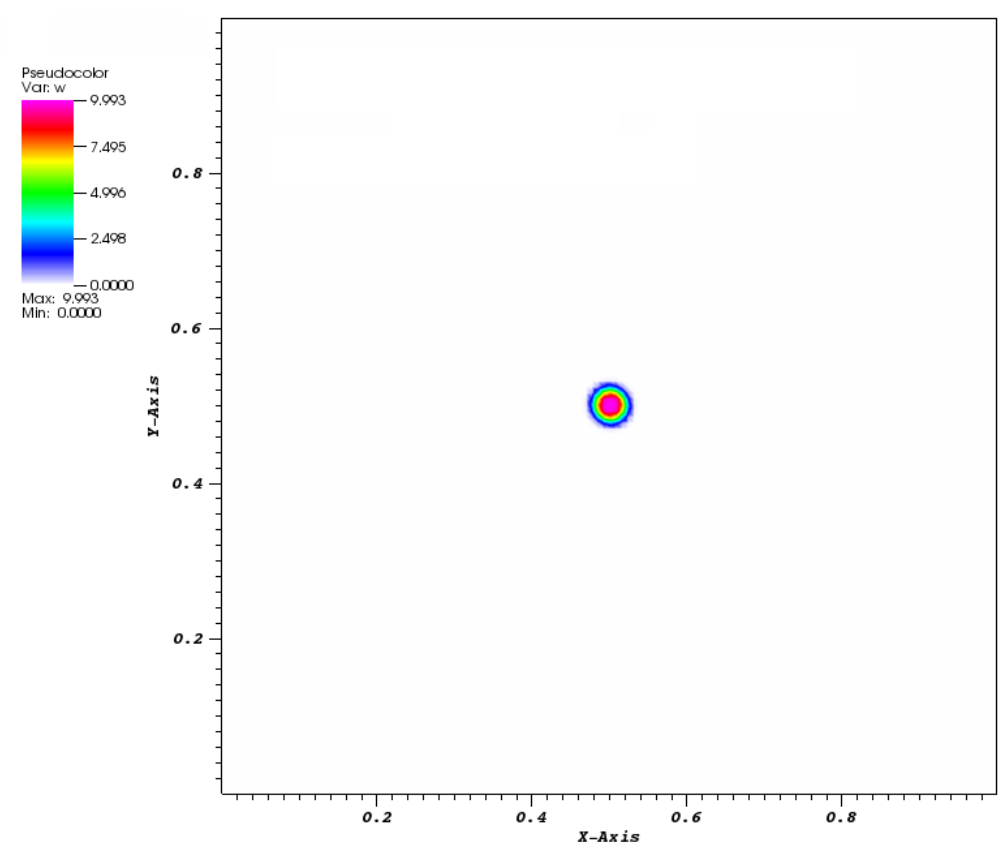

Figura 5.5: Bocal centrado no plano $z=0$

As funções definidas nas condições iniciais são descontínuas. Para o bom funcionamento dos métodos numéricos são necessárias funções contínuas. A função indicadora pode ser aproximada por

$$
w(0, x, y, 0)=5+5 \tanh (K(0.02-r))
$$

onde,

$$
\begin{gathered}
r=\sqrt{\left(x-\frac{1}{2}\right)^{2}+\left(y-\frac{1}{2}\right)^{2}}, \\
K=250
\end{gathered}
$$

representam a localização do bocal e o fator de aproximação da função tanh de uma função indicadora, ou seja, para $K \rightarrow+\infty$ vamos obter

$$
w(0, x, y, 0) \rightarrow\left\{\begin{array}{ll}
10 & \text { if } r \leq 0.02 \\
0 & \text { if } r>0.02
\end{array} .\right.
$$

O efeito desejado é obtido como visto na Figura 5.510 na região do círculo e 0 fora e como se trata de uma função que se aproxima continuamente da indicadora há uma região de transição perceptível na figura em questão. As condições de fronteira são

$$
\frac{\partial \varphi}{\partial n}=0
$$


em todas as direções com a exceção do plano $z=0$ que possui condição de Dirichlet. Para as velocidades procede-se da mesma forma com exceção de $z=1$ que possui condição de Dirichlet (jato confinado).

A ideia é criar, no instante $t=0$, uma entrada de um fluido com velocidade definida pela entrada no plano $z=0$ (bocal) e este fazer com que o escalar $\varphi$ seja advectado e difundido por todo o domínio, baseando-se em [6]. O escalar possuirá uma entrada constante que produzirá um efeito similar ao do jato laminar na região do bocal e no exterior um efeito de difusão pura.

Para acoplar as equações, as equações de Navier-Stokes (5.30) são resolvidas e depois usa-se as velocidades obtidas para resolver a equação de geral de advecção-difusão (5.29). O Algoritmo 4 mostra um passo no tempo para a resolução do sistema de equações em questão

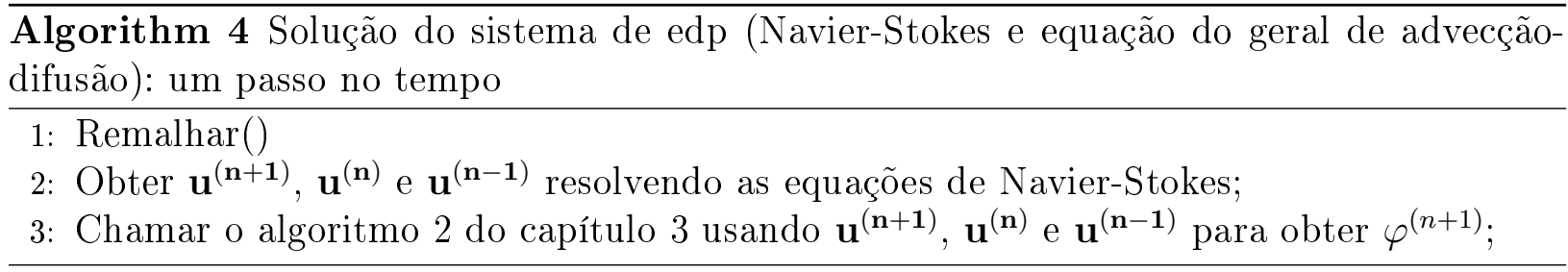

A simulação é realizada em uma malha cartesiana bloco-estruturada tridimensional adaptativa, composta por uma malha base mais dois níveis de refinamento totalizando três níveis. A malha base possui $32 \times 32 \times 32$ células computacionais. O nível de refinamento mais fino possui espaçamento de $7.8125 \times 10^{-3} \mathrm{~m}$. O domínio computacional inicial é dado por $\Omega_{0}=[0.4365,0.5625] \times[0.4365,0.5625] \times[0,0.0625]$. O tempo final de simulação é de $t_{f}=0.5$ e o método numérico empregado é o de Crank-Nicolson. A remalhagem acontece de modo fixo a cada 50 passos no tempo e usa-se o critério do gradiente do escalar, conforme Capítulo 3 , com uma tolerância de $5 \times 10^{-2}$. A Figura 5.6(a) mostra o escalar na direção normal a $z=0$ em um plano de corte no meio do domínio computacional com a malha bloco-estruturada de três níveis de refinamento enquanto a Figura 5.6(b) mostra o escalar em malha uniforme. As Figuras 5.7(a) - 5.7(d) mostram, no mesmo plano de corte, a evolução do escalar na direção do escoamento do jato laminar. 


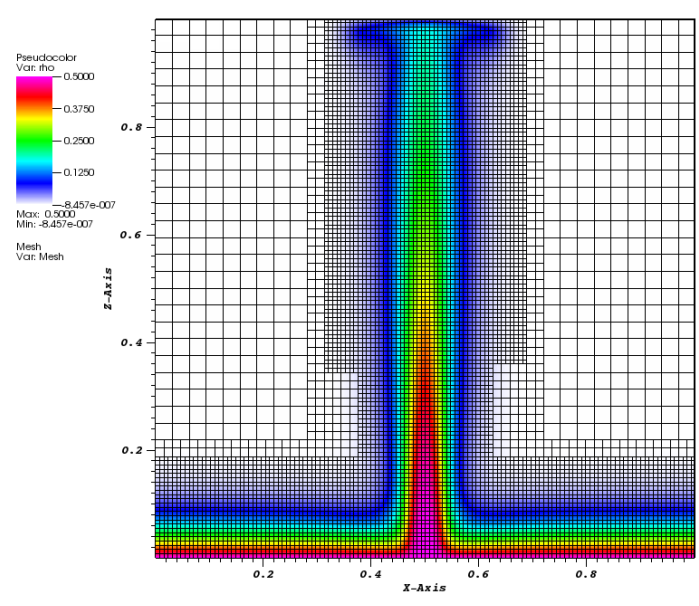

(a)

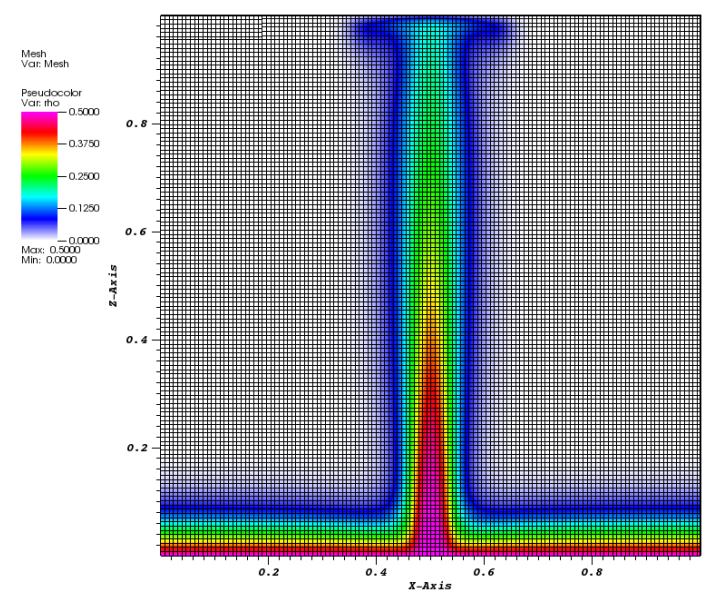

(b)

Figura 5.6: Escalar $\varphi$ disposto em malhas composta com três níveis de refinamento e uniforme respectivamente;

É possível enxergar que a remalhagem acompanha o escalar $\varphi$ na direção normal ao plano $z=0$ de acordo com a Figura 5.6(a)-(b) e é possível ver também que o número de células computacionais gasto pelo método de refinamento adaptativo dinâmica é bem menor em relação a malha uniforme. Na malha uniforme é gasto 1653 passos no tempo até o final da simulação enquanto na composta é gasto 27 passos a mais. 


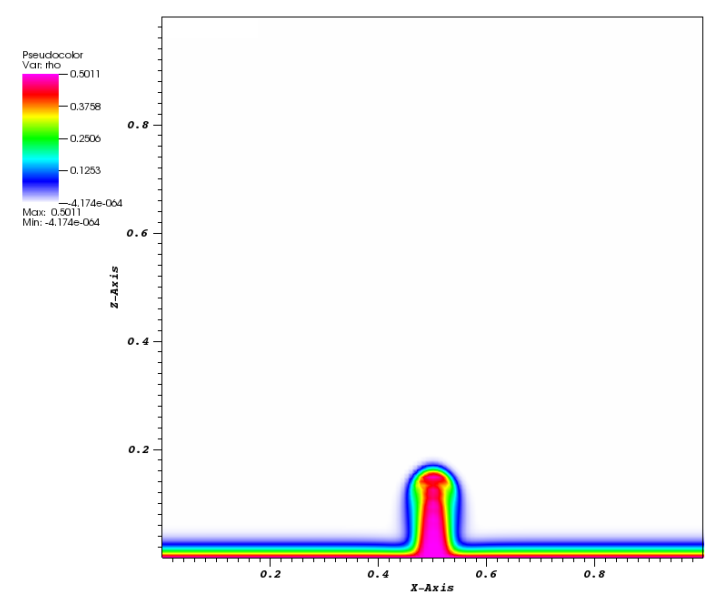

(a)

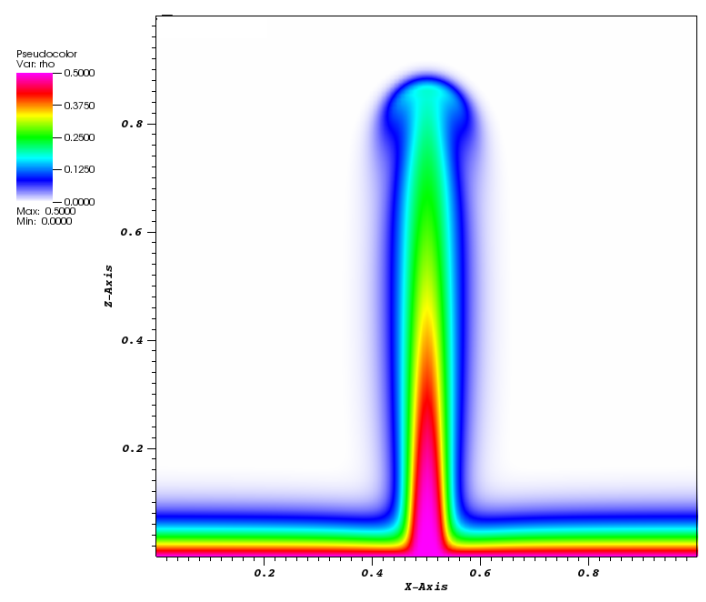

(c)

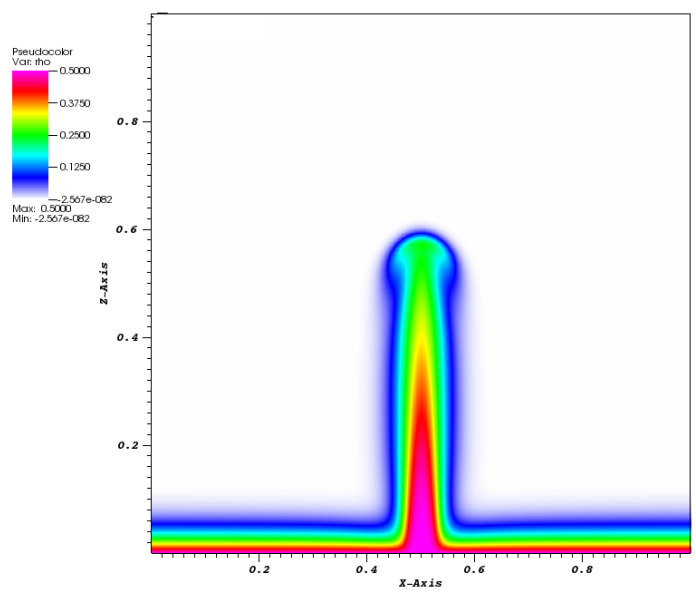

(b)

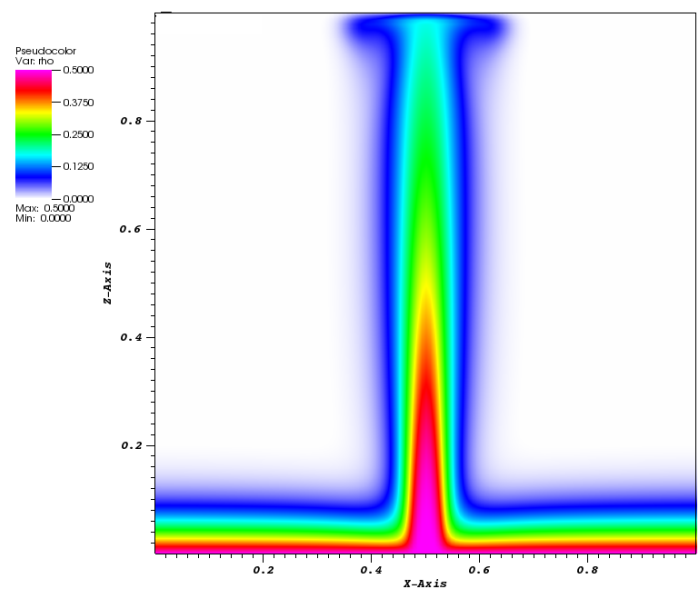

(d)

Figura 5.7: Escalar $\varphi$ na direção do escoamento em diferentes instantes de tempo; 
É sabido que o número de células computacionais em uma malha composta dinâmica varia com o tempo, para ilustar esta situação foram obtidas informações sobre este número em cada instante de troca de malhas. A Figura 5.8 mostra o gráfico tempo $\times$ ncell, onde ncell é a variável computacional que representa o número total de células computacionais de uma malha no programa AMR3D. A variável ncell foi relativizada com o número de células usada na simulação usando malha uniforme de tamanho $128 \times 128 \times 128$ que é 2983147 .

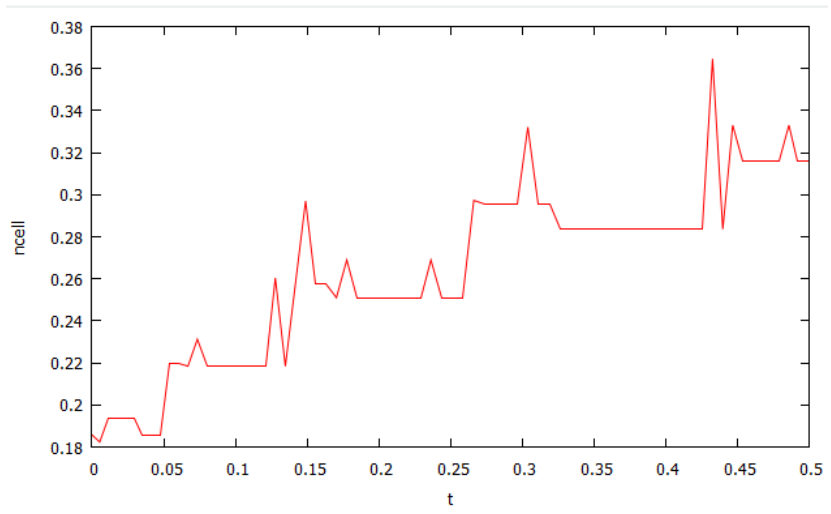

Figura 5.8: Número de células computacionais, em relação a malha uniforme, ao longo do tempo de simulação

Com base no gráfico da Figura 5.8, o número de células computacionais usadas no final da simulação correponde a aproximadamente $30 \%$ do número de células presente na malha uniforme. O pico de uso de células computacionais corresponde a pouco mais da metade comparando-se com a mesma malha uniforme. O comportamento obtido é esperado pois a quantidade escalar é advectada na direção do jato e difundida na parte de baixo do domínio. A malha inicial começa com 88820 células computacionais atingindo seu máximo de 1498421 próximo do meio da simulação como mostra o gráfico. É possível notar o ganho computacional do método de refinamento adaptativo em relação a performance, para isto, é introduzido a Tabela 5.13 que mostra o total de tempo gasto por passo de integração em algumas simulações deste jato. Os casos uniformes gastaram 1653 passos de integração e o composto 1680 ao longo do meio segundo simulado. No caso adaptativo e paralelo 1776 passos de integração foram completos até o fim da simulação.

\begin{tabular}{cc}
\hline Casos & Tempo gasto (s/passo) \\
\hline Uniforme & 62.24 \\
Malha adaptativa & 27.65 \\
Paralelo 4 processadores - Uniforme & 27.87 \\
Paralelo 2 processadores - Uniforme & 47.75 \\
Paralelo 4 processadores - Adaptativa & 6.77 \\
Paralelo 2 processadores - Adaptativa & 12.18 \\
\hline
\end{tabular}

Tabela 5.13: Teste de convergência na malha uniforme com propriedades físicas variáveis.

A malha adaptativa é aproximadamente 2.4 vezes mais rápida que a malha uniforme neste teste. Usando o módulo de resolução em questão em sua versão paralela com 4 cortes na 
direção $\mathrm{x}$, obteu-se uma velocidade de processamento de aproximadamente 2.2 vezes maior e com dois cortes na mesma direção é obtida uma velocidade 1.3 vezes maior aproxidamente. Esses resultados mostram que o método do refinamento adaptativo de malhas se mostra extremamente eficiente para esta simulação sendo inclusive mais eficiente do que a malha uniforme executada em paralelo com 4 processadores. A Figura 5.9 ilustra o escalar $\varphi$ em malha uniforme tanto em serial quanto em paralelo com quatro processadores. $O$ resultado de maior impacto ocorre quando a técnica de refinamento adaptativo é paralelizada em 4 processadores que produz uma velocidade na simulação maior que no caso uniforme serial e quatro vezes maior se comparada com a malha adaptativa serial.

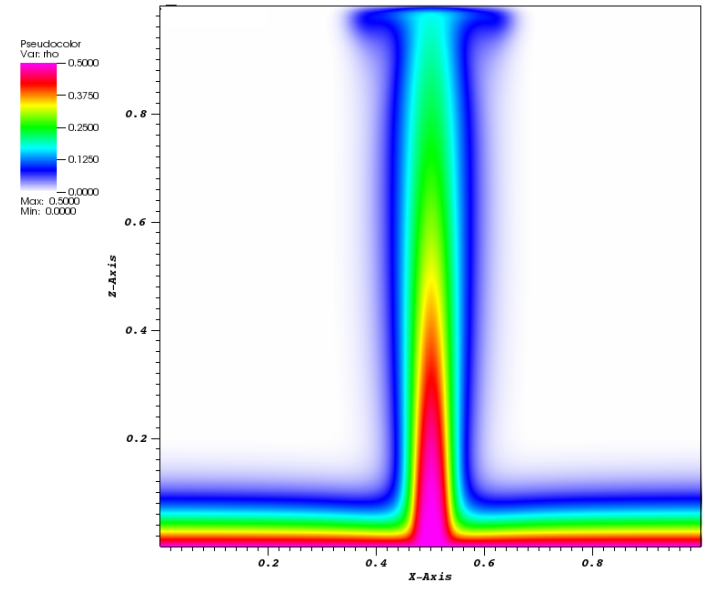

(a)

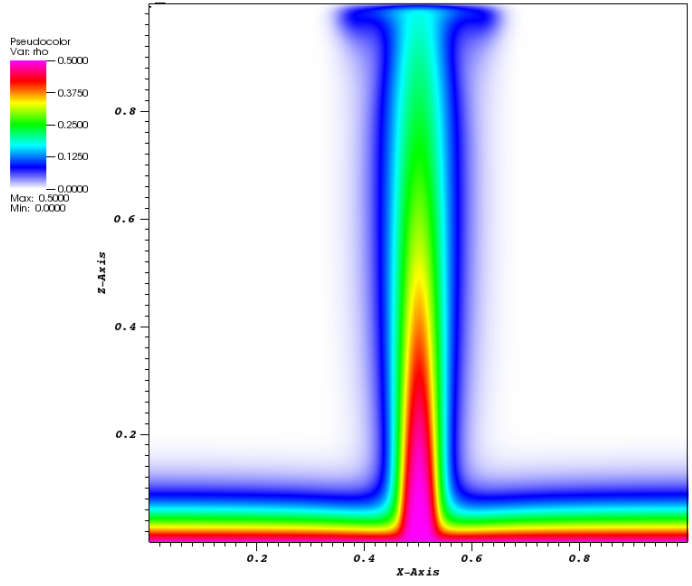

(b)

Figura 5.9: Escalar $\varphi$ disposto em malhas uniforme em serial e paralelo;

Nota-se na Figura 5.9 que a mesma topologia do escoamento é obtida, com diferenças pouco significativas e invisíveis na visualização da figura. A Figura 5.11 ilustra uma comparação entre as simulações, no caso paralelo e serial, nos casos adaptativos. 


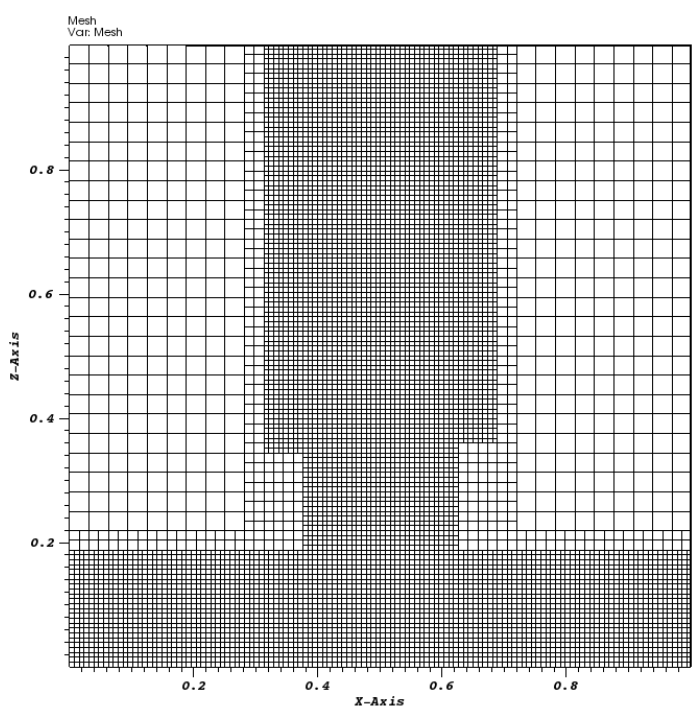

Figura 5.10

Figura 5.11: Malha gerada, tanto em serial quanto em paralelo, no instante de tempo 0.5;

Como é possível observar na Figura as malhas geradas não possuem diferenças significativas, uma figura para serial e paralelo é mostrada para evitar redundâncias, mostrando que não há erros de implementação no código computacional nesses dois casos.

O número de V-ciclos realizados pelo algoritmo Multigrid-Multinível para a variável escalar $\varphi$ se manteve em 12 na maioria dos passos temporais. Somente nos passos temporais inicial que obteve-se números maiores que 12. É interessante ressaltar que durante a simulação $\varphi$ foi a variável que mais precisou de V-ciclos com a tolerância do método sendo igual as demais tendo o valor de $10^{-8}$. Por via experimental observou-se que o número de $\mathrm{V}$-ciclos é diretamente proporcional ao valor empregado ao coeficiente de difusão $\omega \rho$, ou seja, quanto maior $\omega \rho$ maior é o número de V-ciclos necessários para se obter a tolerância em questão. 


\section{Capítulo 6}

\section{Considerações finais}

Um dos objetivos deste trabalho era apresentar todos os passos necessários para se resolver a Equação Geral de Conservação usando o aparato numérico proveniente da métodologia de refinamento adaptativo muito estudado na área de dinâmica de fluidos. Foi abordado a discretização espacial utilizando o Método de Volumes Finitos, a discretização temporal usando métodos implícitos de resolução, a resolução do sistema linear pelo método multigrid-multinível e a geração dinâmicas de malha usando a técnica AMR.

Como produto final foi confeccionado um código computacional usando a linguagem FORTRAN, utilizado no código computacional AMR3D-P, que representa uma biblioteca com o fim de resolver a equação em discussão. O código possui suporte a alguns métodos numéricos não relatados neste trabalho e usados por outros membros do grupo de pesquisa. $\mathrm{O}$ código também foi desenvolvido utilizando a versão paralela usando a bibliotca OPENMPI. Os testes propostos aqui de modo a validar o código foram satisfatórios e produziram o efeito esperado. Os métodos empregados na resolução apresentaram resultados de acordo com o previsto na teoria. O presente trabalho teve contribuição para pesquisas com surfactantes e escoamentos térmicos de membros do grupo de pesquisa do IME-USP e do MFLab/FEMECUFU.

É proposto como trabalhos futuros a melhora na performance do módulo que resolve o sistema linear pelo método multigrid-multinível que durante os testes mostrou-se a rotina mais custosa e também a melhoria da performance do código paralelo, pois, o módulo de resolução da equação de geral de advecção-difusão foi baseado em versões antigas do código computacional AMR3D-P. 


\section{Referências Bibliográficas}

[1] C.M.R Alvarez. Simulação computacional adaptativa de escoamentos bifásicos viscoelásticos. Tese de Doutorado, Universidade de São Paulo, São Paulo, Brasil, 2013. 33

[2] T. Apostol. Calculus Volume II. John Willey and Sons, 1969. 8

[3] U.M. Ascher, S.J. Ruuth, e B.T.R. Wetton. Implicit-explicit methods for timedependent partial differential equations. SIAM J. Numer. Anal., 32(3):797-823, 1995. 2,16

[4] M.J. Berger e P. Colella. Local adaptive mesh refinement for shock hydrodynamics. J. Comput. Phys., 82:64-84, May 1989. 2, 3, 4, 22, 23

[5] M.J. Berger e I. Rigoutsos. An algorithm for point clustering and grid generation. IEEE Transactions on Systems, Man, and Cybernetics, 21:1278-1286, 1991. 24

[6] P.C. Calegari. Simulações de escoamentos bifásicos tridimensionais empregando métodos adaptativos e modelos de campo de fase. Tese de Doutorado, Universidade de São Paulo, São Paulo, Brasil, 2013. 1, 2, 3, 4, 6, 12, 13, 16, 19, 22, 23, 24, 25, 26, 28, 32, $33,34,48,50$

[7] Ervin V.J. Jenkins E.W. Chrispell, J.C. A fractional step theta-method for convectiondiffusion problems. Journal of Mathematical Analysis and Applications, 333(1):204 218, 2007. 45, 46

[8] Boris Diskin. Comparison of node-centered and cell-centered unstructured finite-volume discretizations. part i: viscous fluxes. Technical report, NASA, 2009. 16

[9] T. Poinsot e D. Veynante. Theoretical and numerical combustion. RT Edwards, Inc, 2005. 12,13

[10] S.M. Toscano e F.M. Neto. Mecânica dos fluidos e equações diferenciais. IMPA, 1991. $7,8,9,11$

[11] H. K. Versteeg e W. Malalasekera. An introduction to computational fluid dynamics: the finite volume method. Prentice Hall, 2007. 12, 13, 32

[12] W. Hundsdorfer. Finite Difference Methods for Differential Equations. Thomas Stieltjes Institute, 2000. 3

[13] F. McCormick L. Briggs., E. Henson. A Multigrid Tutorial. SIAM, 2000. 4, 28

[14] R. LeVeque. Finite Difference Methods for Differential Equations. University of Washington, 2005. 21 
[15] R.S Lima. Desenvolvimento e Implementação de Malhas Adaptativas BlocoEstruturadas para COmputação Paralela em Mecânica dos Fluídos. Tese de Doutorado, Universidade Federal de Uberlândia, Uberlândia, Brasil, 2012. 1, 2

[16] R.L. Nós. Simulações de escoamentos bifásicos tridimensionais empregando métodos adaptativos e modelos de campo de fase. Tese de Doutorado, Universidade de São Paulo, São Paulo, Brasil, 2007. 1, 2, 22, 23, 24, 25, 28, 29, 30, 48

[17] L. Angerman P. Knaber. Numerical Methods for Elliptic and Parabolic Partial Differential Equations. Springer, 2003. 16, 21

[18] Pope S. Popov P. e Wang H. Specific volume coupling and convergence properties in hybrid particle/finite volume algorithms for turbulent reactive flows. Journal of computational physics, 52(4):455-471, 2012.

[19] Y. Ramachers. Proof of divergence and stokes theorem, 2007. http://www2.warwick.ac.uk/fac/sci/physics/current/teach/module_home/px263/handouts2007/ 7

[20] Pope S. The pdf method for turbulent combustion. International Journal for Numerical Methods in Fluids, 52(4):455-471, 1990. 13

[21] S.B. Pope S. James, M.S. Anand. The Lagrangian PDF Transport Method for Simulations of Gas Turbine Combustor Flows. Joint Propulsion Conference and Exhibit, 38, 2002. 13

[22] U. Trottenberg, C.W. Oosterlee, e A. Schuller. Multigrid. Academic Press, Inc., Orlando, FL, USA, 2001. 28

[23] S. R. Turns. An introduction to combustion: concepts and applications. McGraw-Hill, 1996. 12

[24] J.M. Vedovoto. Mathematical and numerical modeling of turbulent reactive flows using a hybrid LES/PDF methodology. Tese de Doutorado, L'Ecole Nationale Superieure de Mecanique et d'aerotechnique - Universidade Federal de Uberlândia, França - Brasil, 2011. 1, 3, 6, 13, 16, 18

[25] M.M. Villar. Análise numérica detalhada de escoamentos multifásicos bidimensionais. Tese de Doutorado, Universidade Federal de Uberlândia, Uberlândia, Brasil, 2007. 1, $25,26,28,29,48$

[26] H. Wang, J. Kearney, e K. Atkinson. Arc-length parameterized spline curves for realtime simulation. In in Proc. 5th International Conference on Curves and Surfaces, pages $387-396,2002.19$ 